Leonardo Ishida Abe

\title{
Reconstrução da Superfície Diafragmática em Movimento a Partir de Múltiplas Sequências Coronais e Sagitais Temporais de Ressonância Magnética
}

Dissertação apresentada à Escola Politécnica da Universidade de São Paulo para obtenção do Título de Mestre em Engenharia. 


\section{Reconstrução da Superfície Diafragmática em Movimento a Partir de Múltiplas Sequências Coronais e Sagitais Temporais de Ressonância Magnética}

Dissertação apresentada à Escola Politécnica da Universidade de São Paulo para obtenção do Título de Mestre em Engenharia.

Área de concentração:

Engenharia Mecatrônica

Orientador:

Prof. Dr. Marcos de Sales Guerra Tsuzuki 
Este exemplar foi revisado e alterado em relação à versão original, sob responsabilidade única do autor e com anuência de seu orientador.

São Paulo, 23 de Setembro de 2013.

Assinatura do Autor

Assinatura do Orientador

\section{Ficha Catalográfica}

Leonardo Ishida Abe,

Reconstrução da Superfície Diafragmática em Movimento a Partir de Múltiplas Sequências Coronais e Sagitais Temporais de Ressonância Magnética. São Paulo, 2013. 93 p.

1. Ressonância magnética 2. Imageamento (Bioengenharia) 3. Pulmão 4. Respiração (Sistemas) I. Universidade de São Paulo. Escola Politécnica. Departamento de Engenharia de Mecatrônica e de Sistemas Mecânicos. II. 
Dedico esta obra à toda minha familía Politécnica (Pai, Mãe e Avô materno). 


\section{Agradecimentos}

Agradeço ao Prof. Dr. Marcos Sales de Guerra Tsuzuki, pela orientação durante todo desenvolvimento.

Aos colegas do Laboratório de Geometria Computacional, que me receberam bem e auxiliaram na familizarização do ambiente, além da ótima companhia.

Aos professores e pesquisadores da UDESC, pelas sugestões no desenvolvimento de uma solução para o problema da segmentação automática.

À minha família, por todo apoio nos períodos mais difíceis e acreditar no que faço, mesmo quando nada parece dar certo.

À Louise, que me faz companhia à mais de metade da minha vida e para muitos anos que virão futuramente. 


\section{Resumo}

A visualização direta do movimento pulmonar é impossível. Os pulmões ficam apoiados na caixa torácica e, ao abri-la, os pulmões colapsam, perdendo suas funções. A única maneira de visualizar o movimento pulmonar é por meio de técnicas de imageamento. A ressonância magnética, comparada às demais formas de imageamento, é ideal para a este tipo de análise. Até o momento, a análise da respiração é feita por métodos globais, tais como espirometria e pletismografia. Desta forma, os resultados locais não podem ser avaliados. A observação do movimento pulmonar, identificando a contribuição de cada lóbulo, permitirá avaliar a eficiência no diagnóstico e tratamento de doenças pulmonares. Um grande desafio que envolve as pesquisas sobre imageamento médico é identificar se o algoritmo proposto apresenta os resultados esperados. Isto normalmente é feito pela comparação com um padrão ouro, que no trabalho em questão não está disponível, Neste trabalho, serão utilizadas sequências de imagens bidimensionais com grande redundância de informação, que serão utilizadas para validar os resultados obtidos. Este trabalho propõe um algoritmo para reconstruir a superfície diafragmática em movimento, associadas às imagens das sequências de RM coronal ou sagital. Inicialmente, todas os padrões respiratórios diafragmáticos são segmentados e um algoritmo encontra todas os registros temporais. Baseado nos registros temporais, são definidos os melhores instantes registrados e a superfície diafragmática será reconstruída. 


\section{Abstract}

It is impossible to visualize the lung movement directly. The lungs are sustained by the the chest and colapses when opened. The only way to analyze it is by using imaging systems. The magnetic ressonance, when compared to other medical imaging devices, is the ideal device for this kind of analysis. So far, the breathing analysis was evaluated globally, using spirometry or plethysmography and, as such, couldnt analyze locally. By observing the lungs movement directly, it will be possible to identify the contributions of each side of the lungs, enhancing the efficiency on diagnosis and treatment. One challeged posed on medical imaging topics is the consistency on the results of a proposed algorithm. Usually this is done by comparing with a gold standard, which is not available for this work. Several 2D sequences, with a large amount of redundancies, will be used to validade the results. This work proposes an algorithm to reconstruct the diaphragmatic surface in movement, associated with the images of MR sagittal and coronal sequences . Initially, all diaphragmatic respiratory patterns are segmented, and an algorithm finds all temporal registrations. Based on the temporal registrations, the best frames registered are defined and the lung surface is reconstructed. 


\section{Conteúdo}

\section{Lista de Figuras}

1 Introdução 17

1.1 Motivação . . . . . . . . . . . . . . . . . . 17

1.2 Estrutura do Trabalho . . . . . . . . . . . . . . . . . 18

2 Conceitos Básicos Correlatos $\quad 19$

2.1 Ressonância Magnética Aplicada ao Pulmão . . . . . . . . . . . . 19

2.1.1 Mecânica Respiratória . . . . . . . . . . . . . . 20

2.1.2 Imageamento do Movimento Respiratório . . . . . . . . . . 21

2.2 Arquivos DICOM . . . . . . . . . . . . . . . . 22

2.3 Imagens Espaço Temporal . . . . . . . . . . . . . . . . . . . . . 23

2.4 Função Respiratória Padrão . . . . . . . . . . . . . . . . . . . . . 23

2.5 Transformada de Hough Modificada . . . . . . . . . . . . . . 23

2.6 Algoritmo de Contornos Ativos . . . . . . . . . . . . 26

2.7 Segmentação Automática do Padrão Respiratório Diafragmático 27

2.7.1 Máscara Baseada em Limiarização . . . . . . . . . . . . 28

2.7.2 Máscaras Baseadas em Operadores Morfológicos . . . . . . 29

2.7.3 Aplicação das Máscaras . . . . . . . . . . . . . . . . . 32

2.8 Transformação para o Espaço Tridimensional . . . . . . . . . . . . 32

2.9 Registro Temporal . . . . . . . . . . . . . . . . . . . . . . 34

3 Reconstrução da Superfície Diafragmática $\quad 37$

3.1 Registro Linear . . . . . . . . . . . . . . . . . . 37

3.2 Registro Cíclico . . . . . . . . . . . . . . . . . . . . . . . . 38 
3.3 Interpolação do Padrão Respiratório por B-Spline . . . . . . . . . 39

3.4 Algoritmo Proposto . . . . . . . . . . . . . . . . . . . 42

3.4.1 Determinação dos Múltiplos Registros Temporais . . . . . 43

3.4.2 Processamento da Árvore de Registros . . . . . . . . . . 46

3.4.3 Algoritmo de Reconstrução da Superfície Diafragmática . . 48

$\begin{array}{llr}4 & \text { Sistema proposto } & 50\end{array}$

4.1 Arquitetura do Sistema . . . . . . . . . . . . . 50

4.2 Triagem de Sequências, Função Respiratória Padrão e Matriz de Mapeamento ........................ 51

4.3 Obtenção das Máscaras . . . . . . . . . . . . . . . . 52

4.4 2DSTs, Segmentação Automática . . . . . . . . . . . . . . 54

4.4.1 Segmentação Manual . . . . . . . . . . . . . . . . 55

4.5 Conversão para o Espaço Tridimensional e Reconstrução da Superfície Diafragmática . . . . . . . . . . . . 55

$\begin{array}{llr}5 & \text { Resultados } & 57\end{array}$

6 Conclusões e Trabalhos Futuros $\quad 85$

$\begin{array}{ll}\text { Apêndice A - Morfologia Matemática } & 86\end{array}$

A.1 Dilatação Binária . . . . . . . . . . . . . . . . . . 86

A.2 Erosão Binária . . . . . . . . . . . . . . . . . . . . 86

A.3 Abertura (Opening) . . . . . . . . . . . . . . . . . . . . 87

A.4 Fechamento (Closing) . . . . . . . . . . . . . 87

A.5 Imagens em Tons de Cinza . . . . . . . . . . . . . . . . . . . . 88

A.6 Dilatação em Tons de Cinza . . . . . . . . . . . . . . . 88

A.7 Erosão de Tons de Cinza . . . . . . . . . . . . . . . . . . . . . . 89

A.8 Abertura de Tons de Cinza . . . . . . . . . . . . . . . . . . . 90 
A.9 Fechamento de Tons de Cinza . . . . . . . . . . . . . . . . . 90

A.10 Abertura de área . . . . . . . . . . . . . . . . . . . 990

A.11 Fechamento de buracos . . . . . . . . . . . . . . . . . . . 90

Referências 


\section{Lista de Figuras}

2.1 Imagem de RM do pulmão, fatia (a) coronal e (b) sagital. . . . . . 20

2.2 Mecânica respiratória. Fonte: http://www.kmph.matrik.edu.my/ . 21

2.3 Sequência de imagens de RM temporal com corte sagital. . . . . . 22

2.4 Sequência de imagens de RM temporal com corte coronal. . . . . 22

2.5 Empilhamento de uma sequência coronal, formando um STV. . . 24

2.6 (a) Imagem original. (b) Imagem 2DST extraída do corte na posição da linha verde. . . . . . . . . . . . . . . . . . . . . . . 24

2.7 Exemplo de função respiratória padrão. . . . . . . . . . . . . . . . 25

2.8 (a) Função respiratória padrão.(b) Mapeamento da imagem 2DST para o espaço paramétrico de Hough. . . . . . . . . . . . . 26

2.9 Um padrão respiratório resultante da transformada de Hough modificada. O algoritmo de contornos ativos procura por uma posição de menor energia na adjacência vertical dos pixels pertencentes ao padrão respiratório. . . . . . . . . . . . . . . . . . 26

2.10 (a) Imagem de uma sequência coronal. A linha vertical representa a posição de corte para formar a 2DST. (b) Imagem aresta da 2DST com padrão respiratório encontrado, que não corresponde ao diafragma. (c) Posição do padrão encontrado no espaço de Hough paramétrico. . . . . . . . . . . . . . . . . 28

2.11 Criação de uma máscara definindo o contorno pulmonar. (a) Imagem de RM original. (b) Imagem binarizada, com limiar definido manualmente. (c) Isolamento dos pulmão pelo algoritmo de rotulação. (d) Aplicação de filtros de mediana para remoção de ruído.

(e) Interior do pulmão determinado. (f) Máscara determinada após a aplicação de operadores morfológicos e do operador XOR. . . . . 
2.12 Aplicação passo-a-passo do algoritmo para sequências coronais: (a) Imagem original. (b) Simplificação da imagem. (c) Reforço das delimitações da ilha. (d) Preenchimento da ilha. (e) Subtração entre os dois passos anteriores para evidenciar a ilha. (f) Simplificação da imagem. (g) Binarização da imagem por limiarização. (h) Suavização do contorno. (i) Preenchimento de buracos. (j) Máscara final após, a aplicação de dilatação e erosão sobre a imagem anterior, e operador XOR entre elas. . . . . . . . . . .

2.13 Aplicação passo-a-passo do algoritmo para sequências coronais: (a) Imagem original (b) Barreira de contenção. (c) Sobreposíção da barreira sobre a imagem. (d) Simplificação da imagem. (e) Reforço das bordas das ilhas escuras. (f) Preenchimento da ilha. (g) Subtração dos dois passos anteriores para evidenciar a ilha. (i) Novo preenchimento da ilha para cobrir buracos remanescentes. (h) Simplificação da imagem. (j) Binarização da imagem. (k) Suavização do contorno. (l) Limpeza de pequenos componentes conectados. (m) Máscara final após, a aplicação de dilatação e erosão sobre a imagem anterior, e operador XOR entre elas. . . .

2.14 Reaplicando a segmentação ilustrada na Fig. 2.10. (a) Imagem coronal onde a linha exibe a posição de corte para extrair a 2DST. (b) 2DST da imagem aresta com as máscaras sobrepostas. (c) Espaço de Hough paramétrico com aplicação das máscaras, no qual há apenas um ponto de máximo correspondente ao padrão respiratório diafragmático. . . . . . . . . . . . . . . . . .

2.15 (a) Padrão respiratório diafragmático coronal, deseja-se registrar o instante associado ao ponto $P$. (b) Padrão respiratório diafragmático sagital. Registros temporais representados pelos círculos verdes. As setas determinam a fase respiratória: para baixo, o indivíduo está em inspiração e para cima o indivíduo está em expiração 36

2.16 Registro temporal entre duas imagens. . . . . . . . . . . . . 36 
3.1 Exemplo de registro linear para uma imagem coronal, representada verticalmente e as diversas sagitais cruzadas a ela. O registro linear busca uma sagital para cada ponto de cruzament que registre a esta coronal. As informações para reconstrução são extraídas a partir das sagitais encontradas . . . . . . . . . . . . . . . 38

3.2 Registro cíclico. . . . . . . . . . . . . . . . . . . . . . . . . . . 39

3.3 Interpolação de B-Spline. (a) Vértices $P_{1}, \ldots, P_{n}$ como pontos de controle e a B-Spline resultante. Para cada vértice, o ponto mais próximo entre a B-Spline e os vértices são dados por $f_{i}^{(1)}$. (b) Os pontos de controle serão transladados na direção da normal (os círculos brancos), obtém-se uma nova B-Spline, com pontos de controle $P_{1}^{(2)}, \ldots, P_{n}^{(2)}$. (c) para cada vértice de entrada, atualizamse os pontos mais próximos, definindo $f_{i}^{(2)}$. (d) B-Spline final do polígono $P_{i}^{(k)}$, interpolando os vértices de entrada $P_{i}$. . . . . . .

3.4 Comparação da interpolação linear (em vermelho tracejado) e gerado por B-Spline, nota-se que ao utilizar a interpolação linear ocorre imprecisão na mudança de fase respiratória, diferente da B-Spline. . . . . . . . . . . . . . . . .

3.5 Dado uma sequência, definem-se diversos padrões respiratórios padrões, associados aos cruzamentos entre as sequências.

3.6 Definido um instante de tempo e uma sequência,obtém-se todos os níveis diafragmáticos e fases respiratórias nos cruzamentos existentes. 44

3.7 Execução do algoritmo para 3 sequências sagitais e 3 sequências coronais. As linhas verdes indicam a posição de cruzamento entre as sequências coronais e sagitais. . . . . . . . . . . . . . 45

3.8 Estrutura em árvore do segundo passo do algoritmo proposto. . .

3.9 Estrutura em árvore do terceiro passo do algoritmo proposto e formação da árvore de registros temporais. . . . . . . . . . . . .

3.10 Segundo passo do algoritmo proposto, visualizado no espaço. Os pontos azuis representam a ocorrência de registro temporal e os pontos verdes os locais onde o nível diafragmático pode ser definido pelo instantes de registro encontrados. . . . . . . . . . . . . . . . 47 
3.11 Terceiro passo do algoritmo proposto. Os pontos verdes correspondem aos registros temporais encontrados apenas na primeira etapa e os pontos em vermelho apresentam registros temporais na terceira etapa. Os pontos em amarelo indicam locais em que o nível diafragmático e a fase respiratória podem ser definidos a partir dos instantes de registro encontrado na terceira etapa. A ausência de pontos indica que não foram encontrados registros temporais e o nível diafragmático não pode ser determinado. . . . . . . . . . . 47

3.12 Resultado da árvore de registros. A cor de cada ponto define a forma com que a superfície diafragmática pode ser determinada. .

4.1 Sistema proposto para obtenção de registros temporais automaticamente e reconstrução da superfície diafragmática sincronizada. . 51

4.2 Aba de definição dos diretórios e tipos de sequência. . . . . . . . . 52

4.3 Aba de pré-visualização dos arquivos DICOMs e obtenção da função respiratório padrão. Na imagem da direita exibe-se o editor de função respiratória, no qual os pixels em azul podem ser movidos para pequenas correções. . . . . . . . . . . . . . . . . 53

4.4 Sequências descartadas por apresentarem pouca informação da superfície diafragmática. (a) Coronal. (b) Sagital. . . . . . . . . 53

4.5 Aba de criação das máscaras. . . . . . . . . . . . . . . . 54

4.6 Aba de segmentação por Transformada de Hough modificada com máscaras. . . . . . . . . . . . . . . . . . 55

4.7 Aba de segmentação manual por Transformada de Hough modificada. 56

5.1 Imagem 1 (a) P2. (b) P3. Imagem 2 (c) P2. (d) P3. . . . . . . 57

5.2 Imagem 3 (a) P2. (b) P3. Imagem 4 (c) P2. (d) P3. . . . . . . 58

5.3 Imagem 5 (a) P2. (b) P3. Imagem 6 (c) P2. (d) P3. . . . . . . 58

5.4 Imagem 7 (a) P2. (b) P3. Imagem 7 (c) P2. (d) P3. . . . . . . 58

5.5 Imagem 9 (a) P2. (b) P3. Imagem 10 (c) P2. (d) P3. . . . . . . . 59

5.6 Imagem 11 (a) P2. (b) P3. Imagem 12 (c) P2. (d) P3. . . . . . 60

5.7 Imagem 13 (a) P2. (b) P3. Imagem 14 (c) P2. (d) P3. . . . . . . 60 
5.8 Imagem 15 (a) P2. (b) P3. Imagem 16 (c) P2. (d) P3. . . . . . . 61

5.9 Imagem 17 (a) P2. (b) P3. Imagem 18 (c) P2. (d) P3. . . . . . . 61

5.10 Imagem 19 (a) P2. (b) P3. Imagem 20 (c) P2. (d) P3. . . . . . . 61

5.11 Imagem 21 (a) P2. (b) P3. Imagem 22 (c) P2. (d) P3. . . . . . . 62

5.12 Imagem 23 (a) P2. (b) P3. Imagem 24 (c) P2. (d) P3. . . . . . . 62

5.13 Caso 1. Imagem 1. . . . . . . . . . . . . . . . . . . . . 62

5.14 Caso 1. Imagem 2. . . . . . . . . . . . . . . . . . . . 63

5.15 Caso 1. Imagem 3. . . . . . . . . . . . . . . . . . . 63

5.16 Caso 1. Imagem 4. . . . . . . . . . . . . . . . . . . . . . 64

5.17 Caso 1. Imagem 1. . . . . . . . . . . . . . . . . . . . 65

5.18 Caso 1. Imagem $6 . \ldots \ldots 5$

5.19 Caso 1. Imagem $7 . \ldots \ldots 66$

5.20 Caso 1. Imagem $8 \ldots \ldots \ldots 6$

5.21 Caso 1. Imagem 9. . . . . . . . . . . . . . . . . . . . . . . . 67

5.22 Caso 1. Imagem 10. . . . . . . . . . . . . . . . . . . . . 67

5.23 Caso 1. Imagem 11. . . . . . . . . . . . . . . . . . . 68

5.24 Caso 1. Imagem 12. . . . . . . . . . . . . . . . . . . . . 69

5.25 Caso 1. Imagem 13. . . . . . . . . . . . . . . . . . . . . 69

5.26 Caso 1. Imagem 14. . . . . . . . . . . . . . . . . . . 70

5.27 Caso 1. Imagem 15. . . . . . . . . . . . . . . . . . . . 70

5.28 Caso 1. Imagem 16. . . . . . . . . . . . . . . . . . . . 71

5.29 Caso 1. Imagem 17. . . . . . . . . . . . . . . . . . . . 71

5.30 Caso 1. Imagem 18. . . . . . . . . . . . . . . . . . . . 72

5.31 Reconstrução sagital da mesma sequência. . . . . . . . . . . . . . 72

5.32 Caso 1. Imagem $1 \ldots \ldots 73$

5.33 Caso 1. Imagem $2 \ldots \ldots 73$ 
5.34 Caso 1. Imagem $3 \ldots \ldots$. . . . . . . . . . . . . . . . . . 74

5.35 Caso 1. Imagem $4 \ldots \ldots . \ldots . \ldots . \ldots . \ldots 74$

5.36 Caso 1. Imagem 5 . . . . . . . . . . . . . . . . . . . . 75

5.37 Caso 1. Imagem $6 \ldots \ldots \ldots 75$

5.38 Caso 1. Imagem $7 \ldots \ldots \ldots 76$

5.39 Caso 1. Imagem $8 \ldots \ldots \ldots 76$

5.40 Caso 1. Imagem $9 \ldots \ldots$. . . . . . . . . . . . . . . 77

5.41 Caso 1. Imagem $10 \ldots \ldots 77$

5.42 Caso 1. Imagem $11 \ldots \ldots \ldots 78$

5.43 Caso 1. Imagem $12 \ldots \ldots \ldots 78$

5.44 Caso 1. Imagem $13 \ldots \ldots 79$

5.45 Caso 1. Imagem $14 \ldots \ldots . \ldots . \ldots . \ldots$

5.46 Caso 1. Imagem $15 \ldots \ldots$. . . . . . . . . . . . . . . 80

5.47 Caso 1. Imagem $16 \ldots \ldots$. . . . . . . . . . . . . . . . . . 81

5.48 Caso 1. Imagem $17 \ldots \ldots$. . . . . . . . . . . . . 81

5.49 Caso 1. Imagem $18 \ldots \ldots$. . . . . . . . . . . . . . . . 82

5.50 Comparação entre duas imagens sagitais das sequências utilizadas, pode pode-se observar a diferença em contraste entre elas. . . . . 84

A.1 Operação de dilatação binária com elemento estruturante $B$. . . 86

A.2 Operação de erosão binária com elemento estruturante $B$. . . . . 87

A.3 Operação de abertura binária com elemento estruturante $B$. . . 87

A.4 Operação de fechamento binária com elemento estruturante B. . . 88

A.5 Exemplo de aplicação de operadores morfológicos em imagens em tons de cinza. Fonte: http://rsbweb.nih.gov/ij/plugins/gray-morphology.html 88 


\section{Introdução}

A visualização direta do movimento pulmonar é impossível. Os pulmões ficam apoiados na caixa torácica e, ao abri-la, os pulmões colapsam, perdendo suas funções. A única maneira de visualizar o movimento pulmonar é indiretamente, por meio de técnicas de imageamento.

Existem atualmente três técnicas capazes de realizar o imageamento do pulmão: Tomografia Computadorizada (TC), Tomografia por Impedância Elétrica (TIE) e Ressonância Magnética (RM). A visualização por TC é utilizada na radioterapia de câncer do pulmão, auxiliando no planejamento de radioterapia $4 \mathrm{D}{ }^{[8,10,17,27]}$. No entanto, a TC emprega radiação ionizante, o que limita o seu uso. A TIE, técnica mais recente entre as apresentadas, baseia-se na estimação da distribuição de condutividade elétrica quando uma corrente de baixa amplitude é aplicada na superfície do corpo ${ }^{[24]}$. Como o ar tem grande diferença de condutividade comparado aos tecidos do tórax, esta técnica permite mapear com clareza o interior dos pulmões. A TIE, comparada com as demais, apresenta como vantagens o baixo custo, a portabilidade do equipamento e ser inofensivo ao ser humano. A principal desvantagem é a baixa resolução da imagem, o que limita sua aplicação.

A RM, baseada em excitação dos núcleos de hidrogênio por campo magnético, tem como vantagens: ausência de riscos ao paciente (exceto em condições especiais como portadores de marcapasso) e boa resolução de imagem, com contraste de tecidos moles. As principais desvantagens são a necessidade de longo tempo de amostragem e, para o caso particular do tórax, grande volume de ar

interno e a presença do coração e do sistema circulatório no mesmo espaço ${ }^{[10]}$. Comparativamente, a RM é a melhor forma para a visualização do movimento pulmonar.

\subsection{Motivação}

Até o momento, a análise da respiração é feita por métodos globais, tais como espirometria e pletismografia. Desta forma, os resultados locais não podem ser 
avaliados ${ }^{[7]}$. A observação do movimento pulmonar, identificando a contribuição de cada lóbulo, permitirá avaliar a eficiência no tratamento de doenças pulmonares. Iwasawa et al. ${ }^{[4]}$ utilizaram imagens de RM do pulmão para correlacionar alterações no movimento do diafragma em indivíduos com doença pulmonar obstrutiva crônica (DPOC).

Um grande desafio que envolve as pesquisas sobre imageamento médico é identificar se o algoritmo proposto apresenta os resultados esperados. Isto normalmente é feito pela comparação com um padrão ouro, que no caso de estudo não existe. Desta forma, é necessário que o próprio algoritmo tenha um método de autovalidação dos resultados. Utilizando como entrada múltiplas sequências bidimensionais de RM, uma mesma informação será obtida de por diferentes modos. Pela comparação das informações redundantes, pode-se verificar a qualidade dos resultados.

Este trabalho propõe um algoritmo para reconstruir a superfície diafragmática em diversos instantes, associadas a cada uma das imagens das sequências de RM coronal ou sagital. A reconstrução ocorrerá pela análise temporal da intersecção entre uma sequência coronal e uma sagital.

\subsection{Estrutura do Trabalho}

Este trabalho está estruturado da seguinte maneira. No capítulo 2, são apresentados conceitos básicos. No capítulo 3, o algoritmo proposto é apresentado. No capítulo 4, o sistema desenvolvido para automatizar o processo é apresentado. No capítulo 5, são apresentados os resultados e, no capítulo 6, as conclusões. 


\section{Conceitos Básicos Correlatos}

Neste capítulo, diversos conceitos são definidos. Inicialmente, será feita uma discussão sobre a aplicação da RM ao pulmão, a mecânica respiratória e as formas de imageamento do movimento respiratório. Em seguida, será feita uma breve explicação sobre o padrão DICOM, formato de arquivo adotado pela comunidade médica. Os conceitos de imagens espaço temporal tridimensional e bidimensional serão explicados. Também será explicado o conceito de função respiratória padrão, que é uma estimativa do movimento das estruturas pulmonares na imagem espaço temporal. Será feita uma explicação da transformada de Hough modificada, que determina padrões respiratórios presentes na imagem espaço temporal. Será explicado o algoritmo de contornos ativos, utilizado para relaxar a condição de sincronismo da transformada de Hough modificada. Devido ao grande volume de imagens espaço temporal que devem ser processados, deseja-se determinar automaticamente os padrões respiratórios diafragmáticos. Isto será feito utilizando a transformada de Hough modificada combinada com máscaras sobre o contorno pulmonar. Duas propostas de máscaras serão apresentadas, uma baseada em limiar de pixels e outra em operadores morfológicos. Será explicada a transformação dos padrões respiratórios diafragmáticos para o espaço tridimensional, utilizados para obtenção dos registros temporais.

\subsection{Ressonância Magnética Aplicada ao Pulmão}

Por muito tempo, desconsiderava-se o uso de RM para imageamento do pulmão. A sua estrutura fisiológica possui pouca quantidade de tecido, grande volume de ar interno e a presença do coração e do sistema circulatório no mesmo espaço. Todos

estes fatores geram diversas distorções nas imagens ${ }^{[7]}$. Nos anos 80 , algumas tentativas de aplicação de RM para o pulmão foram investigadas, porém com resultados extremamente negativos: a qualidade das imagens era baixa e o tempo necessário para gerar algum resultado plausível era longo. Com o advento da TC de alta resolução, com aplicações diretas no diagnóstico de doenças pulmonares, o uso de RM foi praticamente esquecido pela comunidade científica, médica e até mesmo pelos fabricantes de equipamentos. 


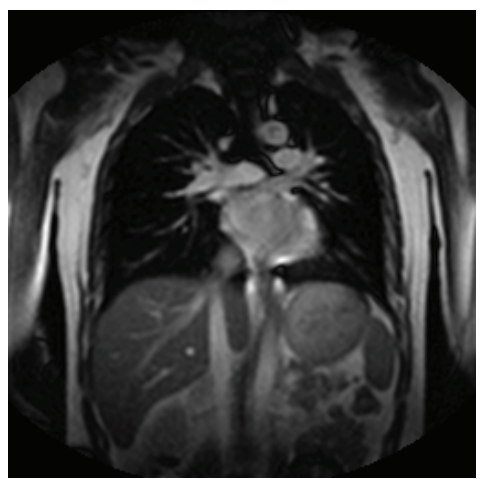

(a)

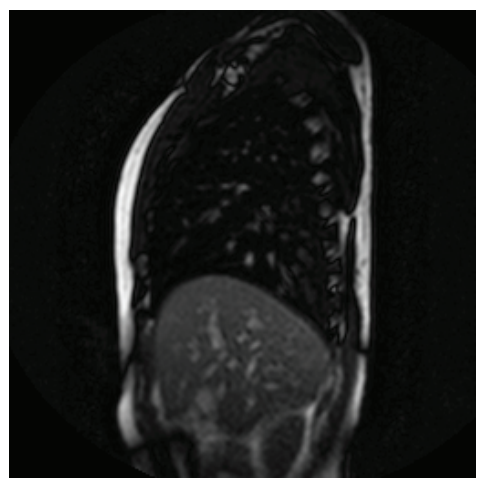

(b)

Figura 2.1: Imagem de RM do pulmão, fatia (a) coronal e (b) sagital.

Com o tempo, dois grupos tentaram reaplicar a RM ao pulmão. O primeiro grupo, composto por radiologistas interessados em RM cardíaca, descobriu importantes interações cardiorrespiratórias. Essas pesquisas investigaram a RM com contraste injetado nas veias e artérias pulmonares, analisando também a função do ventrículo direito ${ }^{[2]}$. O segundo grupo, composto por fisiologistas, propôs o uso de gases nobres hiperpolarizados como uma forma de contraste para a RM, permitindo gerar imagens de melhor qualidade em tempo de aquisição viável ${ }^{[12]}$.

Em linhas gerais, quanto à análise estrutural, a TC é ainda superior à RM. Neste aspecto, a principal vantagem da RM, o contraste de tecidos moles, não é utilizada, pois grande parte do seu interior é composto por ar, e o parênquima pulmonar não gera sinal suficiente para se tornar visível na imagem ${ }^{[7]}$. No entanto, um dos tópicos mais proeminentes tem sido a análise funcional do pulmão por imageamento. Com a evolução dos equipamentos, com maior resolução temporal, tornou-se possível analisar diversos aspectos funcionais que a TC não consegue capturar. Desta forma, a TC e a RM, aplicadas ao pulmão, são técnicas complementares. A Fig. 2.1 exibe uma imagem sagital e uma imagem coronal do pulmão em RM.

\subsubsection{Mecânica Respiratória}

O movimento respiratório apresenta componentes passivos e ativos. Os componentes passivos são: ossos, ligamentos e articulações da caixa torácica, enquanto que os componentes ativos são os grupos de músculos encarregados do bombeamento. Destes, o diafragma é quem providencia maior alteração de volume. Outros músculos que contribuem para alteração do volume pulmonar são os músculos intercostais internos e externos com ação inspiratória e expiratória, denomi- 

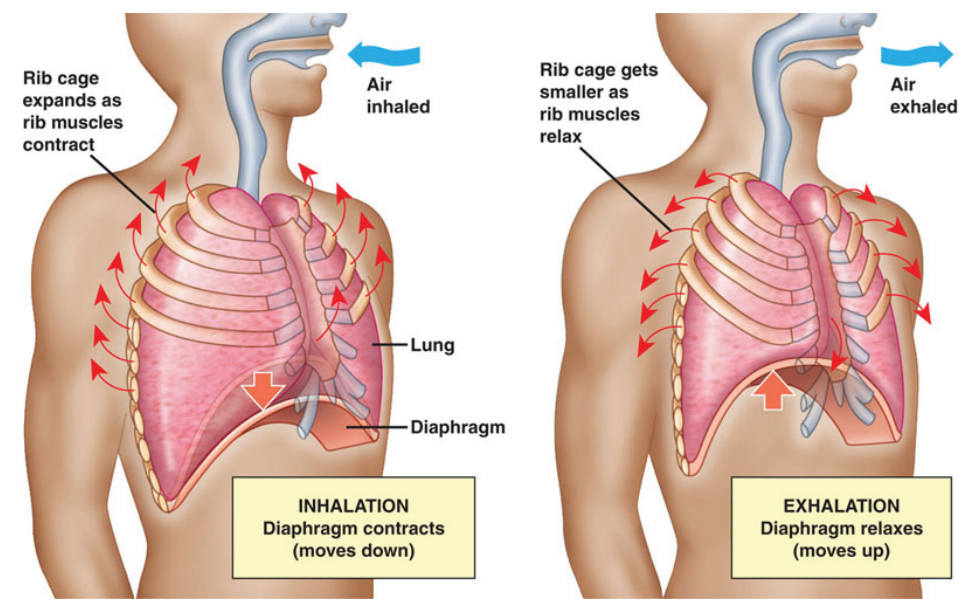

Figura 2.2: Mecânica respiratória. Fonte: http://www.kmph.matrik.edu.my/

nados músculos acessórios. As forças geradas pelo bombeamento respiratório são transmitidas aos pulmões pelo espaço pleural, que adicionalmente reduz a fricção do ar e permite que o pulmão deforme livremente. O movimento pulmonar é a reação dos tecidos a estas forças e depende principalmente das propriedades elásticas e resistivas da estrutura pulmonar. A Fig. 2.2 ilustra as mudanças durante a inspiração e respiração.

\subsubsection{Imageamento do Movimento Respiratório}

Existem essencialmente duas abordagens para o imageamento do movimento respiratório por RM. A primeira abordagem, denominada estática, utiliza sequências de imagens com o paciente com a respiração presa em pelo menos dois estágios diferentes. Esta abordagem resulta em imagens de alto detalhe anatômico com aplicações práticas para utilização em algoritmos de registro temporal. O revés desta abordagem é que o pulmão alcança um estágio uniforme de distribuição de tensões e pressão com respiração presa, diferente da respiração livre.

A segunda abordagem utiliza sistemas rápidos de aquisição em respiração livre. O aumento da velocidade de aquisição resulta em perda de detalhes na imagem. Em respiração tranquila, a frequência respiratória é de aproximadamente 12 ciclos por minuto, com movimentação do diafragma de aproximadamente 1.5 cm, ou seja, a máxima velocidade do diafragma é de aproximadamente $0.94 \mathrm{~cm} / \mathrm{s}$. Para evitar saltos na sequência e uma imagem de resolução utilizável, é necessária a utilização de uma taxa de aquisição inferior a 1s. Se imagens de RM tridimensional forem obtidas nesta taxa temporal, a qualidade das imagens será baixa. Como neste trabalho é desejável observar o movimento respiratório em estado nor- 

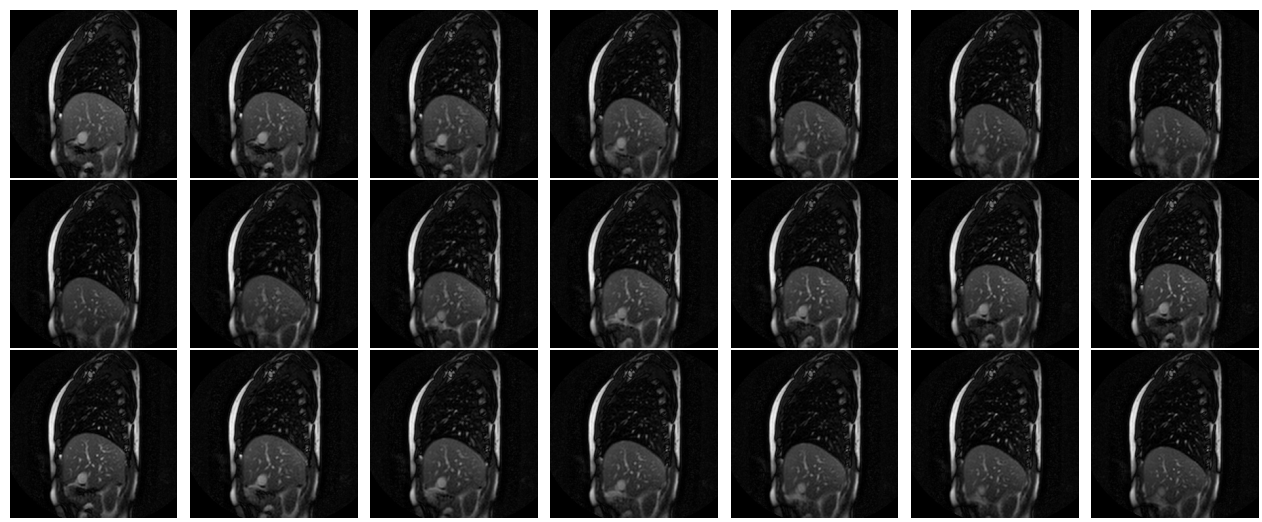

Figura 2.3: Sequência de imagens de RM temporal com corte sagital.
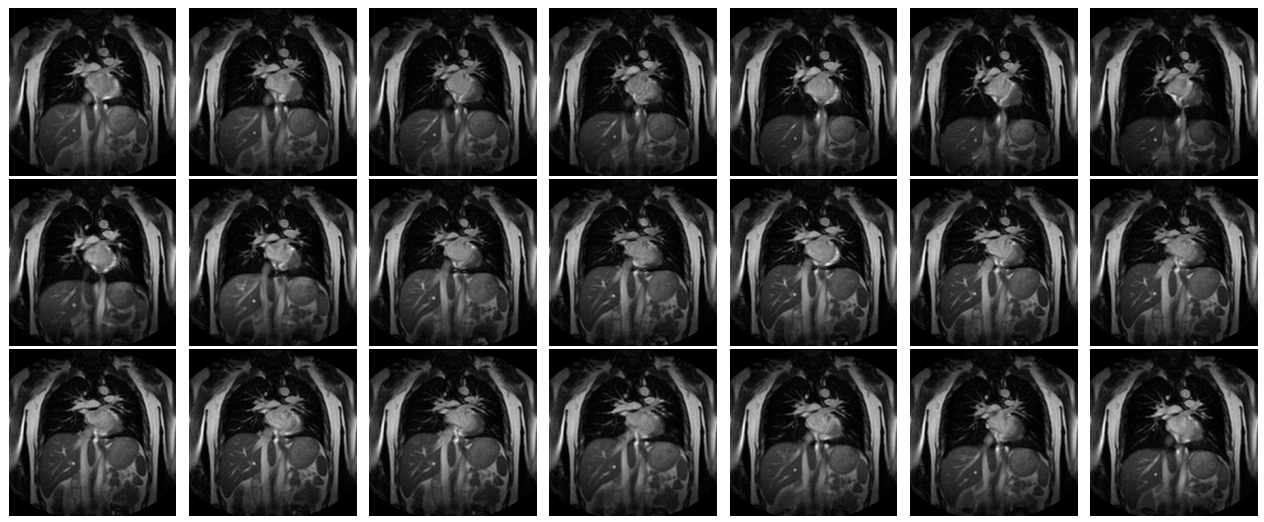

Figura 2.4: Sequência de imagens de RM temporal com corte coronal.

mal, a segunda abordagem utilizando imageamento bidimensional assíncrono será utilizada e, portanto, será necessário contornar os diversos problemas decorrentes da qualidade da imagem. As Figs 2.3 e 2.4 exibem exemplos de sequências sagital e coronal, extraídas utilizando a segunda abordagem de um mesmo voluntário. Nota-se que, como mencionado anteriormente, as sequências são assíncronas entre si.

\subsection{Arquivos DICOM}

Neste trabalho, são utilizadas sequências temporais de imagens de RM, armazenadas em formato DICOM (Digital Imaging Communications in Medicine). Este formato é um padrão definido em imagens médicas para impressão, armazenamento e transmissão de informações ${ }^{[14]}$. Arquivos em formato DICOM permitem a integração de diversos equipamentos.

Os arquivos DICOM suportam imagens de alta qualidade de até 16 bits em tons de cinza. Dentro do próprio arquivo são armazenadas informações do indivíduo, posição no espaço, espessura das fatias da imagem, parâmetros de exposição 
de imagem, dados do equipamento utilizado, dentre outras informações. Neste trabalho, são utilizadas sequências de imagens em tons de cinza com resolução de 12 bits, extraídas em diversas posições em cortes sagitais e coronais.

\subsection{Imagens Espaço Temporal}

Empilhando uma sequência temporal de imagens de RM, define-se um volume espaço temporal (STV) $I(x, y, t)$, onde $x$ e $y$ são coordenadas de cada pixel da imagem e $t$ é o tempo (vide Fig. 2.5). Considere a definição de um plano vertical $Q_{s}\left(x_{s}, y_{s}\right)$ que passa por um ponto $\left(x_{s}, y_{s}\right)$ paralelo ao eixo $t$. A intersecção do STV com este plano arbitrário define uma imagem espaço temporal (2DST) (vide Fig. 2.6). Nesta imagem, pode-se observar um padrão de movimento associado às estruturas internas: vasos sanguíneos, parede do pulmão, diafragma e coração. A imagem $2 \mathrm{DST} F_{s}(s, t)$ corresponde à intersecção do STV com o plano vertical. A superfície diafragmática será reconstruída baseada nas informações das imagens 2DST.

\subsection{Função Respiratória Padrão}

Como observado na Fig. 2.6, considerando que o movimento presente em todas as 2DSTs de um STV é síncrono, pode-se definir uma função que representa o movimento de todas as estruturas pulmonares, denominada função respiratória padrão. A superfície diafragmática é bem visível, pois possui um bom gradiente e maior amplitude quando comparada ao movimento de outras estruturas torácicas. A determinação da função respiratória padrão é melhor determinada ao redor do diafragma. Uma função respiratória padrão $f_{s}(t)$ é exibida na Fig. 2.7, representando uma sequência de valores inteiros não negativos no tempo. Supondo que todo movimento pulmonar é síncrono, a função respiratória padrão é uma estimativa do movimento das estruturas pulmonares em uma imagem 2DST.

\subsection{Transformada de Hough Modificada}

A transformada de Hough é uma técnica de extração de características utilizada em análise de imagens, visão computacional e processamento digital de imagens ${ }^{[9]}$. Ela é utilizada para detectar padrões na imagem, como retas e curvas. O objetivo da técnica é encontrar instâncias imperfeitas de padrões por meio de 

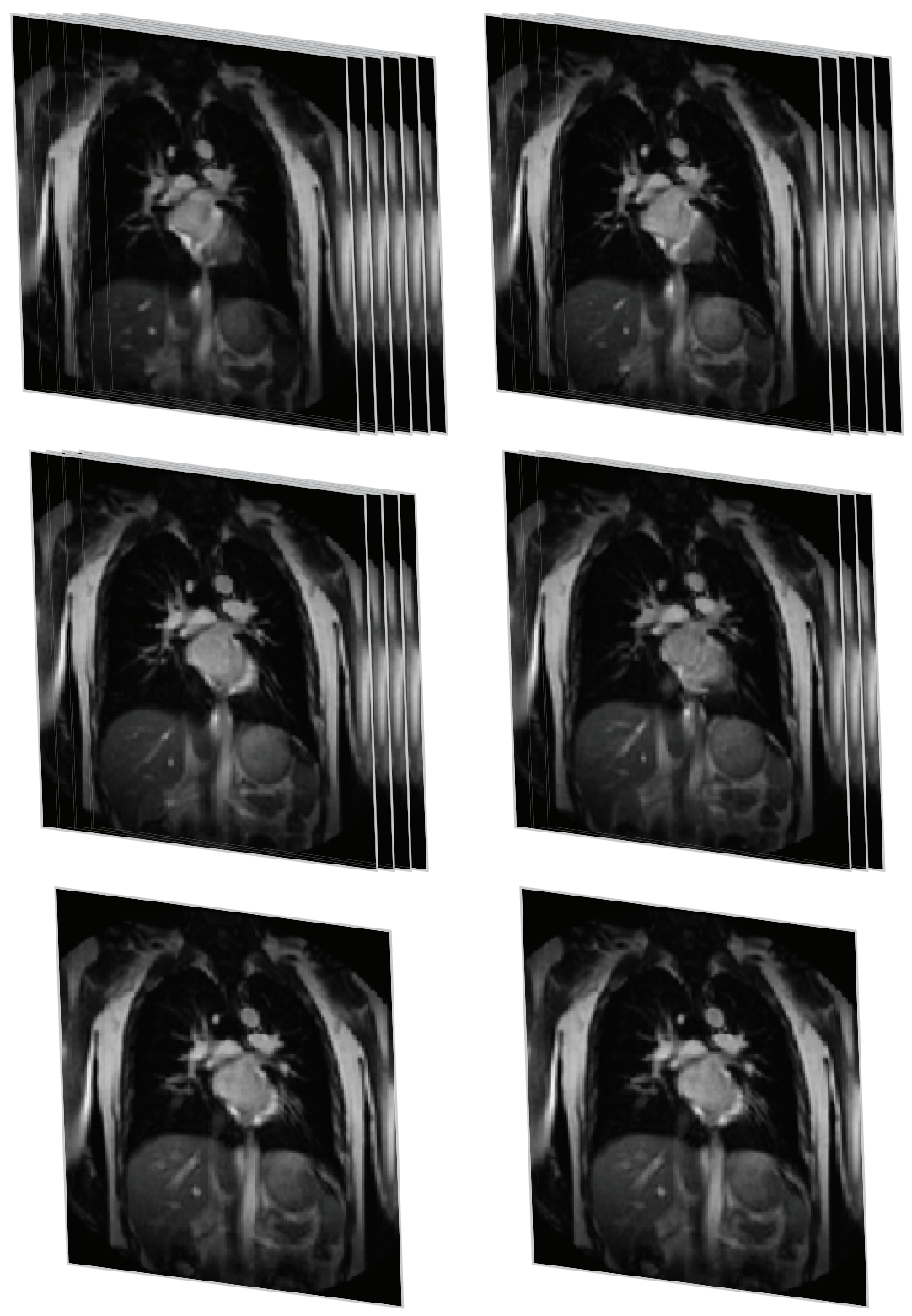

Figura 2.5: Empilhamento de uma sequência coronal, formando um STV.

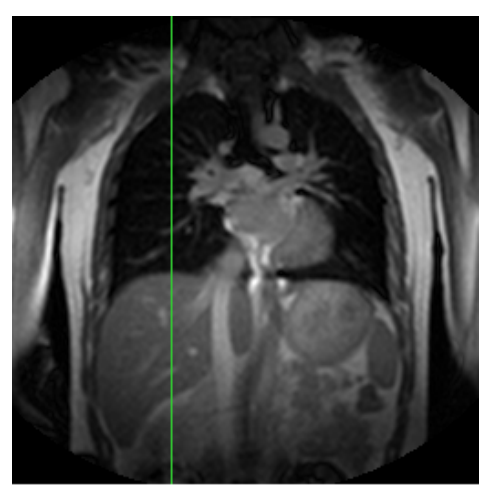

(a)

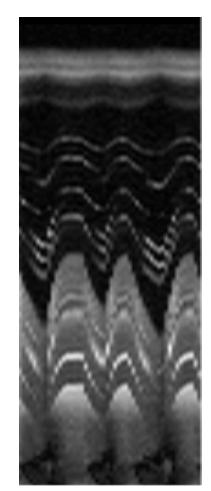

(b)

Figura 2.6: (a) Imagem original. (b) Imagem 2DST extraída do corte na posição da linha verde. 


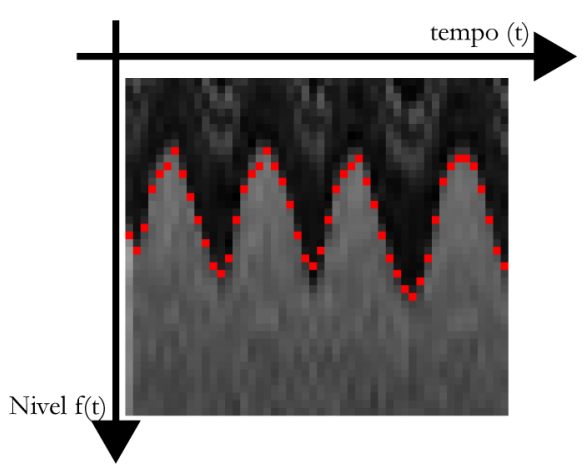

Figura 2.7: Exemplo de função respiratória padrão.

um procedimento de votação. A transformada de Hough modificada foi proposta para determinar a presença de padrões respiratórios $f_{k}(t)$ em uma imagem 2DST por Matsushita et al. ${ }^{[11]}$. Supõe-se que cada ponto se movimente sincronamente no tempo de acordo com a função respiratória padrão segundo uma escala e um deslocamento. Portanto, o movimento temporal de cada ponto é descrito por

$$
y=a \cdot f_{s}(t)-b
$$

onde $a$ e $b$ são a escala e o deslocamento da $f_{s}(t)$, respectivamente. A busca por padrões respiratórios $f_{k}(t)$ pode ser resumida como sendo a identificação de um grande conjunto de pares $(a, b)$ para o maior número possível de imagens 2DST para um dado STV.

Uma imagem de aresta é determinada a partir de uma imagem 2DST utilizando um filtro de gradiente vertical ${ }^{[3]}$. Um padrão respiratório é completamente especificado por um par $(a, b)$. Para a detecção de um padrão respiratório, a transformada de Hough modificada mapeia cada pixel aresta $(t, y)$ a partir da imagem 2DST para o espaço paramétrico de Hough, que é dividido em células, e cada célula corresponde a um par $(a, b)$. Cada pixel aresta $(t, y)$ na imagem 2DST representa uma reta no espaço paramétrico de Hough, as células correspondentes são incrementadas. Este processo é repetido para todos os pixels característicos. Todas as células no espaço paramétrico de Hough mapeiam um padrão respiratório na imagem 2DST.

Desta maneira, a intensidade de cada célula $(a, b)$ no espaço paramétrico de Hough é proporcional à probabilidade de encontrar uma escala e um deslocamento para a função respiratória padrão na imagem aresta 2DST. A Fig. 2.8 exibe dois pixels da imagem 2DST que foram mapeados para duas retas no espaço paramétrico de Hough. Estas duas retas se interseccionam em uma célula no 


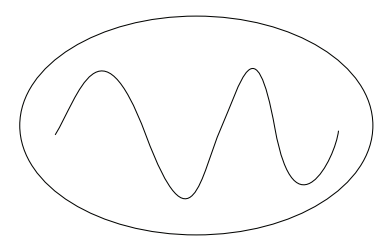

(a)

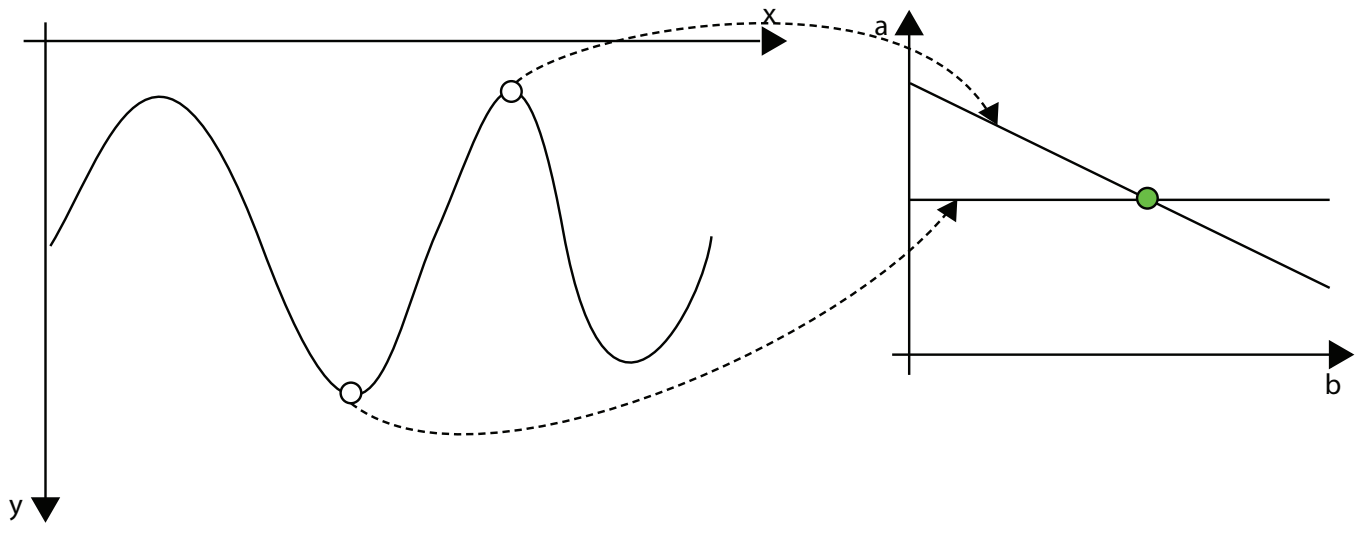

(b)

Figura 2.8: (a) Função respiratória padrão.(b) Mapeamento da imagem 2DST para o espaço paramétrico de Hough.

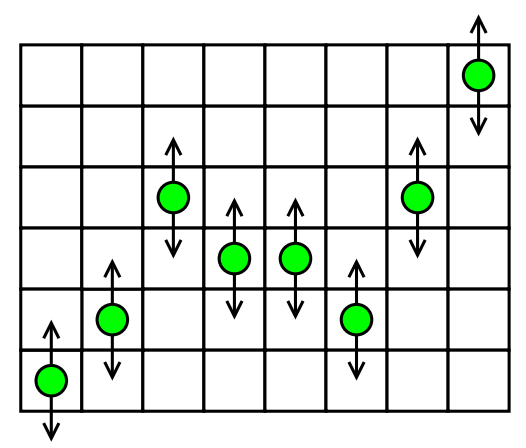

Figura 2.9: Um padrão respiratório resultante da transformada de Hough modificada. O algoritmo de contornos ativos procura por uma posição de menor energia na adjacência vertical dos pixels pertencentes ao padrão respiratório.

espaço paramétrico de Hough, esta célula é mapeada para um padrão respiratório na imagem 2DST. O algoritmo determina que a célula com maior intensidade representa com maior confiança um padrão respiratório.

\subsection{Algoritmo de Contornos Ativos}

A transformada de Hough modificada procura por padrões respiratórios totalmente síncronos à função respiratória padrão. Entretanto, é conhecido que o pulmão não se movimenta de forma totalmente síncrona e assim esta condição necessita ser relaxada. Isto será feito por meio do algoritmo de contornos ativos ${ }^{[6]}$. Stevo ${ }^{[21]}$ e Kadota et al. ${ }^{[5]}$ utilizaram uma adaptação do algoritmo de contornos ativos proposta por Williams e Shah ${ }^{[28]}$. Um padrão respiratório $f_{k}(t)$ é 
um conjunto de pixels com apenas um elemento por linha vertical. Considerando como uma sequência de pontos

$$
f_{k}(t)=\left\{y_{0}, y_{1},, \ldots, y_{n}\right\}
$$

onde $0 \leq t \leq n$, tal que $n$ é o número de imagens. A função energia a ser minimizada é definida como

$$
\operatorname{MinE}\left(f_{k}(t)\right)=E_{\text {int }}\left(f_{k}(t)\right)+E_{\text {image }}\left(f_{k}(t)\right)
$$

onde $E_{\text {int }}$ é a energia interna e é definida como

$$
E_{\text {int }}\left(f_{k}(t)\right)=\frac{1}{2} \alpha\left|\frac{\partial f_{k}(t)}{\partial t}\right|^{2}+\beta\left|\frac{\partial^{2} f_{k}(t)}{\partial t^{2}}\right|^{2}
$$

onde $\alpha$ e $\beta$ são parâmetros positivos. $E_{\text {image }}$ é o termo que atrai o padrão respiratório aos pixels com maior intensidade na imagem aresta. É definido como

$$
E_{\text {image }}\left(f_{k}(t)\right)=-\frac{\gamma}{\sigma\left(f_{k}(t)\right)}\left|\nabla I\left(f_{k}(t)\right)\right|
$$

onde $\gamma$ é um parâmetro positivo, $\sigma\left(f_{k}(t)\right)$ é o desvio padrão da intensidade dos pixels que compõem o padrão respiratório no instante $t$ e $\nabla I\left(f_{k}(t)\right)$ é a média do gradiente de intensidade dos pixels da imagem aresta que compõem o padrão respiratório no instante $t$. $\mathrm{O}$ algoritmo analisa as verticais ímpares ( $t$ ímpar) na sequência e depois as verticais pares ( $t$ par) na sequência. Na busca por um padrão respiratório com menor energia, a adjacência vertical de cada pixel do padrão respiratório atual é analisada. O processo é repetido até que nenhuma mudança ocorra.

\subsection{Segmentação Automática do Padrão Respiratório Dia- fragmático}

Stevo ${ }^{[21]}$ comprovou que a transformada de Hough modificada, com a função respiratória padrão, é uma forma robusta de detecção do padrão respiratório diafragmático. No entanto, a sua aplicação direta em 2DSTs necessita de uma verificação, pois o ponto de máximo do espaço de Hough paramétrico não corresponde necessariamente ao padrão respiratório diafragmático. Para a automação do processo, existem duas alternativas: adicionar alguma regra à busca de pontos de máximo no espaço de Hough paramétrico ou alterar a 2DST utilizada, de forma que o ponto de maior intensidade sempre corresponda ao padrão respira- 


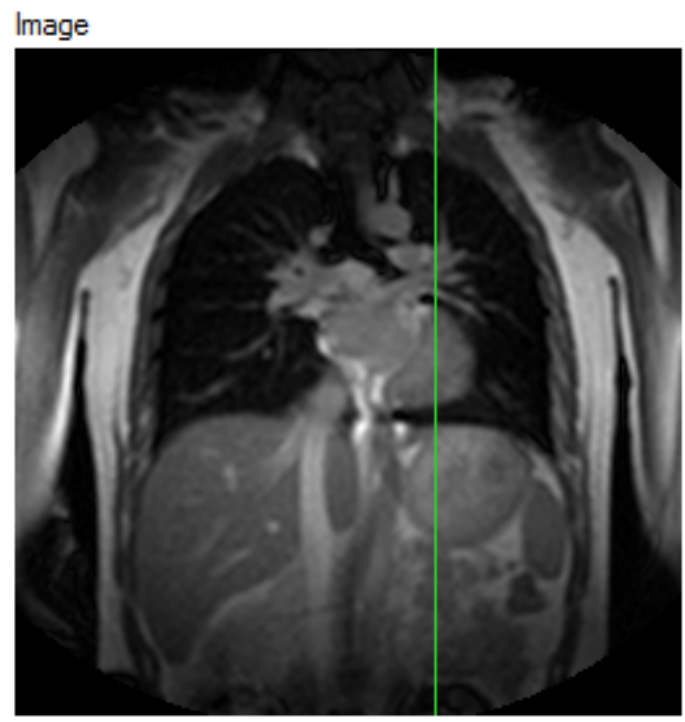

(a)

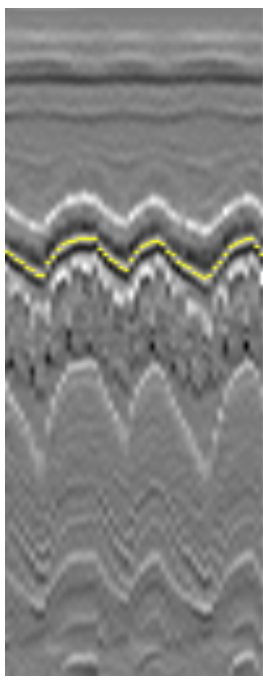

(b)

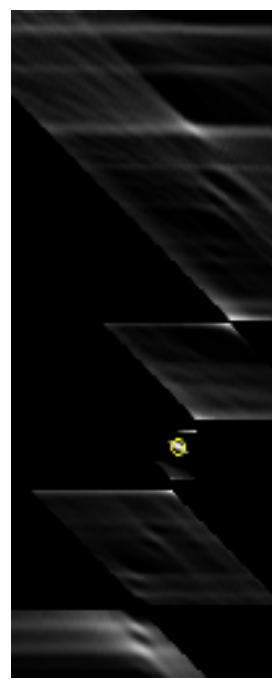

(c)

Figura 2.10: (a) Imagem de uma sequência coronal. A linha vertical representa a posição de corte para formar a 2DST. (b) Imagem aresta da 2DST com padrão respiratório encontrado, que não corresponde ao diafragma. (c) Posição do padrão encontrado no espaço de Hough paramétrico.

tório diafragmático. A Fig. 2.10 ilustra a ocorrência deste problema, no qual o ponto de máximo do espaço de Hough paramétrico não corresponde ao padrão respiratório diafragmático.

Assim sendo, foram utilizados dois algoritmos que permitem determinar automaticamente o padrão respiratório diafragmático: um baseado em limiarização de pixels e outro em operadores morfológicos.

\subsubsection{Máscara Baseada em Limiarização}

Tavares et al. ${ }^{[23]}$ propuseram um algoritmo de segmentação do pulmão por limiarização de pixels. Sabe-se que o pulmão tem o interior preenchido por ar e, portanto, com baixa intensidade de pixels na imagem. Assim, pode-se binarizar a imagem pela definição de um limiar de pixels. O resultado são duas regiões escuras, representando o fundo e uma estimativa do interior do pulmão, e uma região clara, que equivale ao corpo do indivíduo.

Para isolar a região do pulmão, é aplicado um algoritmo derotulação, que agrupa pixels conectados e extrai a região de interesse. Filtros de mediana são aplicados, para remoção de ruidos de sal e pimenta, e o contorno pulmonar é segmentado. Aplicando os operadores morfológicos de erosão e dilatação ao contorno obtido obtém-se duas imagens. Aplicando um operador XOR entre as imagens, 


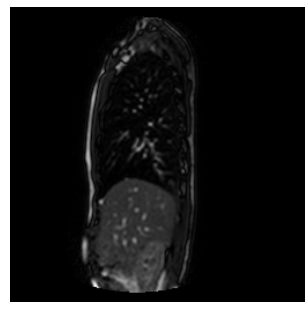

(a)

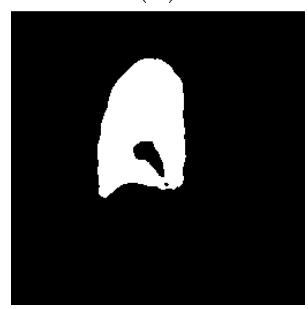

(d)

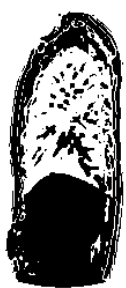

(b)

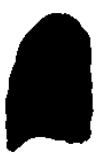

(e)

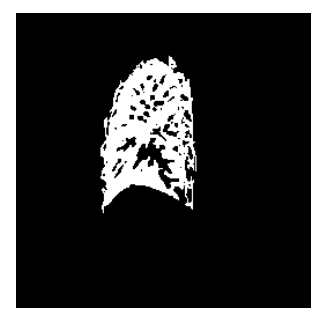

(c)

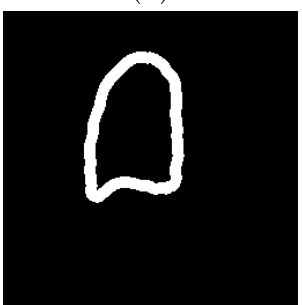

(f)

Figura 2.11: Criação de uma máscara definindo o contorno pulmonar. (a) Imagem de RM original. (b) Imagem binarizada, com limiar definido manualmente. (c) Isolamento dos pulmão pelo algoritmo de rotulação. (d) Aplicação de filtros de mediana para remoção de ruído. (e) Interior do pulmão determinado. (f) Máscara determinada após a aplicação de operadores morfológicos e do operador XOR.

obtém-se a máscara do contorno pulmonar. A Fig. 2.11 ilustra a execução do algoritmo.

Embora este algoritmo apresente resultados confiáveis para uma boa quantidade de sequências, surgem alguns problemas na sua utilização. O primeiro deles é a escolha dos parâmetros, que necessitam de avaliação individual para cada imagem o que impossibilita sua utilização de forma automática. Em especial, a seleção do limiar é influenciada pelo pulsar sanguíneo, que resulta em alta intensidade de pixels, gerando máscaras inadequadas. Desta forma, determinar um bom limiar é uma tarefa complexa.

\subsubsection{Máscaras Baseadas em Operadores Morfológicos}

Um algoritmo alternativo de segmentação por operadores morfológicos foi desenvolvido. Considerando a imagem em tons de cinza como uma superfície topográfica, na qual a intensidade de cada pixel representa uma cota, este algoritmo consiste na busca por ilhas escuras (regiões fechadas rodeadas por pixels de alta intensidade) com área suficientemente grande. Analisando as imagens de RM, nota-se que o interior dos pulmões é primariamente composto por ar e, portanto, com baixa intensidade de sinal (pixels escuros). Pode-se considerar que o pulmão é uma área de depressão ou vale na topografia da imagem. Como imagens co- 
ronais e sagitais apresentam características diferentes, o algoritmo utilizado para cada tipo é diferente.

Para sagitais, inicialmente é feita uma simplificação das imagens, aplicando uma abertura morfológica de área 500. No segundo passo, é feito um fechamento morfológico com elemento estruturante quadrado $7 \times 7$, a imagem é homogeneizada e os elementos internos são removidos. No terceiro passo, é usado fechamento de furos morfológico, facilitando a formação da ilha escura no interior do pulmão. No quarto passo, é feito o preenchimento da ilha escura, evidenciando os contornos do pulmão. No quinto passo, é feita uma subtração entre o quarto e o terceiro passos, removendo partes não pertencentes ao contorno do pulmão. No sexto passo, é feito uma abertura morfológica de área 1000, simplificando a imagem. No sétimo passo, é feita uma binarização da imagem. No oitavo passo é feita uma suavização do contorno utilizando sucessivas aberturas e fechamentos morfológicos com um elemento estruturante em disco de raio 5. No último passo, aplica-se fechamento de furos e o contorno do pulmão é segmentado. A esse contorno são aplicados uma dilatação e uma erosão, formando duas imagens. Realizando o operador XOR entre ambas define-se a máscara. A Fig. 2.12 exibe a execução do algoritmo passo-a-passo.

As imagens coronais exibem dois pulmões em cada imagem, logo o algoritmo deve ser capaz de reconhecer duas ilhas escuras. Inicialmente é construída uma barreira de contenção, composta por um círculo e dois retângulos. Esta barreira é necessária para a formação das ilhas no interior dos pulmões, evitando vazamento pela parte superior (que apresenta intensidade de pixels inferior à média) ou conexão entre os dois pulmões. Em sequência, é feito uma abertura morfológica com elemento estruturante retangular 20x10. No passo seguinte é feito um fechamento com elemento estruturante de linha horizontal com comprimento 5, reforçando as bordas do contorno dos pulmões. Aplica-se fechamento de buracos morfológicos e as ilhas são preenchidas, isolando a área interna dos pulmões. Uma subtração entre as imagens dos dois passos anteriores é feita, destacando as ilhas. Aplica-se novamenteo fechamento de buracos morfológicos e e uma abertura morfológica de área 1000 é aplicado, simplificando os contornos. A imagem resultante é binarizada por limiar de Otsu ${ }^{[19]}$. Em seguida é aplicado uma abertura com elemento estruturante de linha vertical com comprimento 20 , suavizando o contorno. No último passo é feito um abertura morfológica de área 


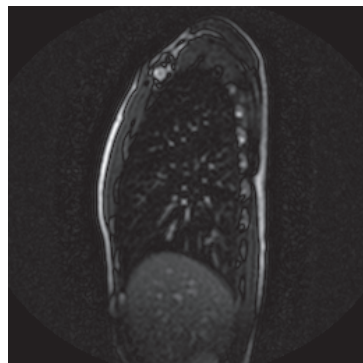

(a)

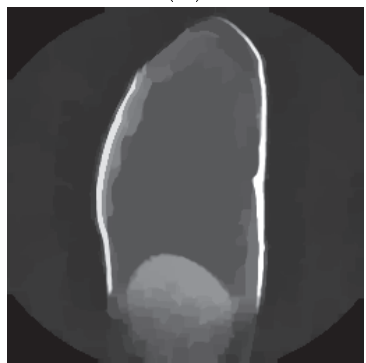

(d)

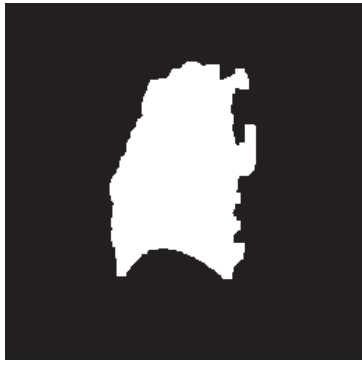

(g)

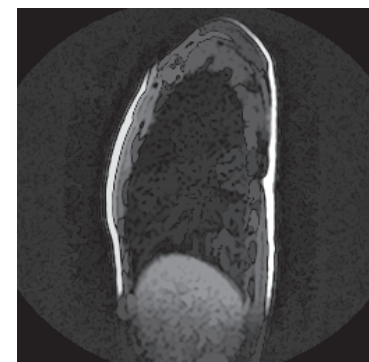

(b)

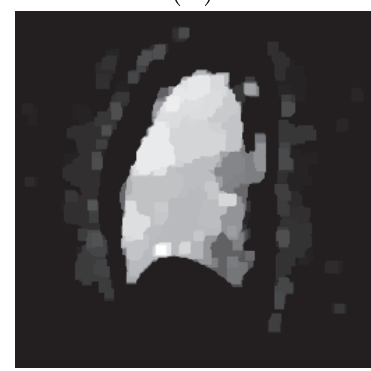

(e)

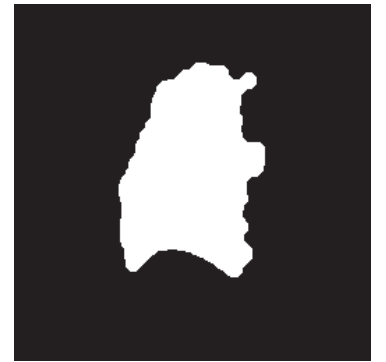

(h)

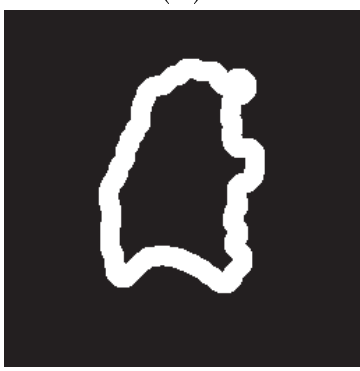

(j)

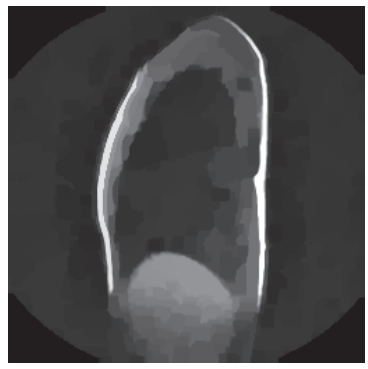

(c)

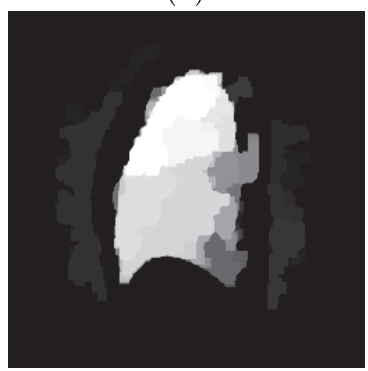

(f)

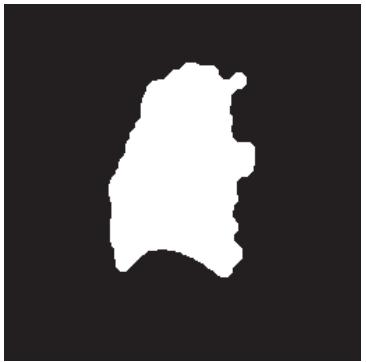

(i)

Figura 2.12: Aplicação passo-a-passo do algoritmo para sequências coronais: (a) Imagem original. (b) Simplificação da imagem. (c) Reforço das delimitações da ilha. (d) Preenchimento da ilha. (e) Subtração entre os dois passos anteriores para evidenciar a ilha. (f) Simplificação da imagem. (g) Binarização da imagem por limiarização. (h) Suavização do contorno. (i) Preenchimento de buracos. (j) Máscara final após, a aplicação de dilatação e erosão sobre a imagem anterior, e operador XOR entre elas. 
100 para remoção de pequenos componentes. A esse contorno são aplicados uma dilatação e uma erosão, formando duas imagens. Realizando o operador XOR entre ambas define-se a máscara. A Fig. 2.13 exibe um exemplo do algoritmo passo-a-passo.

\subsubsection{Aplicação das Máscaras}

De posse das máscaras, torna-se possível aplicar o método da transformada de Hough modificada nas 2DSTs para segmentação automática do padrão respiratório diafragmático. Nota-se que com as máscaras, as 2DSTs apresentam somente duas regiões visíveis: o apex (superior) e a base dos pulmões. Como a região de interesse é o diafragma (portanto, a base dos pulmões), a região superior da 2DST é ocultada. Assim, o espaço de Hough paramétrico resultante fica consideravelmente simplificado, com ponto de máxima intensidade correspondendo sempre ao padrão respiratório diafragmático.

Em sequência, é feito um relaxamento do padrão respiratório diafragmático obtido, utilizando o algoritmo de contornos ativos com a imagem 2DST aresta. O algoritmo realiza ajustes finos nos padrões respiratórios diafragmáticos. A Fig. 2.14 ilustra o mesmo procedimento utilizando as máscaras. Nota-se a diferença no espaço paramétrico de Hough ao comparar com a Fig. 2.10.

\subsection{Transformação para o Espaço Tridimensional}

Até o momento, cada sequência temporal foi analisada separadamente. Para utilizar todas as sequências combinadas, é necessário converter os padrões respiratórios diafragmáticos para o espaço tridimensional. Um pixel na imagem é convertido para o espaço tridimensional por

$$
\left[\begin{array}{c}
p_{x} \\
p_{y} \\
p_{z} \\
1.0
\end{array}\right]=\left[\begin{array}{cccc}
x_{x} \Delta_{i} & y_{x} \Delta_{j} & 0.0 & s_{x} \\
x_{y} \Delta_{i} & y_{y} \Delta_{j} & 0.0 & s_{y} \\
x_{z} \Delta_{i} & y_{z} \Delta_{j} & 0.0 & s_{z} \\
0.0 & 0.0 & 0.0 & 1.0
\end{array}\right] \cdot\left[\begin{array}{c}
i \\
j \\
0.0 \\
1.0
\end{array}\right]
$$




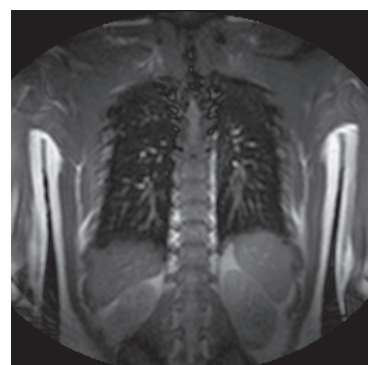

(a)

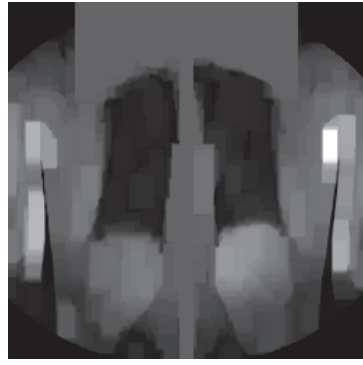

(d)

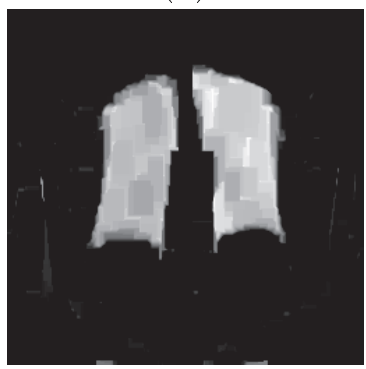

(g)

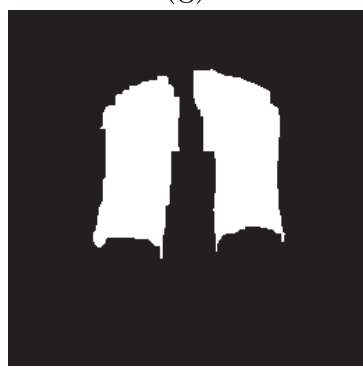

(j)

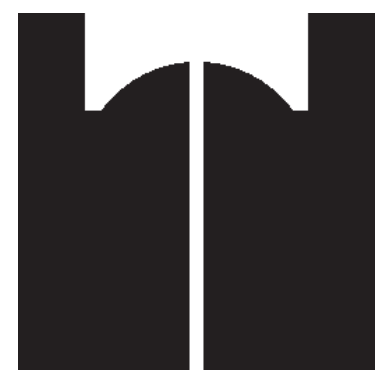

(b)

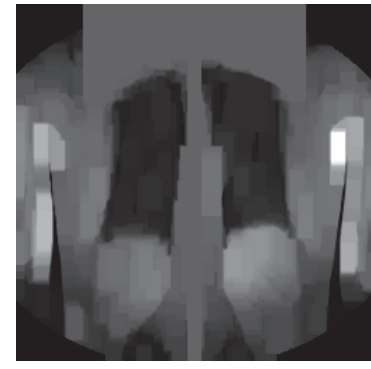

(e)

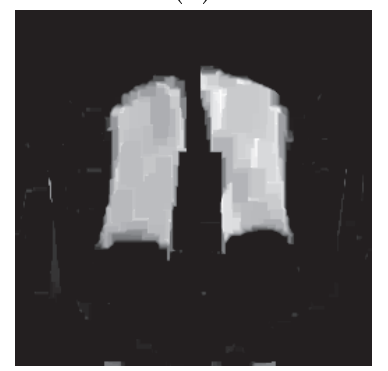

(h)

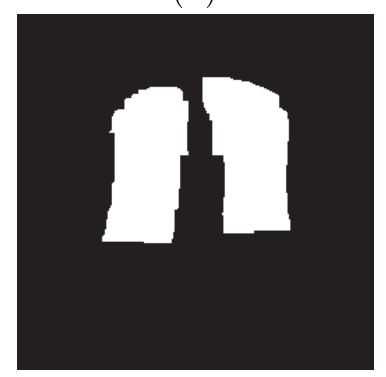

(k)

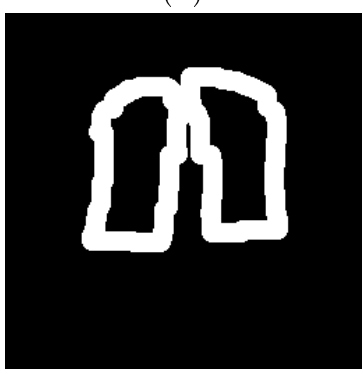

(m)

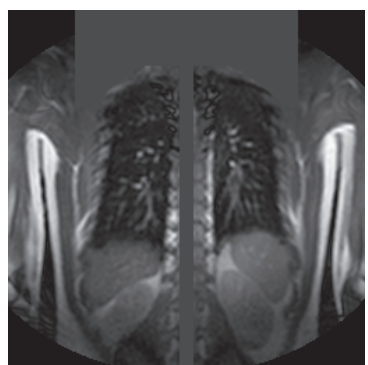

(c)

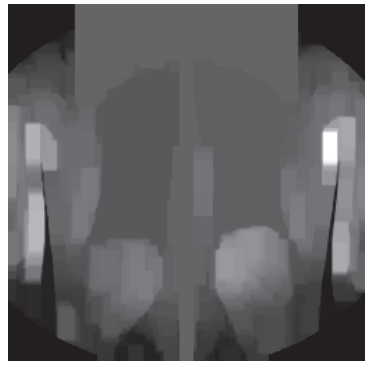

(f)

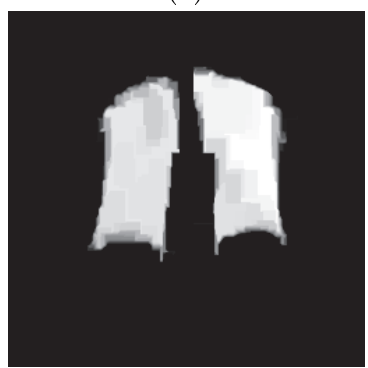

(i)

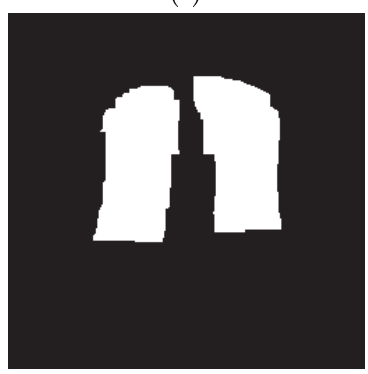

(1)

Figura 2.13: Aplicação passo-a-passo do algoritmo para sequências coronais: (a) Imagem original (b) Barreira de contenção. (c) Sobreposíção da barreira sobre a imagem. (d) Simplificação da imagem. (e) Reforço das bordas das ilhas escuras. (f) Preenchimento da ilha. (g) Subtração dos dois passos anteriores para evidenciar a ilha. (i) Novo preenchimento da ilha para cobrir buracos remanescentes. (h) Simplificação da imagem. (j) Binarização da imagem. (k) Suavização do contorno. (l) Limpeza de pequenos componentes conectados. (m) Máscara final após, a aplicação de dilatação e erosão sobre a imagem anterior, e operador XOR entre elas. 


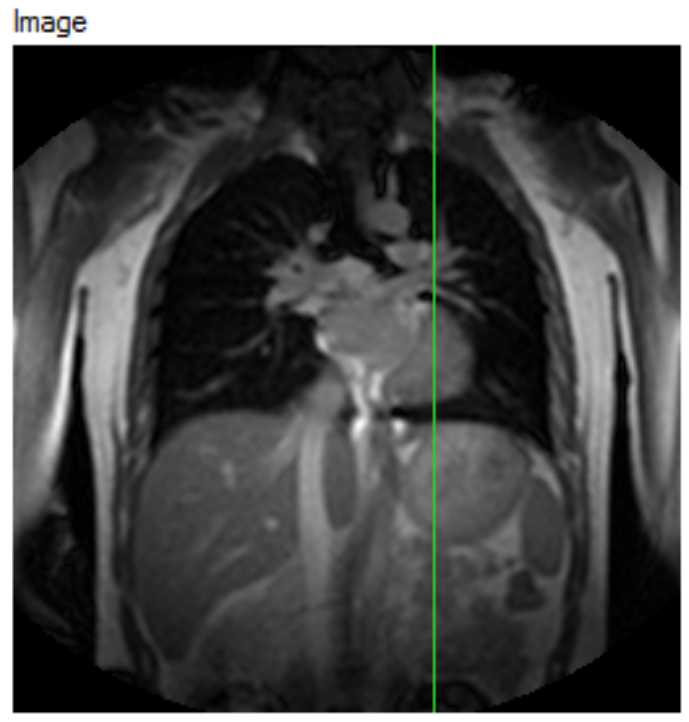

(a)

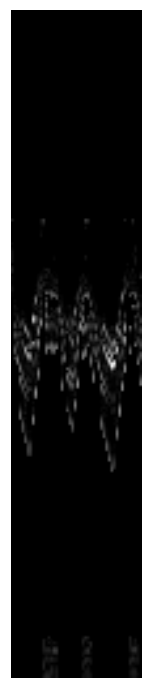

(b)

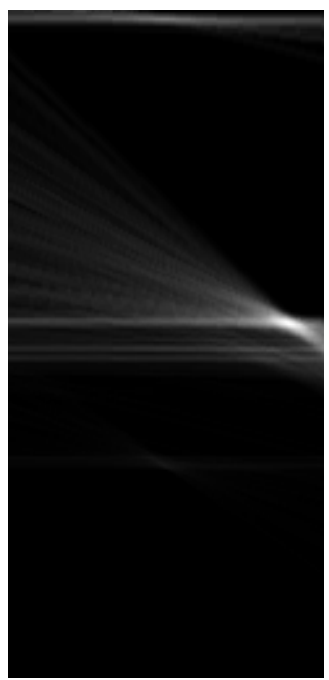

(c)

Figura 2.14: Reaplicando a segmentação ilustrada na Fig. 2.10. (a) Imagem coronal onde a linha exibe a posição de corte para extrair a 2DST. (b) 2DST da imagem aresta com as máscaras sobrepostas. (c) Espaço de Hough paramétrico com aplicação das máscaras, no qual há apenas um ponto de máximo correspondente ao padrão respiratório diafragmático.

$$
\left[\begin{array}{c}
p_{x} \\
p_{y} \\
p_{z} \\
1.0
\end{array}\right]=\left[\begin{array}{c}
x_{x} \Delta_{i} i+y_{x} \Delta_{j} j+s_{x} \\
x_{y} \Delta_{i} i+y_{y} \Delta_{j} j+s_{y} \\
x_{z} \Delta_{i} i+y_{z} \Delta_{j} j+s_{z} \\
1.0
\end{array}\right]
$$

onde $x_{x}, x_{y}$ e $x_{z}$ definem as direções do eixo $x$ no espaço tridimensional, $y_{x}, y_{y}$ e $y_{z}$ definem as direções do eixo $y$ no espaço tridimensional. $\Delta_{i}$ é o espaçamento da coluna e $\Delta_{j}$ é o espaçamento da linha. $s_{x}, s_{y}$ e $s_{z}$ correspondem ao posicionamento inicial do primeiro pixel. $p_{x}, p_{y}$ e $p_{z}$ correspondem às coordenadas de $(i, j)$ no espaço tridimensional.

Desta forma, todos os padrões respiratórios diafragmáticos coronais e sagitais são transformados para um único sistema de coordenadas.

\subsection{Registro Temporal}

Define-se registro temporal de imagens como o casamento entre duas imagens, uma coronal e outra sagital, de forma que exista continuidade nas posições das estruturas pulmonares, para imagens adquiridas em instantes distintos.

Stevo et al. ${ }^{[20]}$ realizaram o registro temporal entre duas sequências de 
imagens, uma coronal e outra sagital, pela comparação da intensidade dos pixels presentes na vertical comum. Entretanto, este método fornece como solução pares de imagens cujo registro sem sempre é visualmente adequado, além de grande suscetibilidade a ruídos. Sato. et al ${ }^{[18]}$ propuseram uma outra forma de registro temporal, pela análise do nível diafragmático e da fase respiratória. O inflar e desinflar dos alvéolos durante a inspiração e expiração alteram a tensão superficial, de modo que ocorre a histerese característica do pulmão. Isto significa que a inalação segue uma relação diferente de pressão por volume, quando comparada com a expiração ${ }^{[16]}$. Desta forma, a fase respiratória deve ser considerada na definição de registros temporais. O padrão respiratório diafragmático corresponde a uma sequência temporal de níveis diafragmáticos de onde é possível obter a fase respiratória.

Inicialmente, é feita uma classificação de fases respiratórias, pela diferença entre o nível diafragmático atual e o anterior. Caso a diferença seja positiva, o indivíduo está em expiração, caso seja negativa, está em inspiração. Se o nível diafragmático e a fase respiratória correspondam, ocorre o registro temporal. A Fig. 2.15 ilustra este procedimento para um par de 2DSTs, uma gerada pela sequência sagital e outro pela sequência coronal. Para um dado instante (em verde) no padrão diafragmático coronal (vide Fig. 2.15(a)), o algoritmo busca na sequência sagital (vide Fig. 2.15(b)) pelas condições de registro (nível diafragmático e fase respiratória). Os pontos em verde na sequência sagital correspondem a registros temporais, enquanto os pontos em amarelo indicam mesmo nível diafragmático porém em fase respiratória distinta. A Fig. 2.16 exibe um par de imagens sagital-coronal em registro temporal, nota-se a correspondência exata do nível diafragmático e de outras estruturas pulmonares. 


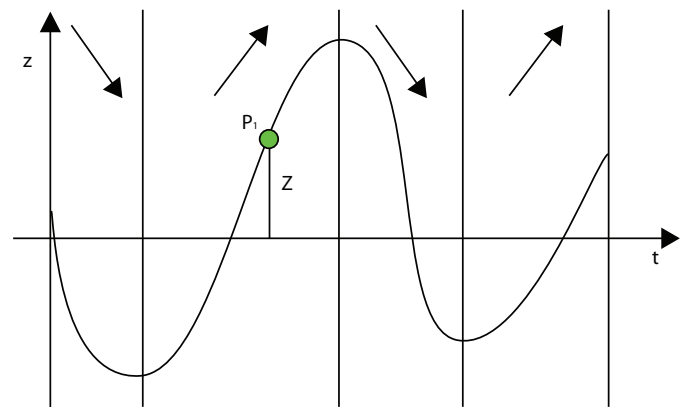

(a)

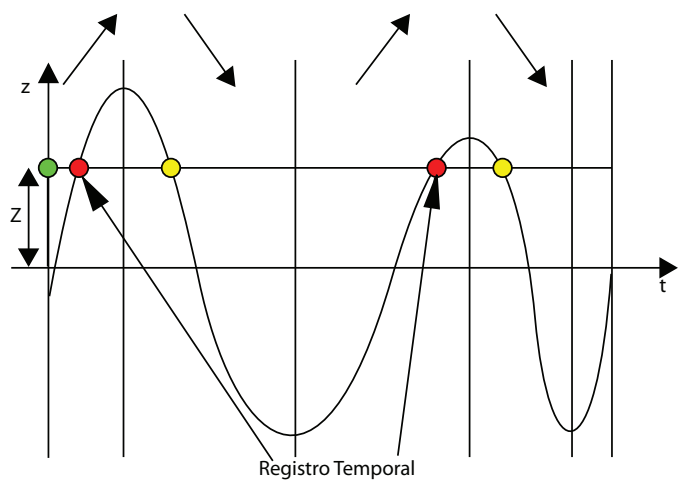

(b)

Figura 2.15: (a) Padrão respiratório diafragmático coronal, deseja-se registrar o instante associado ao ponto $P$. (b) Padrão respiratório diafragmático sagital. Registros temporais representados pelos círculos verdes. As setas determinam a fase respiratória: para baixo, o indivíduo está em inspiração e para cima o indivíduo está em expiração

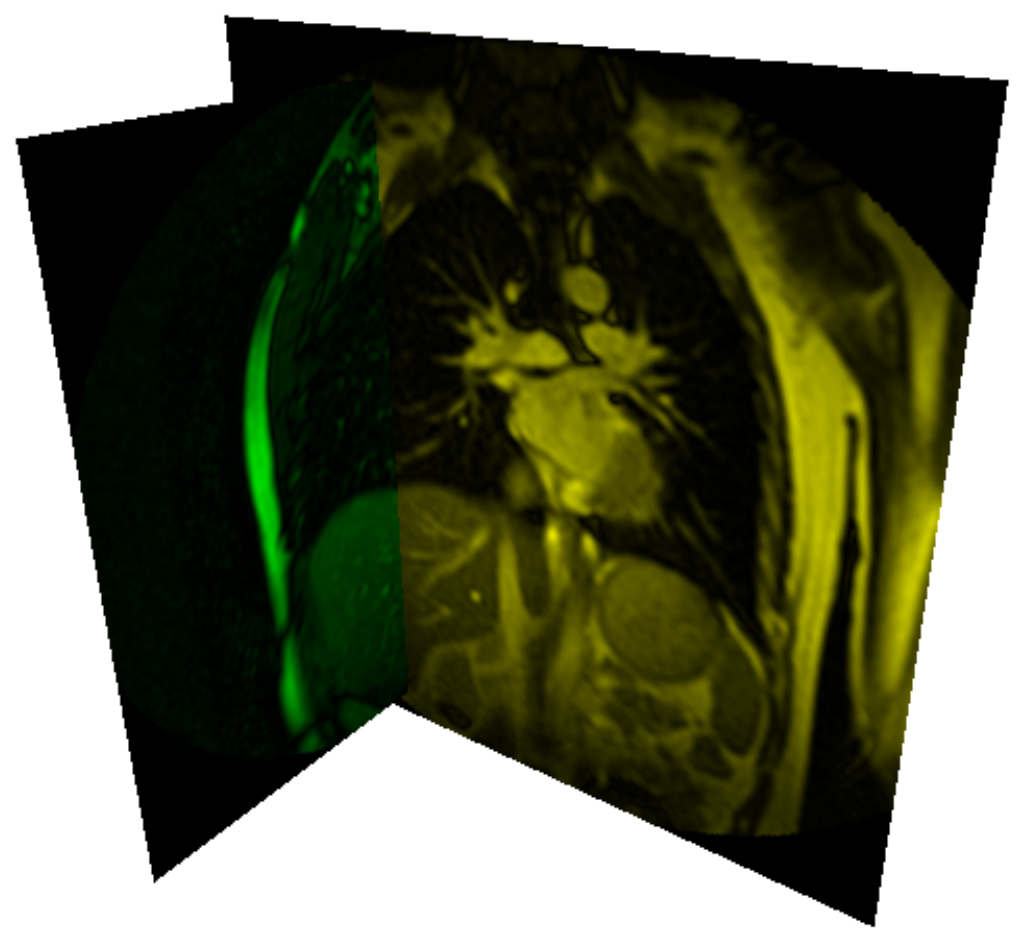

Figura 2.16: Registro temporal entre duas imagens. 


\section{Reconstrução da Superfície Diafragmática}

Neste capítulo, será apresentado o algoritmo proposto de reconstrução da superfície diafragmática tridimensional em movimento, baseado nos padrões respiratórios diafragmáticos. Inicialmente será feita uma revisão bibliográfica sobre a reconstrução da superfície diafragmática, com atenção especial aos algoritmos de registro temporal entre as sequências para obter um modelo tridimensional animado. Em seguida, será apresentada uma proposta de algoritmo de registro envolvendo todos padrões respiratórios diafragmáticos de um grupo de sequências. Ao final, será apresentada a proposta de reconstrução da superfície diafragmática em movimento, estabelecendo as regras de registro entre as sequências e a utilização dos padrões respiratórios diafragmáticos para gerar o modelo tridimensional em movimento.

\subsection{Registro Linear}

Tsuzuki et al. ${ }^{[25,26]}$ e Nakamura et al. ${ }^{[13]}$ pesquisaram o registro temporal de silhuetas vetoriais coronais e sagitais do pulmão extraídas de imagens de RM pelo método proposto por Asakura et al. ${ }^{[1]}$. Um modelo fio arame do pulmão é criado pela composição de silhuetas planares coronais e sagitais representando seções perpendiculares. O registro poligonal acontece no espaço tridimensional. O modelo fio de arame é gerado, definindo um modelo sólido B-Rep. Entretanto, o registro baseado exclusivamente nas informações vetoriais não é confiável, principalmente pelo fato de, ao se sobrepor as imagens originais, é possível observar discrepâncias.

Uma alternativa ao registro vetorial é o registro temporal descrito na seção 2.9. Considere que uma imagem coronal $C_{1}$ seja utilizada. Diversas sequências sagitais $\left(S_{1}, S_{2}, S_{3} . ., S_{n}\right)$ se cruzam à imagem coronal de referência em posições de intersecção no espaço tridimensional. O padrão respiratório diafragmático coronal para cada uma das posições foi determinado. O instante é definido pela imagem coronal inicial. Assim, definem-se o nível diafragmático e a fase respiratória para 


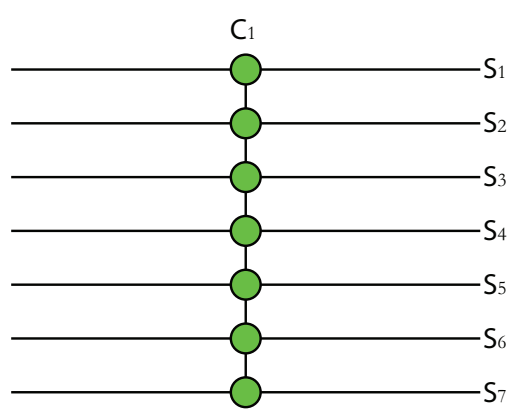

Figura 3.1: Exemplo de registro linear para uma imagem coronal, representada verticalmente e as diversas sagitais cruzadas a ela. O registro linear busca uma sagital para cada ponto de cruzament que registre a esta coronal. As informações para reconstrução são extraídas a partir das sagitais encontradas

cada uma das posições no espaço tridimensional para a imagem coronal. Em seguida, determina-se o instante em que cada sequência sagital registra a imagem coronal. Neste caso, os registros foram efetuados sem nenhuma validação. A Fig. 3.1 ilustra este procedimento, que será denominado registro linear.

\subsection{Registro Cíclico}

Stevo ${ }^{[21]}$ propôs um aprimoramento registro temporal. Considere que uma imagem coronal é escolhida e deseja-se registrá-la com duas sequências sagitais e uma terceira sequência coronal. Neste caso, existem quatro segmentos comuns entre cada par sagital-coronal. O nivel diafragmático e a fase respiratória para cada uma das posições na imagem coronal inicial são determinados. Na Fig. 3.2, as mesmas correspondem aos pontos $P_{1}$ e $P_{2}$. Os instantes que os registros temporais com as duas sequências sagitais ocorrem são determinados. Eles serão denominados por $t_{S_{1}, C 1}$ (instante em que ocorre o registro temporal segundo a sequência sagital $S_{1}$ e a coronal $C_{1}$ ) e $t_{S_{2}, C_{1}}$ (instante em que ocorre o registro temporal seguindo a sequência sagital $\mathrm{S} 2$ e a coronal $C_{1}$ ). O nível diafragmático e as fases respiratórioas nas posições $P_{1}$ e $P_{2}$ são definidos pela substituição dos instantes determinados $\left(t_{S_{1}, C_{1}}\right.$ e $t_{S_{2}, C_{1}}$, respectivamente) nos padrões respiratórios diafragmáticos sagitais correspondentes. Para a última sequência coronal, é necessário analisar os dois padrões respiratórios diafragmáticos simultaneamente. Os registros temporais devem ocorrer no mesmo instante para que apenas uma única imagem coronal esteja registrada com as duas imagens sagitais. Este algoritmo foi denominado como registro cíclico. Stevo ${ }^{[21]}$ descobriu que a condição rígida não era satisfeita para $P_{3}$ e $P_{4}$ em todas ocasiões. 


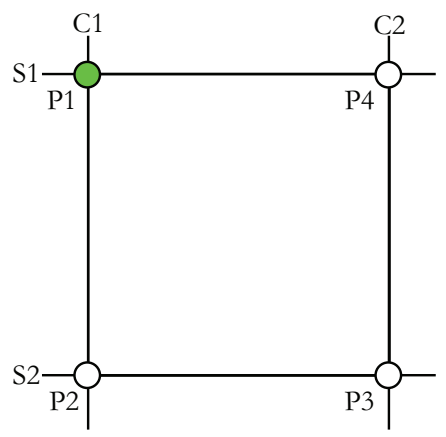

Figura 3.2: Registro cíclico.

\subsection{Interpolação do Padrão Respiratório por B-Spline}

O algoritmo proposto não deve se limitar à resolução temporal da sequência de imagens. Inicialmente foi utilizada a interpolação linear entre os níveis diafragmáticos associados a dois instantes consecutivos. Embora esta solução tenha apresentado resultados razoáveis para diversas posições, para os instantes onde a troca de fase respiratória ocorre, surgem imprecisões, impedindo que o registro temporal seja localizado exatamente. É preciso considerar que o padrão respiratório diafragmático representa um movimento contínuo. Para que isto ocorra efetivamente, o padrão respiratório diafragmático será interpolado por uma curva B-Spline, garantindo continuidade na primeira e na segunda derivada..

Maekawa et al. ${ }^{[22]}$ propuseram um algoritmo de interpolação de curva BSpline. O algoritmo recebe como entrada de $n$ pontos $\left(P_{1}, P_{2}, \ldots, P_{n}\right)$ e gera como saída uma curva B-Spline que interpola os pontos dados. Em outras palavras, o algortimo, a partir dos pontos dados, busca os pontos de controle para uma B-Spline que interpole os pontos de entrada.

No primeiro passo, assume-se que os vértices de entrada são os pontos de controle da B-Spline $P_{i}^{(1)}=P_{i}, i=1, \ldots, n$ onde o sobrescrito (1) representa a primeira iteração. O primeiro resultado obviamente não interpola ainda os vértices de entrada, como visto na Fig. 3.3(a). Para cada vértice calcula-se o ponto mais próximo na B-Spline encontrada, denominada por $f_{i}^{(1)}, i=1, \ldots, n$. Os pontos de controle da curva encontrada são deslocados ao longo do vetor normal em $f_{i}^{(1)}$ por $P_{i}-f_{i}^{(1)}$. Os novos pontos de controle são definidos como $P_{i}^{(2)}, i=1, \ldots, n$ (vide Fig. 3.3(b)). Na segunda iteração, o novo polígono é definido pelos novos pontos de controle $P_{i}^{(2)}, i=1, \ldots, n$ (vide Fig. 3.3(c)) e o processo se repete até uma condição de erro $\left|P_{i}-f_{i}^{(k)}\right|$ é satisfeita. 


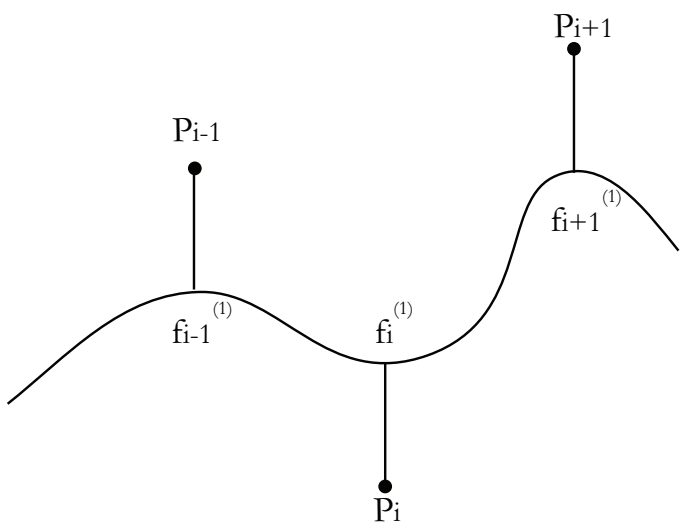

(a)

$$
0^{\mathrm{Pi}^{(2)}}
$$$$
\mathrm{Pi}^{(2)}{ }^{(2)}
$$

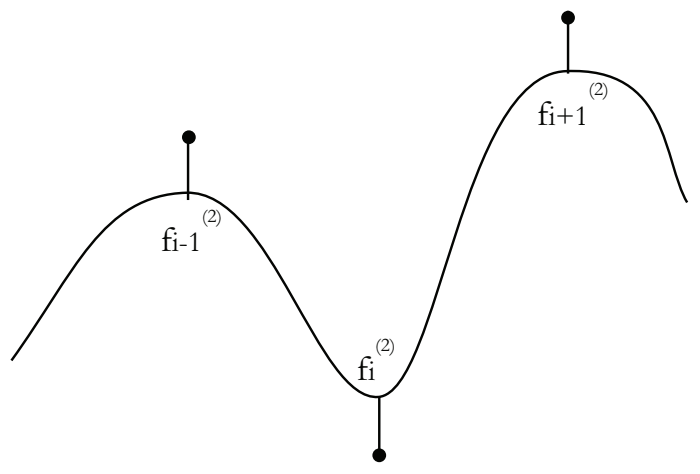

$$
\stackrel{\circ}{\mathrm{Pi}}^{(2)}
$$

(c)

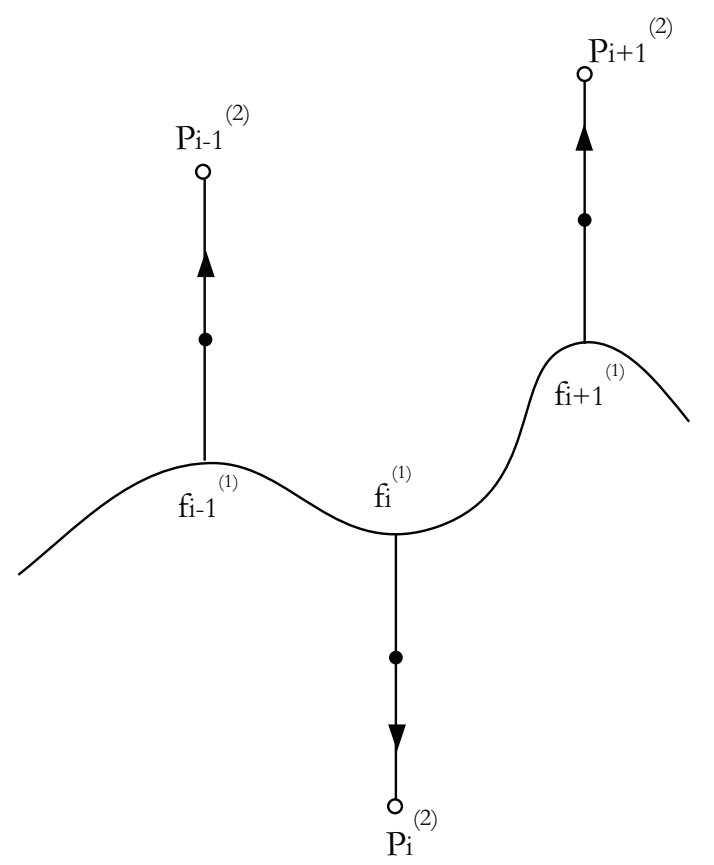

(b)

$$
0^{\mathrm{Pi}+1}{ }^{(k)}
$$

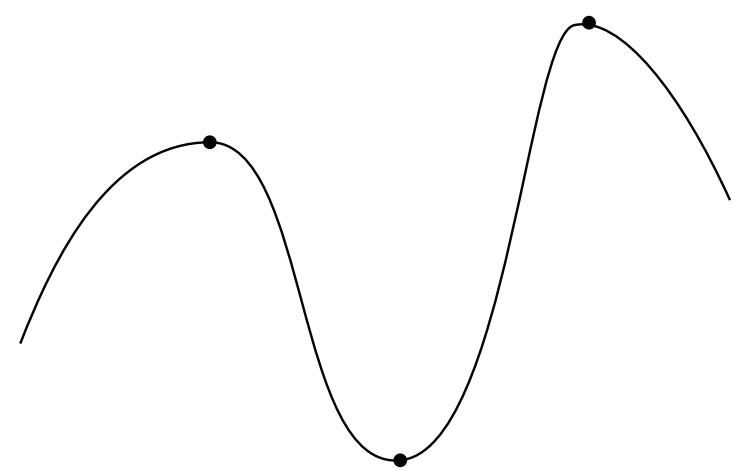

(d)

Figura 3.3: Interpolação de B-Spline. (a) Vértices $P_{1}, \ldots, P_{n}$ como pontos de controle e a B-Spline resultante. Para cada vértice, o ponto mais próximo entre a B-Spline e os vértices são dados por $f_{i}^{(1)}$. (b) Os pontos de controle serão transladados na direção da normal (os círculos brancos), obtém-se uma nova B-Spline, com pontos de controle $P_{1}^{(2)}, \ldots, P_{n}^{(2)}$. (c) para cada vértice de entrada, atualizamse os pontos mais próximos, definindo $f_{i}^{(2)}$. (d) B-Spline final do polígono $P_{i}^{(k)}$, interpolando os vértices de entrada $P_{i}$. 
Considerando que o padrão respiratório diafragmático é uma curva em $(z, t)$, sendo $z$ o nível diafragmático e $t$ o tempo. Como as imagens foram obtidas com espaçamento uniforme de tempo, tem-se que $\delta t=$ constante. Desta forma, os vetores normais entre $f_{i}^{(k)}$ e $P_{i}^{(k)}$ serão sempre paralelos ao eixo $z$, e a projeção será feita apenas pelo eixo $z$. Definidos os pontos de controle será utilizada uma B-Spline cúbica uniforme ${ }^{[15]}$ :

$$
C(u)=\sum_{i=0}^{n} f_{i}(u) P_{i}
$$

onde $f_{i}(u)$ são funções polinomiais por partes $i, P_{i}$ os pontos de controle e $u \in$ $[0,1]$. Cada trecho é composto por polinômios cúbicos, na forma

$$
C(u)=a_{3} u^{3}+a_{2} u^{2}+a_{1} u+a_{0}
$$

onde $a_{3}, a_{2}, a_{1}$ e $a_{0}$ são parâmetros. As restrições de continuidade são:

1. Ordem zero, para manter continuidade da curva

2. Primeira ordem, para manter a curva sem mudanças bruscas

3. Segunda ordem, para manter a curvatura

A equação de cada trecho é dada por

$$
C(u)=B_{0}(u) P_{0}+B_{1}(u) P_{1}+B_{2}(u) P_{2}+B_{3}(u) P_{3}
$$

com funções peso

$$
\begin{gathered}
B_{0}(u)=\frac{(1-u)^{3}}{6} \\
B_{1}(u)=\frac{3 u^{3}-6 u^{2}+4}{6} \\
B_{2}(u)=\frac{-3 u^{3}+3 u^{2}+3 u+1}{6} \\
B_{3}(u)=\frac{u^{3}}{6}
\end{gathered}
$$

ou na forma matricial

$$
C(u)=1 / 6\left[\begin{array}{llll}
u^{3} & u^{2} & u & 1
\end{array}\right] \cdot\left[\begin{array}{cccc}
-1 & 3 & -3 & 1 \\
3 & -6 & 3 & 0 \\
-3 & 0 & 3 & 0 \\
1 & 4 & 1 & 0
\end{array}\right] \cdot\left[\begin{array}{c}
P_{0} \\
P_{1} \\
P_{2} \\
P_{3}
\end{array}\right]
$$




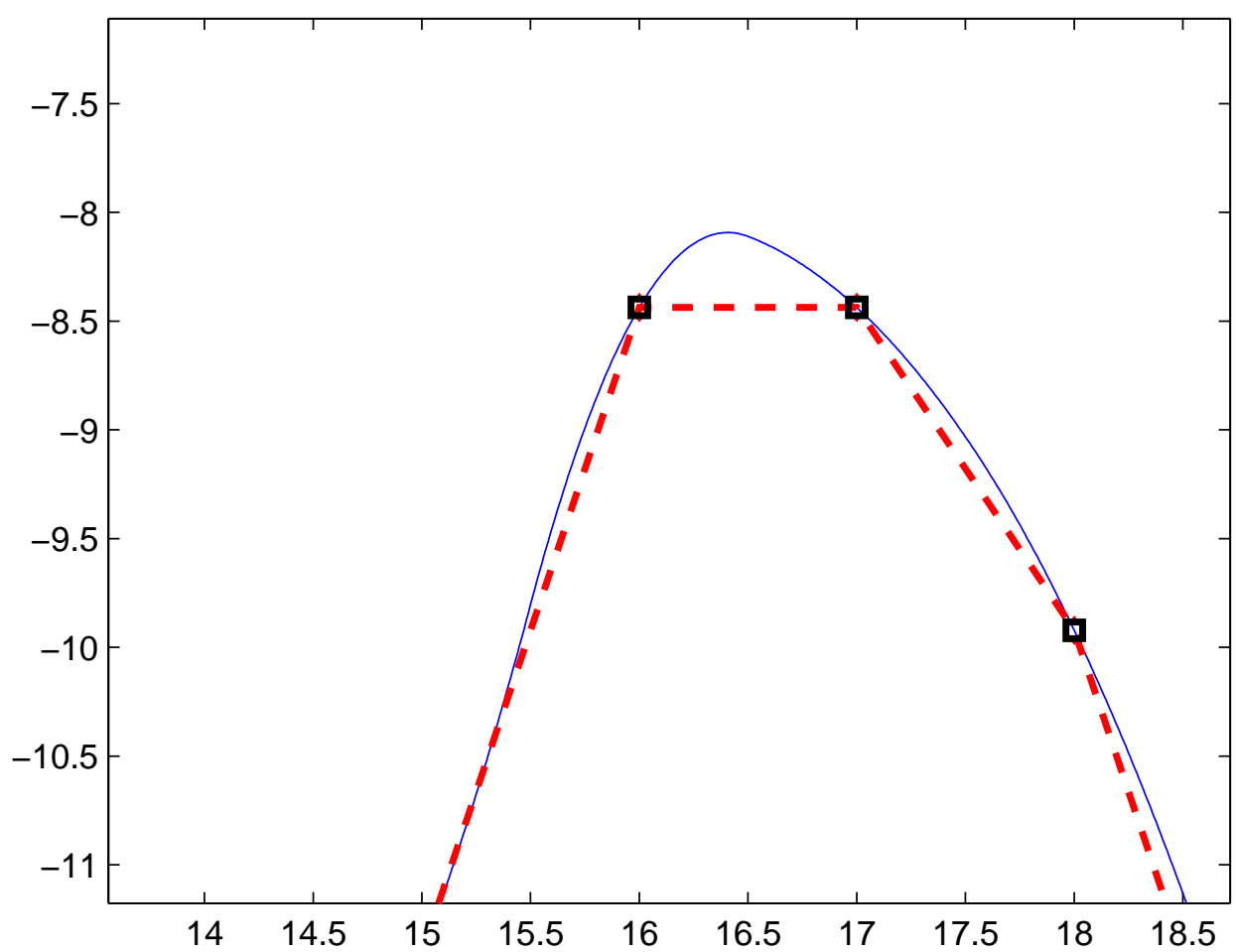

Figura 3.4: Comparação da interpolação linear (em vermelho tracejado) e gerado por B-Spline, nota-se que ao utilizar a interpolação linear ocorre imprecisão na mudança de fase respiratória, diferente da B-Spline.

Para uma curva com $n$ pontos de controle, os pontos de controle são agrupados em grupos de quatro $\left(P_{i-1}, P_{i}, P_{i+1}, P_{i+2}\right)$. Para os valores $i=0$ e $i=n-1$, substitui-se os valores de $P_{-1}=P_{0}$ e $P_{n}+1=P_{n}$. Variando os valores de $u$, entre 0 e 1 , em todos os agrupamentos, determinam-se pontos por onde a curva interpolada passam. Se a quantidade de pontos for suficientemente grande, é possivel realizar a interpolação linear entre dois instantes sem acarretar imprecisões.

A Fig. 3.4 mostra a comparação entre o padrão respiratório diafragmático utilizando a interpolação a linear e a interpolação por B-Spline. Neste trabalho, a curva interpoladora foi amostrada com $\Delta \mathrm{t}=0.01$, portanto para uma sequência padrão de 50 imagens o padrão respiratório diafragmático agora apresenta 5000 pontos.

\subsection{Algoritmo Proposto}

Neste trabalho, é proposta uma expansão do registro cíclico, considerando todas as possibilidades de cruzamento entre sequências de imagens coronais e sagitais. Em vez de ser feito um encadeamento de registros temporais como no registro 


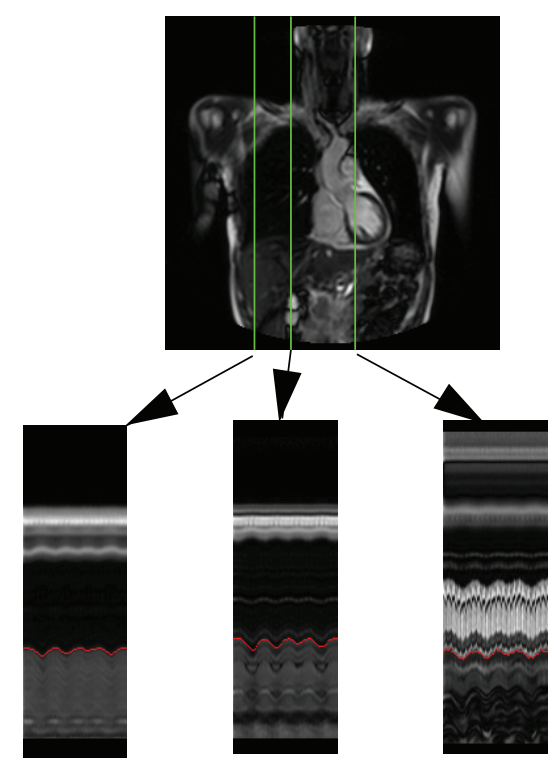

Figura 3.5: Dado uma sequência, definem-se diversos padrões respiratórios padrões, associados aos cruzamentos entre as sequências.

cíclico, serão determinadas todas as possibilidades de registro temporal para cada intersecção sagital-coronal. Posteriormente, os registros temporais serão analisados.

\subsubsection{Determinação dos Múltiplos Registros Temporais}

Todas os registros temporais entre cada par de sequências (uma coronal e outra sagital) são determinados e armazenados em uma estrutura em árvore. Existe um encadeamento de registros temporais, mas não é tão rígido como o registro cíclico. Considera-se que existem $n_{s}$ sequências sagitais e $n_{c}$ sequências coronais e que cada cruzamento entre as sequências resulta em um padrão respiratório diafragmático (Vide Fig. 3.5). Define-se como objeto da árvore de registros uma imagem, definida por uma sequência e um instante de tempo. Ou seja, para uma mesma sequência e um instante de tempo definido, obtém-se o nível diafragmático e a fase respiratória em todos padrões respiratórios associados. O algoritmo proposto segue as seguintes etapas:

1. Define-se uma imagem raiz de uma sequência, podendo ser coronal ou sagital. Nesta descrição será considerada uma imagem coronal apenas para efeito ilustrativo. Encontrar todas imagens sagitais registradas à imagem coronal raiz, armazenando todos os instantes de registro nas sequências sagitais.

2. Para cada ponto de intersecção, determinar todos os instantes em que o 


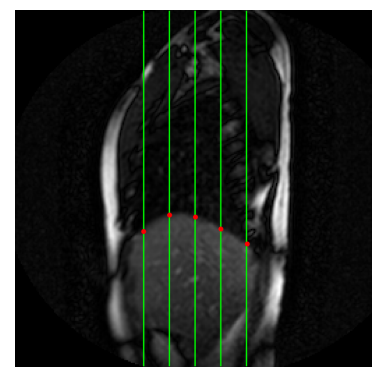

Figura 3.6: Definido um instante de tempo e uma sequência,obtém-se todos os níveis diafragmáticos e fases respiratórias nos cruzamentos existentes.

registro temporal ocorre para cada uma das sequências sagitais. Este processo é semelhante ao registro linear, exceto pelo fato da busca porcurar por todos possíveis registros temporais. O registro linear determina o primeiro registro apenas. Desta maneira, existem três casos: Posições em que não foi possível encontrar o registro temporal, posições em que ele é único (apenas um registro temporal), e posições onde há múltiplos registros. Para cada instante onde o registro temporal ocorre, determinam-se os níveis diafragmáticos e a fase respiratória associada, para cada uma das $n_{s}$ sequências de imagens coronais.

3. Para todas as posições com pelo menos um instante de registro e para cada instante $t$, são determinadas todas as possibilidades de registro temporal com todas as $n_{c}$ sequências de imagens coronais.

A Fig. 3.8 exibe o segundo passo do algoritmo para uma imagem coronal raiz em amarelo e todas imagens sagitais registradas são encontradas. A Fig. 3.9 exibe o resultado final do algoritmo, em que para cada resultado do segundo passo do algoritmo é feita novamente uma busca, encontrando registros temporais em imagens coronais. Os resultados ficam dispostos em forma de árvore. Esta árvore é dividida em dois níveis, sendo o primeiro nível de sagitais (cruzadas com a imagem raiz) e o segundo nível de coronais (paralelas à imagem raiz). A Fig. 3.7 exibe a aplicação do algoritmo supondo 3 sequências sagitais e 3 sequências coronais.

A Fig. 3.10 ilustra a execução do segundo passo do algoritmo proposto segundo uma visão especial. Nesta figura são indicados os pontos de cruzamento entre as sequências de imagens cruzadas, no $x-y$. As linhas verticais e horizontais representam as imagens coronais e sagitais respectivamente, os pontos em azul indicam as posições onde foram determinados o nível diafragmático e a fase respiratória para a primeira imagem coronal. Os pontos em verde indicam os 


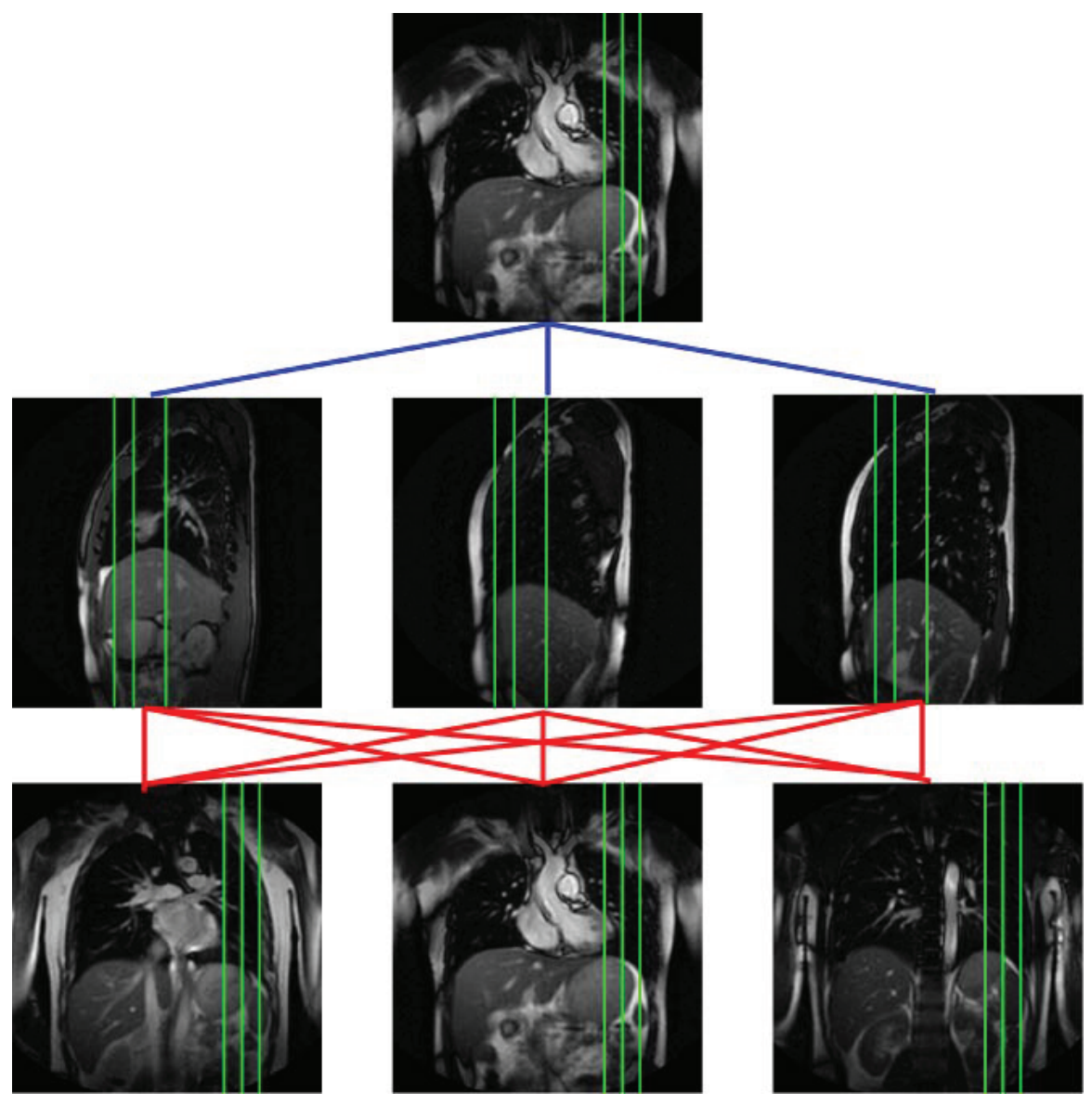

Figura 3.7: Execução do algoritmo para 3 sequências sagitais e 3 sequências coronais. As linhas verdes indicam a posição de cruzamento entre as sequências coronais e sagitais.

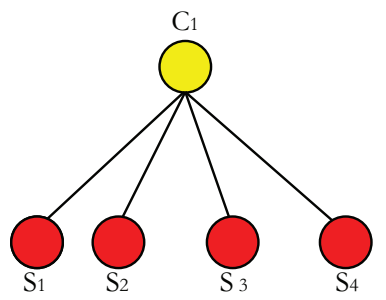

Figura 3.8: Estrutura em árvore do segundo passo do algoritmo proposto.

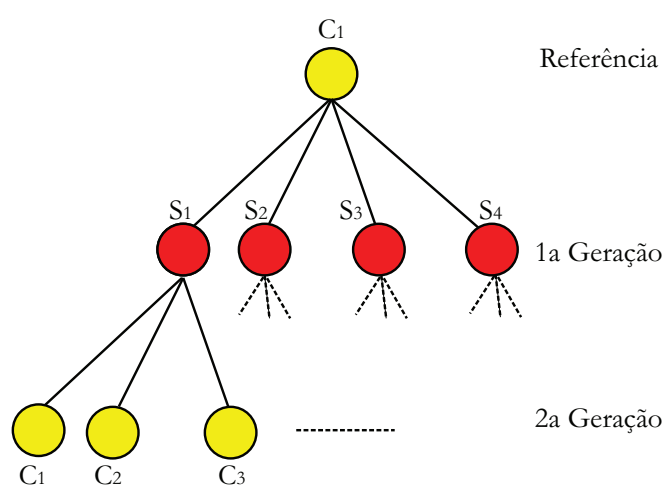

Figura 3.9: Estrutura em árvore do terceiro passo do algoritmo proposto e formação da árvore de registros temporais. 
locais onde o nível diafragmático e a fase respiratória foram determinados para cada instante onde o registro temporal ocorreu. Os pontos em verde determinam posições que o nível diafragmático pode ser determinado a partir do registro temporal encontrado. Por exemplo, dado uma sequência coronal $C_{1}$ e um instante de tempo na $t_{c}$ (portanto, define-se um nível diafragmático e uma fase respiratória), o algoritmo busca na sequência sagital $S_{1}$ e encontra um tempo registrado $t_{s}$. Utilizando este instante de tempo $t_{s}$ para os demais cruzamentos de $S_{1}$ com outras coronais $\left(C_{1}, C_{2}, \ldots, C_{m}\right)$, define-se novos níveis diafragmáticos e fases respiratórias em outras posições na mesma sagital. definidos em verde.

A Fig. 3.11 ilustra os registros temporais encontrados no terceiro passo do algoritmo. Os pontos em vermelho indicam posições onde foi encontrado um registro temporal no terceiro passo. Ou seja, analisando os pontos em verde, surge um ponto vermelho caso um registro temporal seja encontrado. Análogo ao processo da primeira etapa, os pontos em amarelo representam posições onde o nível diafragmático e a fase respiratória podem ser definidos a partir da sequência coronal e instante de tempo coronal $t_{c}$ registrado encontrado. Por exemplo, dado uma sequência coronal $C_{1}$ e um instante de tempo registrado $t_{c}$ encontrado no cruzamento $C_{1}$ e $S_{2}$, é possível obter o nível diafragmático e a fase respiratória nos cruzamentos entre $C_{1}$ e as demais sagitais $\left(S_{1}, S_{3}, \ldots, S_{n}\right)$, inclusive em locais que não foram determinados pelo segundo passo do algoritmo. Cruzamentos que não apresentam registros temporais diretos ou ao menos um registro temporal em algum ponto paralelo (coronal ou sagital) não podem ser definidos diretamente.

\subsubsection{Processamento da Árvore de Registros}

Conforme detalhado anteriormente, a árvore de registros indica as posições em que ocorreram registros com a primeira e segunda imagens. A Fig. 3.12 exibe todas as possibilidades de obtenção do nível diafragmático para reconstrução da superfície diafragmática, diferenciados por cores. O seguinte processamento será feito para determinar o instante de registro mais apropriado para o caso de múltiplos instantes de registros. Para cada vertical, determina-se aquela que possui o maior número de registros para um único instante. Este instante será considerado para os próximos passos. Os pontos em vermelho indicam posições onde ocorrem o registro temporal com a primeira e a segunda imagem. Os pontos em verde indicam locais onde o nível diafragmático e a fase respiratória podem ser 


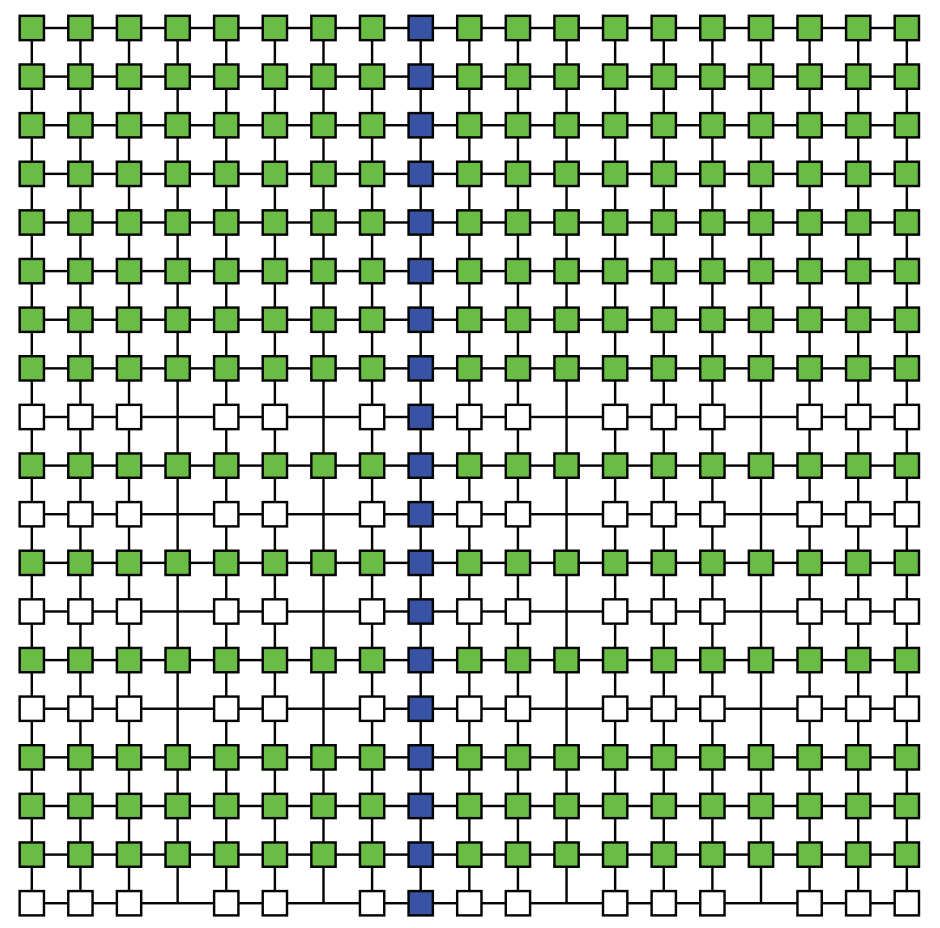

Figura 3.10: Segundo passo do algoritmo proposto, visualizado no espaço. Os pontos azuis representam a ocorrência de registro temporal e os pontos verdes os locais onde o nível diafragmático pode ser definido pelo instantes de registro encontrados.

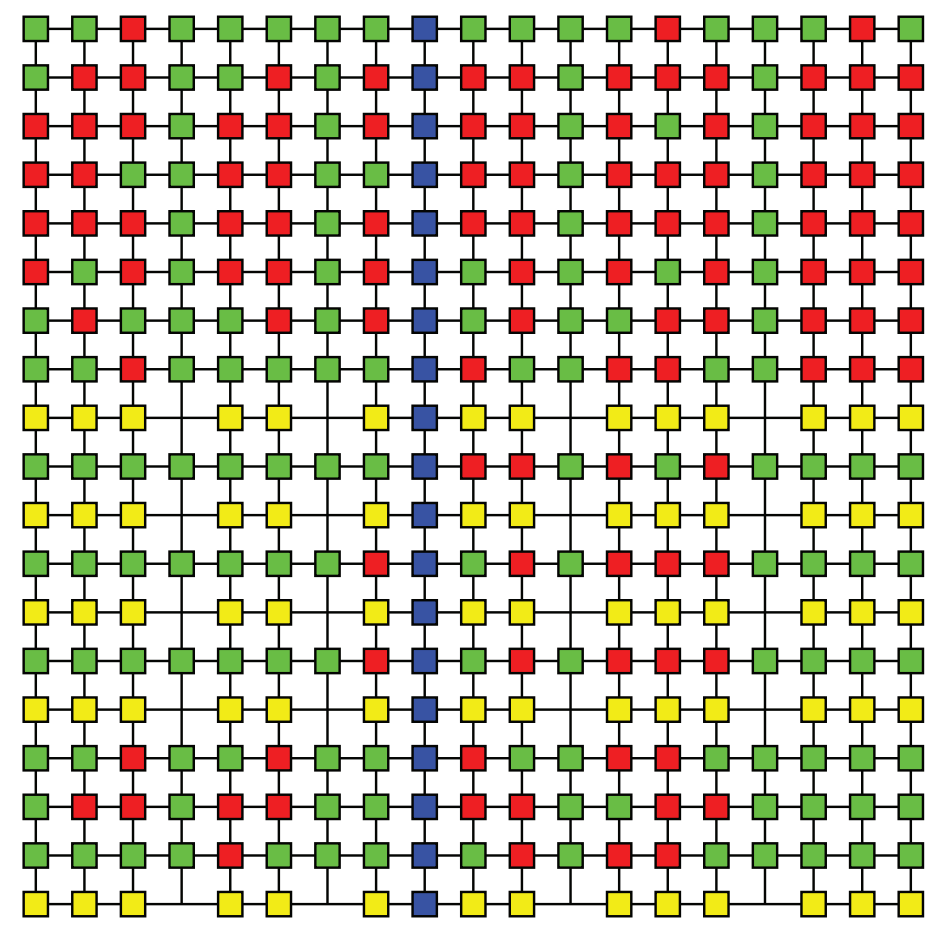

Figura 3.11: Terceiro passo do algoritmo proposto. Os pontos verdes correspondem aos registros temporais encontrados apenas na primeira etapa e os pontos em vermelho apresentam registros temporais na terceira etapa. Os pontos em amarelo indicam locais em que o nível diafragmático e a fase respiratória podem ser definidos a partir dos instantes de registro encontrado na terceira etapa. A ausência de pontos indica que não foram encontrados registros temporais e o nível diafragmático não pode ser determinado. 


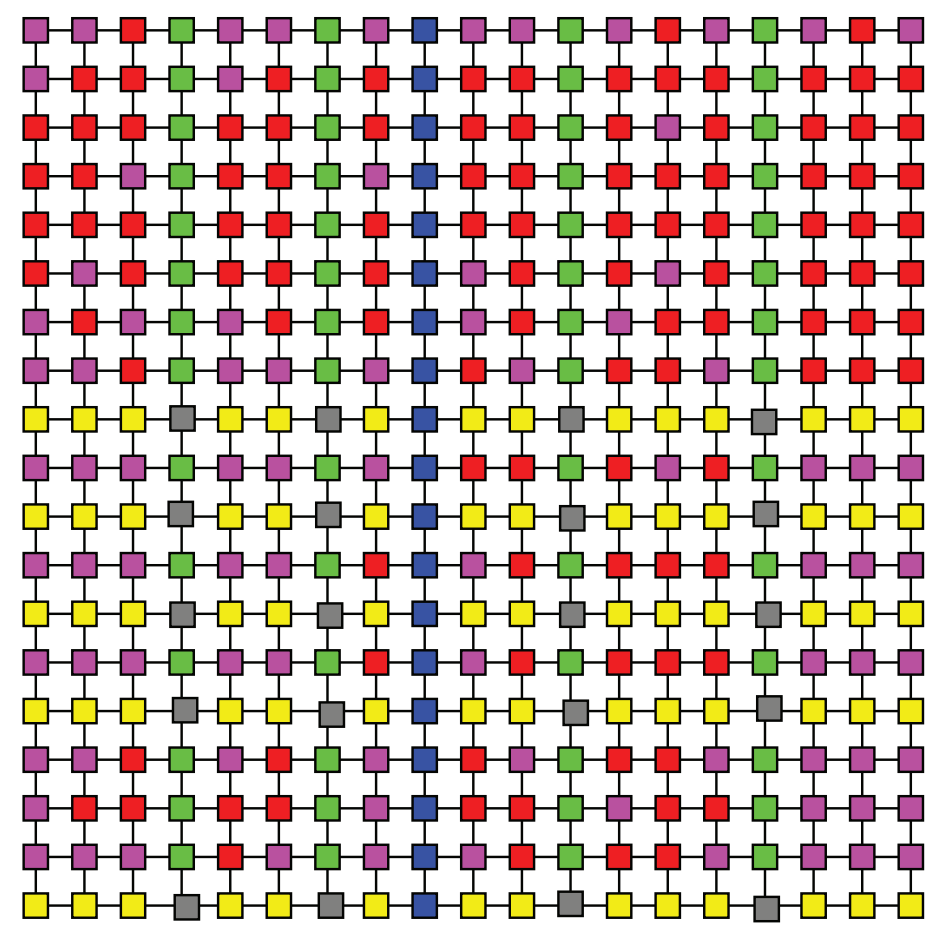

Figura 3.12: Resultado da árvore de registros. A cor de cada ponto define a forma com que a superfície diafragmática pode ser determinada.

determinados utilizando o instante registrado no ponto azul. O mesmo mecanismo pode ser aplicado para posições em uma mesma imagem onde há um registro temporal encontrado na terceira etapa do algoritmo, correspondente a um ponto vermelho na mesma vertical. Esta condição é representada por um ponto amarelo.

As posições representadas por um ponto verde e que na mesma vertical possuem um ponto vermelho, possuem dois registros temporais associados, e o seu nível diafragmático será definido de modo indireto como a média entre os níveis diafragmáticos presentes nas duas imagens que se interseccionam nesta posição. Estas posições estão representadas por pontos roxos. Há posições que ainda não possuem nenhum nível diafragmático. Estes pontos serão determinados por meio de interpolação linear entre as posições adjacentes, horizontalmente e/ou verticalmente. Estas posições correspondem aos pontos cinzas.

\subsubsection{Algoritmo de Reconstrução da Superfície Diafragmática}

Pela árvore de registros, em conjunto com os padrões respiratórios diafragmáticos, pode-se definir o nível diafragmático para cada posição no espaço. Inicialmente foram utilizados apenas pontos que apresentassem registro temporal, equivalentes aos pontos em vermelho no mapa, e os demais pontos eram descartados. No entanto, a quantidade de pontos era muito baixa para gerar um modelo adequado. 
A segunda proposta foi a utilização das diversas redundâncias presentes na árvore.

Para cada sequência (coronal e sagital) presente, o algoritmo seleciona na árvore o instante de tempo com maior número de ocorrências. Baseado neste instante de tempo, determinam-se os níveis diafragmáticos de todos padrões respiratórios diafragmáticos associados à sequência dada. Desta forma, para cruzamentos em que ocorrem o registro temporal, o nível diafragmático encontrado tanto pela coronal quanto pela sagital é o mesmo. Para situações em que não ocorre o registro temporal, o nível diafragmático do modelo é dado pela média entre o nível diafragmático coronal e o nível diafragmático sagital. Caso haja uma diferença muito grande entre o nível diafragmático coronal e o nível diafragmático sagital, o algoritmo avalia qual dos níveis diafragmáticos apresenta melhor coerência com os demais, por comparação com os pontos adjacentes, e utiliza o nível mais adequado. Mesmo assim, em caso de ambos os níveis estarem incoerentes, o algoritmo descarta ambos e calcula o nível diafragmático por interpolação entre os pontos adjacentes.

Para a construção do modelo os pontos são conectados em grupos de 3 e é feita a triangulação de delaunay. 


\section{Sistema proposto}

Neste capítulo será apresentado o sistema para obter os padrões respiratórios diafragmáticos, utilizado para reconstrução da superfície diafragmática em movimento. Inicialmente, será apresentada a arquitetura do sistema, seguida pela explicação detalhada de cada módulo.

\subsection{Arquitetura do Sistema}

Em vista do grande número de sequências que deverão ser processadas, este sistema deve, na medida do possível, automatizar o seu processo. O sistema de forma modular, de fácil substituição de cada parte. Inicialmente, é feita uma classificação das sequências quanto ao tipo (coronal e sagital). Em seguida é feita uma triagem sobre as imagens da sequência, verificando se as mesmas contêm informações relevantes. Uma função respiratória padrão é extraída de cada sequência temporal. Os cabeçalhos dos arquivos DICOM de cada sequência são extraídos para composição da matriz de transformação e os segmentos de cruzamento entre as sequências são calculados. Máscaras das imagens são criadas e as imagens 2DSTs nos cruzamentos (com ou sem máscaras) são calculadas. Em seguida o padrão respiratório diafragmático é segmentado, utilizando o método da transformada de Hough modificada com o algoritmo de contornos ativos. Nas 2DSTs onde a segmentação automática falhou, faz-se uma segmentação manual, aplicando a transformada de Hough modificada sobre a 2DST sem as máscaras, seguida de avaliação manual para determinar os padrões respiratórios diafragmáticos remanescentes.

Com os padrões respiratórios diafragmáticos segmentados, o próximo passo é convertê-los para o espaço tridimensional, utilizando a matriz de transformação. Em seguida, os padrões respiratórios diafragmáticos são interpolados por uma BSpline. Por fim, o algoritmo proposto de múltiplos registros temporais é aplicado e o modelo da superfície diafragmática animado é construído. As etapas do sistema e suas interdependências estão exibidas na Fig. 4.1. Paralelamente, foi projetada uma biblioteca de extensões e arquivos intermediários, de forma que seja possível avaliar todas etapas do programa separadamente. 


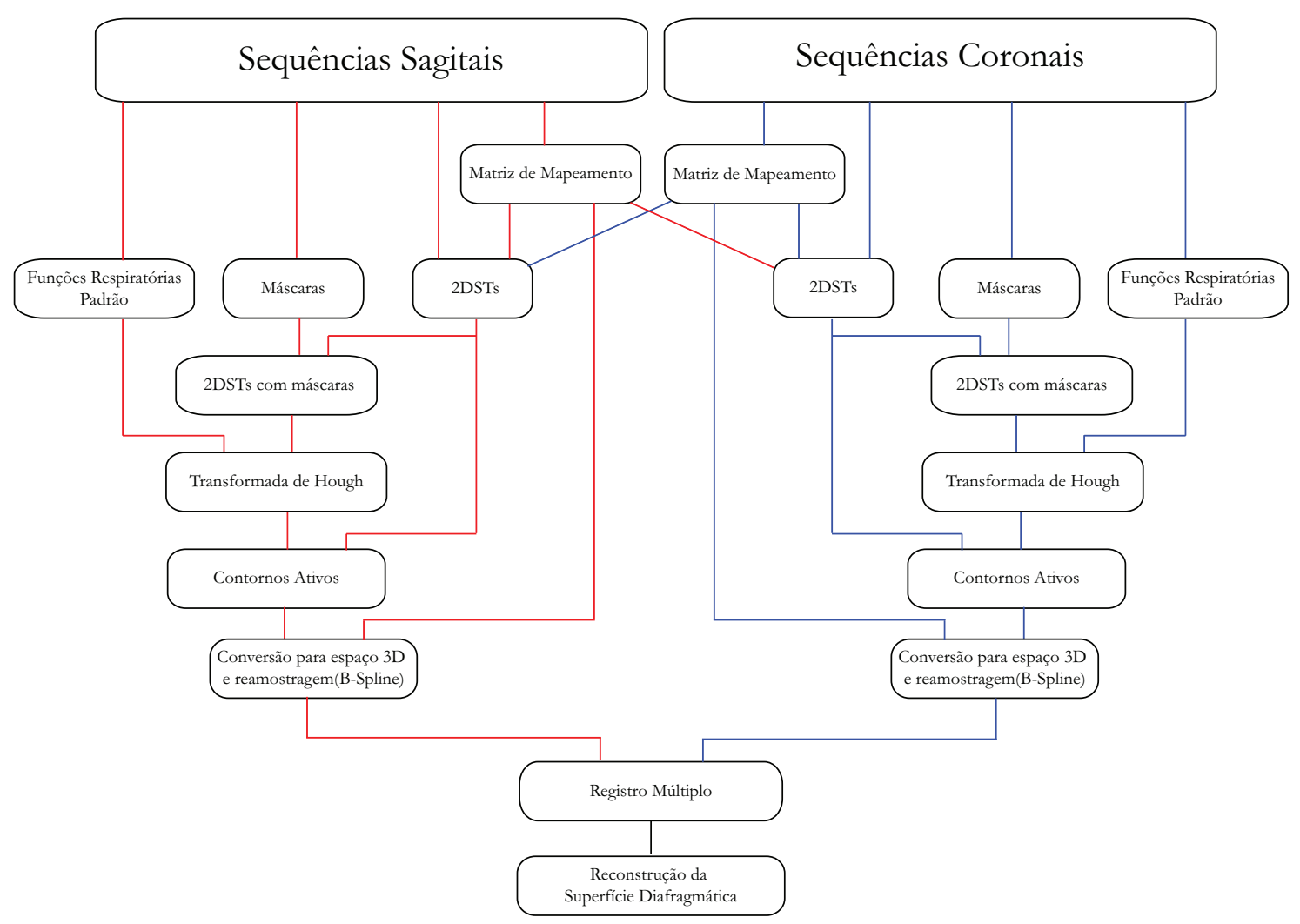

Figura 4.1: Sistema proposto para obtenção de registros temporais automaticamente e reconstrução da superfície diafragmática sincronizada.

\subsection{Triagem de Sequências, Função Respiratória Padrão e Matriz de Mapeamento}

Na primeira etapa ocorre a triagem das sequências. Inicialmente, todas as sequências são classificadas por tipo (sagital ou coronal) e o diretório onde os arquivos DICOMs estão armazenados é definido. A Fig. 4.2 exibe a aba de classificação de sequências. Dado um diretório raiz, o programa exibe todos subdiretórios existentes. Caso os DICOMs estejam em um subdiretório abaixo, pode-se editar os caminhos para o programa encontrar os arquivos DICOMs corretamente. Um arquivo de classificação de diretórios é criado na pasta. Este arquivo contém as informações definidas nesta aba, sendo utilizado pelos módulos para abertura dos arquivos DICOMs e, dependendo do tipo de sequência (sagital ou coronal), o método correto para processamento é acionado.

A Fig. 4.3 ilustra a aba de visualização dos arquivos DICOMs e obtenção do padrão respiratório padrão. Uma avaliação é feita sobre a qualidade das imagens e a posição de aquisição. Sequências com baixa qualidade ou pouca informação da superfície diafragmática são descartadas. A Fig. 4.4 ilustra exemplo de sequência descartada. Das sequências restantes, extrai-se a função respiratória 


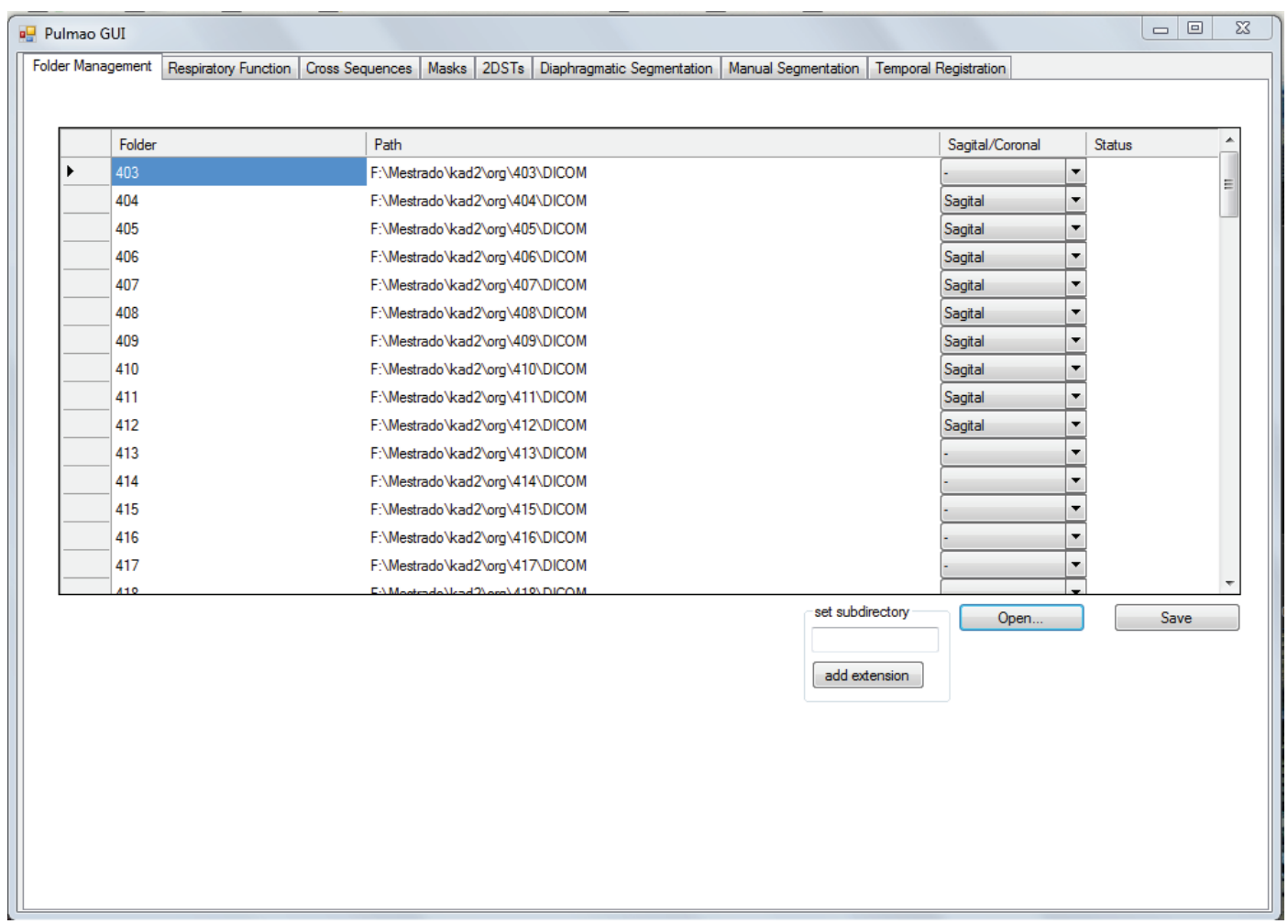

Figura 4.2: Aba de definição dos diretórios e tipos de sequência.

padrão manualmente selecionando um intervalo na imagem com um método de detecção de contornos aplicados sobre a imagem gradiente no intervalo selecionado. Caso existam pequenos desvios na imagem, as correções podem ser feitas manualmente movendo os pixels azuis verticalmente.

A próxima etapa é extrair as informações da matriz de transformação do cabeçalho das sequências. Como a abertura de arquivos DICOMs é um processo relativamente lento e as informações da matriz de mapeamento serão acessadas com frequência, foi decidido extraí-las e separá-las em um arquivo, permitindo acesso mais rápido. As intersecções entre as sequências são calculadas, utilizando as matrizes de mapeamento sagitais e coronais.

\subsection{Obtenção das Máscaras}

Para a criação das máscaras, estão disponíveis os dois métodos descritos no item 2.7. Para a máscara por limiarização de pixels, devem se selecionar o limiar de pixels, a espessura da máscara, os parâmetros dos filtros de mediana e a região do pulmão para a rotulação. Para sequências coronais deve-se segmentar cada lado pulmão (esquerdo e direito) separamente. Para a máscara por operadores morfológicos, o único parâmetro a ser selecionado é a espessura da máscara. A 


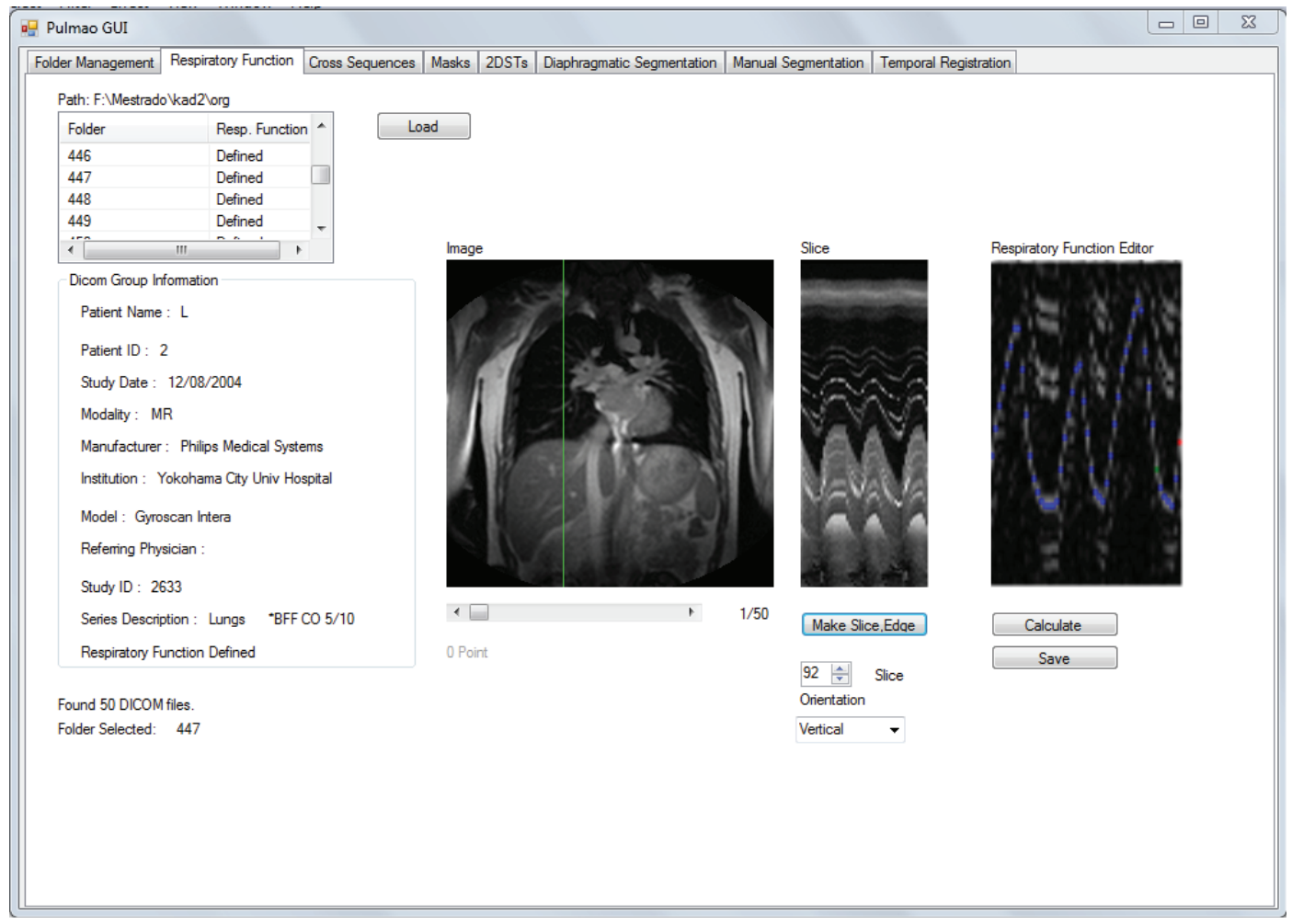

Figura 4.3: Aba de pré-visualização dos arquivos DICOMs e obtenção da função respiratório padrão. Na imagem da direita exibe-se o editor de função respiratória, no qual os pixels em azul podem ser movidos para pequenas correções.

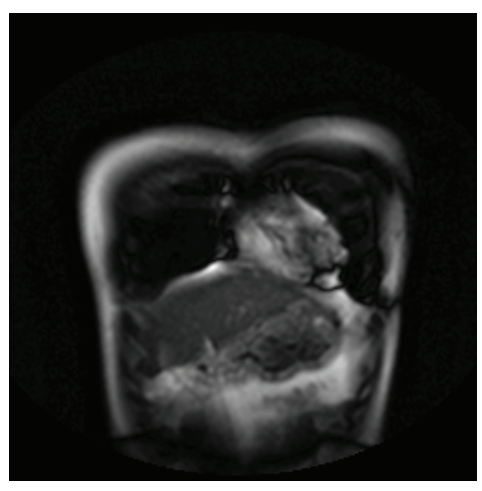

(a)

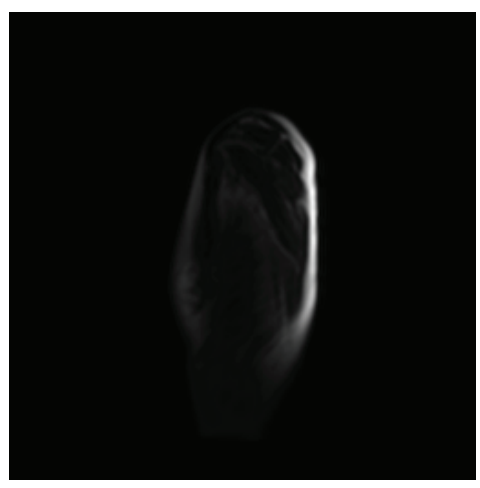

(b)

Figura 4.4: Sequências descartadas por apresentarem pouca informação da superfície diafragmática. (a) Coronal. (b) Sagital. 


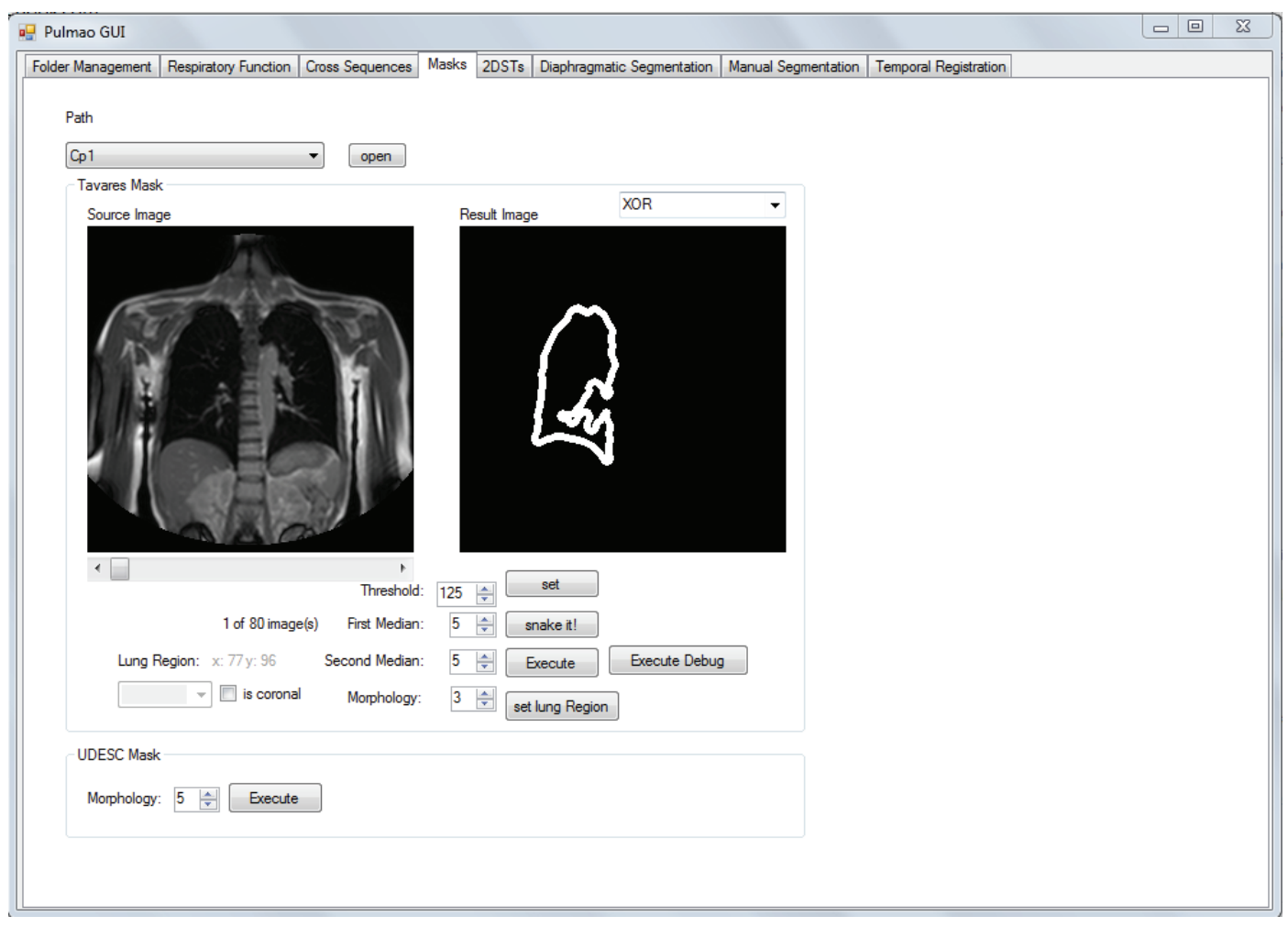

Figura 4.5: Aba de criação das máscaras.

Fig. 4.5 ilustra a aba do sistema para obtenção de máscaras. A região do pulmão é escolhida clicando na imagem de pré-visualização. Para verificar as máscaras para as outras imagens da sequência utiliza-se o slider abaixo da visualização da imagem. É esperado que os parâmetros não sejam adequados para todas as imagens da sequência. No entanto, a Transformada de Hough modificada é robusta o suficiente para garantir o resultado esperado mesmo com alguns defeitos nas máscaras.

\subsection{DSTs, Segmentação Automática}

Na próxima aba, são obtidas todas as imagens 2DSTs das imagens e máscaras, definidas pelos pontos de cruzamento. Em seguida os padrões respiratórios diafragmáticos são extraídos. Para o modo automático, o programa aplica a transformada de Hough modificada sobre as 2DSTs com as máscaras. Os parâmetros a serem definidos são distância da imagem aresta, $\alpha, \beta, \gamma$ e número de iterações do algoritmo de contornos ativos. A Fig. 4.6 exibe a aba de aplicação da transformada de Hough modificada. 


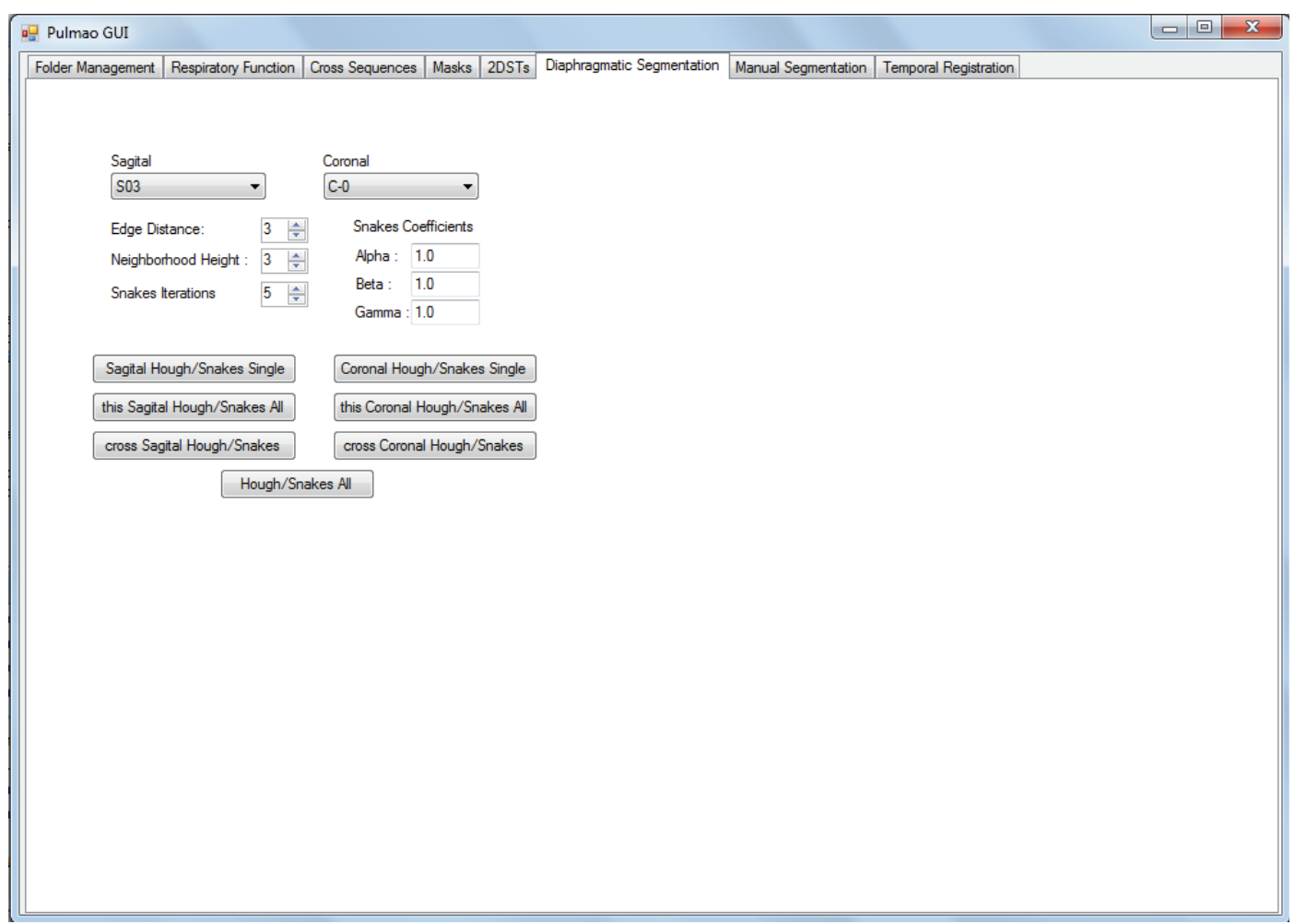

Figura 4.6: Aba de segmentação por Transformada de Hough modificada com máscaras.

\subsubsection{Segmentação Manual}

Caso o algoritmo de segmentação automática falhe, é disponibilizada a possibilidade de segmentação ser feita manualmente, utilizando a transformada de Hough modificada sobre a 2DST e mapeando os pontos de maior intensidade no espaço paramétrico de Hough. O usuário deve, então, selecionar o padrão adequado e salvá-lo. Este método foi utilizado principalmente em locais onde a máscara não consegue segmentar (embaixo do coração) ou a 2DST da máscara está imprópria (presença de vasos sanguíneos por exemplo). A Fig. 4.7 exibe a aba de segmentação manual do padrão respiratório diafragmático. Os parâmetros a serem selecionados são: distância da imagem aresta, parâmetros do algoritmo de contornos ativos e número de padrões respiratórios a serem determinados.

\subsection{Conversão para o Espaço Tridimensional e Reconstru- ção da Superfície Diafragmática}

Na última etapa do sistema, o programa realiza a conversão dos padrões respiratórios diafragmáticos segmentados para o espaço tridimensional e realiza a interpolação por B-Spline. Inicialmente, definiu-se que o novo padrão respirató- 


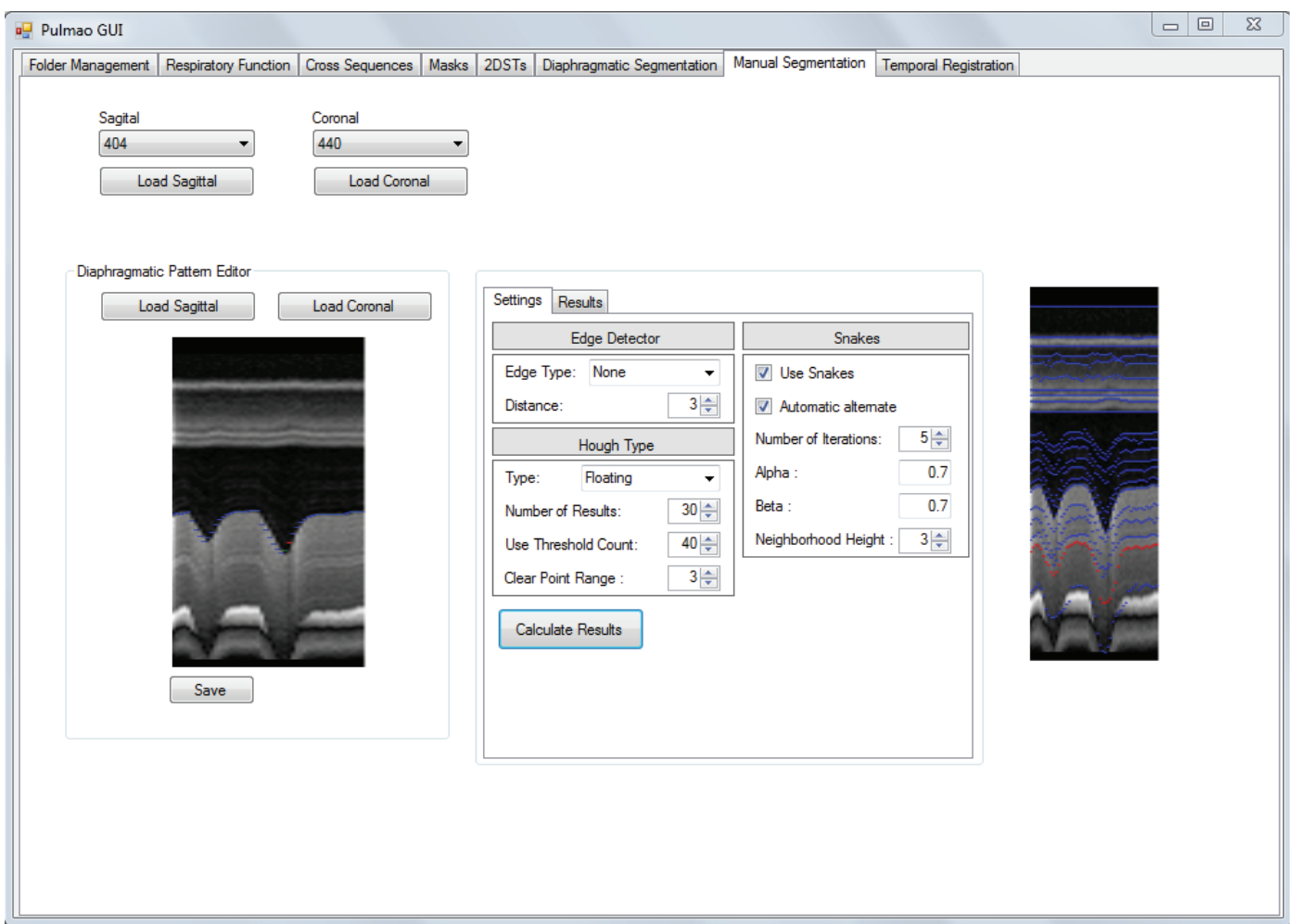

Figura 4.7: Aba de segmentação manual por Transformada de Hough modificada.

rio diafragmático terá $100 n$ pontos. Logo para uma sequência de 50 pontos, o resultado será um padrão respiratório diafragmático de 5000 pontos. Para o registro temporal, todos os padrões respiratórios diafragmáticos são interpolados e o algoritmo proposto neste trabalho é aplicado, resultando num arquivo contendo a árvore de registros. Selecionado uma sequência, o programa considera todas imagens como sendo raiz e gera uma árvore de registros associada a cada uma delas. Em seguida, essas árvores de registros são utilizadas para a reconstrução da superfície diafragmática. 


\section{$5 \quad$ Resultados}

O algoritmo foi executado para dois grupos de sequência, utilizando configuração do equipamento de RM em configurações diferentes. O primeiro caso é composto 31 sequências temporais de 48 imagens, sendo 5 coronais e 27 sagitais. Na triagem, foram descartadas 4 sequências sagitais, por apresentarem pouca informação da superfície diafragmática. O corte utilizado foi bem nas pontas do tórax do individuo. Como referência foi adotada uma sequência coronal no centro.

As Figs. 5.1 a 5.12 exibem os resultados da árvore de registros temporais, com sistema de cores igual ao apresentado no Capítulo 3. Os pontos em vermelho indicam posições onde ocorrem o registro temporal com a primeira e a segunda imagem. Os pontos em verde indicam locais onde o nível diafragmático e a fase respiratória podem ser determinados utilizando o instante registrado no ponto azul. Pontos amarelos indicam posições que podem ter o nível diafragmático definido por pelo instante registrado entre a segunda e a terceira imagem, similar aos pontos verdes. Pontos roxos indicam posições onde o nível diafragmático é definido indiretamente, como a média entre os níveis diafragmáticos presentes nas duas imagens que se interseccionam nesta posicão. Pontos em cinza não apresentam nenhum nível diafragmático e serão definidos por interpolações lineares entre posições adjacentes.

Estão apresentadas 24 árvores, correspondentes a um ciclo completo de respiração.

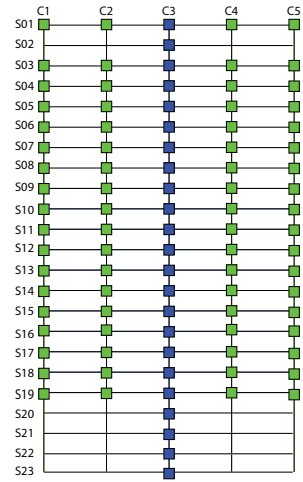

(a)

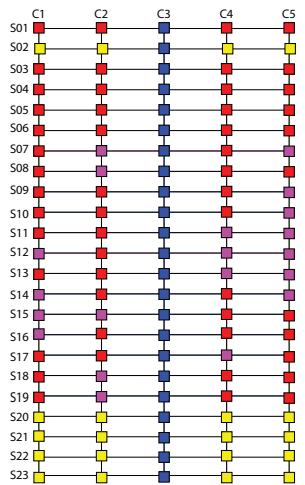

(b)

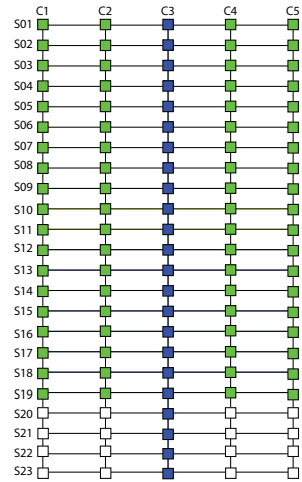

(c)

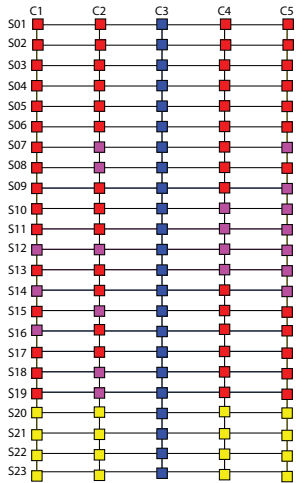

(d)

Figura 5.1: Imagem 1 (a) P2. (b) P3. Imagem 2 (c) P2. (d) P3. 


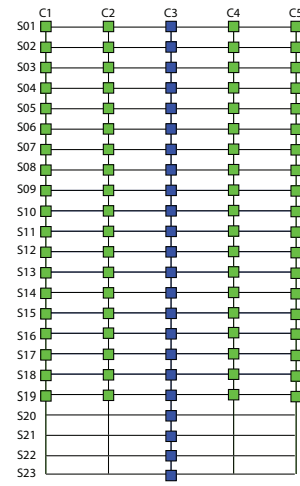

(a)

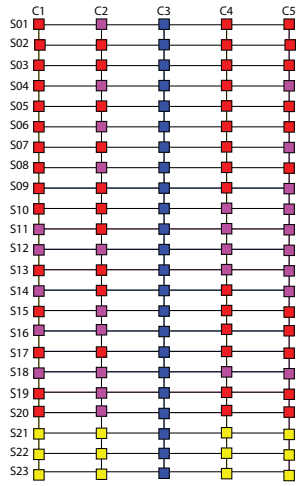

(b)

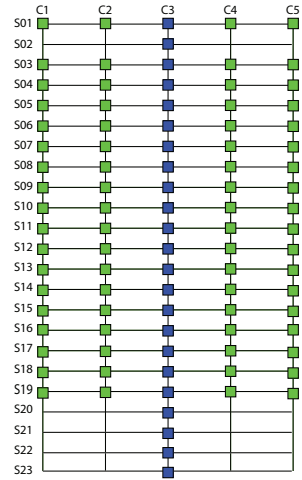

(c)

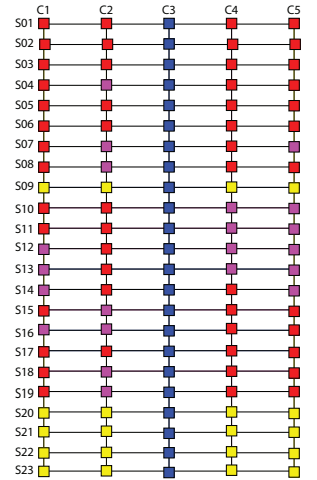

(d)

Figura 5.2: Imagem 3 (a) P2. (b) P3. Imagem 4 (c) P2. (d) P3.

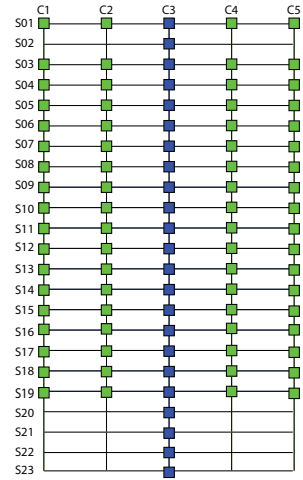

(a)

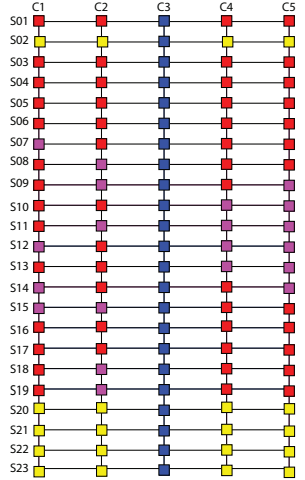

(b)

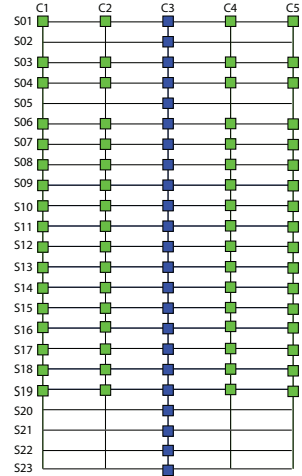

(c)

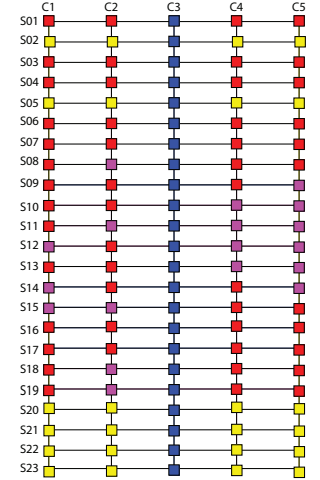

(d)

Figura 5.3: Imagem 5 (a) P2. (b) P3. Imagem 6 (c) P2. (d) P3.

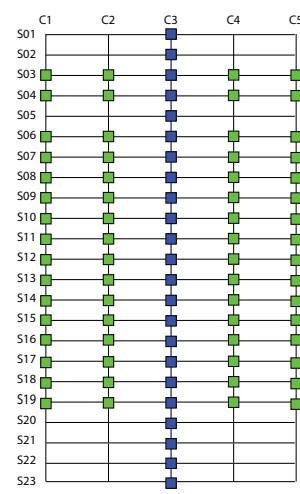

(a)

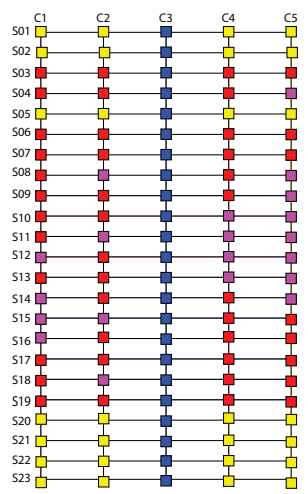

(b)

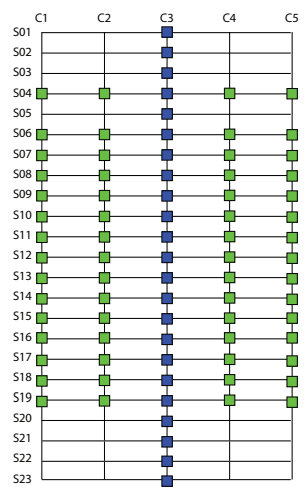

(c)

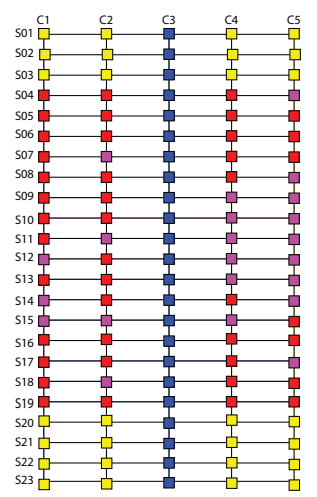

(d)

Figura 5.4: Imagem 7 (a) P2. (b) P3. Imagem 7 (c) P2. (d) P3. 


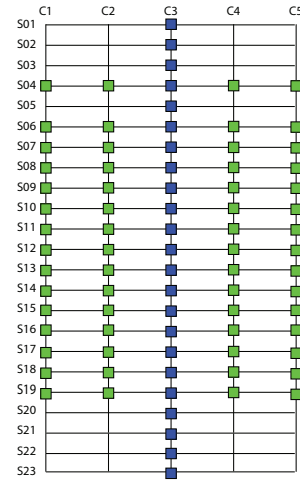

(a)

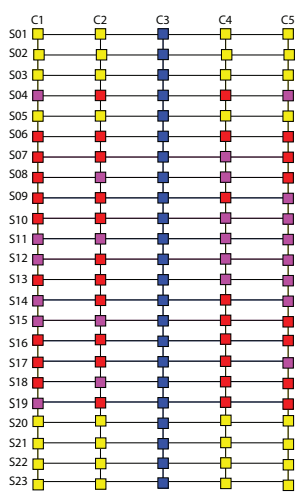

(b)

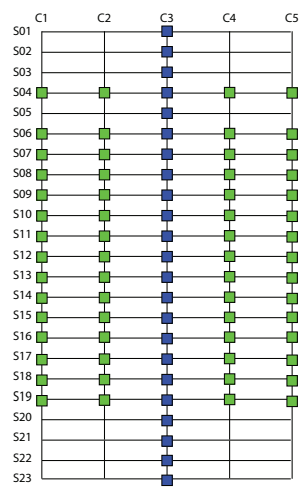

(c)

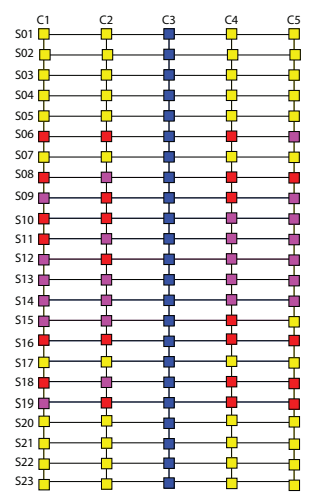

(d)

Figura 5.5: Imagem 9 (a) P2. (b) P3. Imagem 10 (c) P2. (d) P3. 


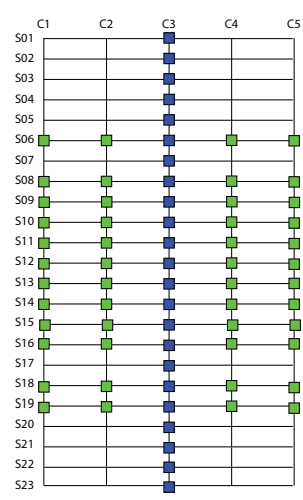

(a)

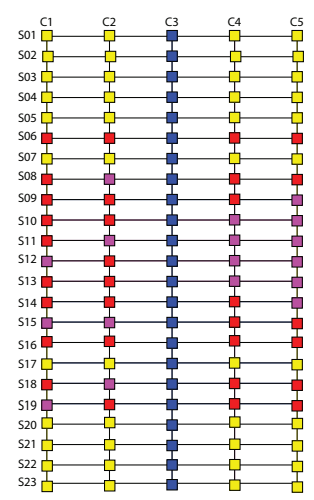

(b)

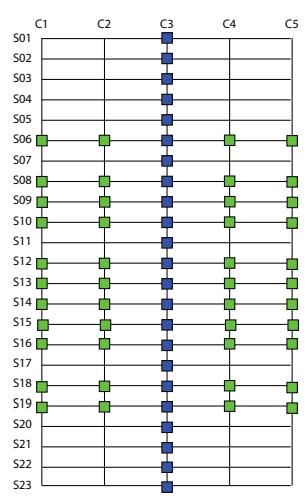

(c)

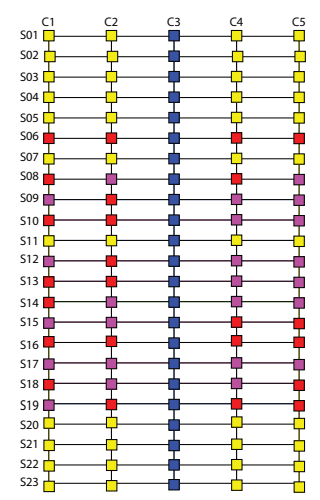

(d)

Figura 5.6: Imagem 11 (a) P2. (b) P3. Imagem 12 (c) P2. (d) P3.

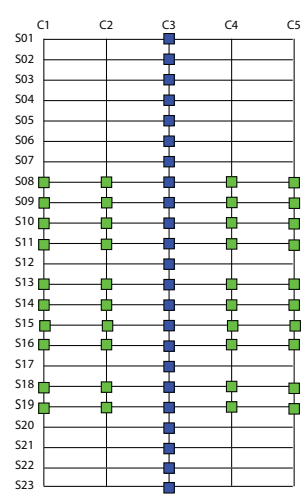

(a)

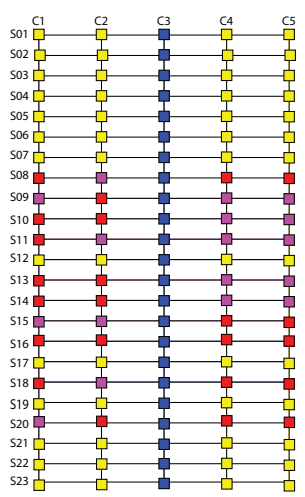

(b)

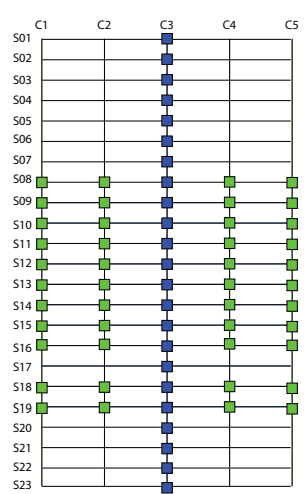

(c)

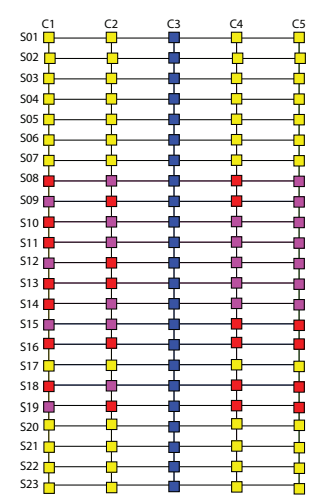

(d)

Figura 5.7: Imagem 13 (a) P2. (b) P3. Imagem 14 (c) P2. (d) P3.

Nota-se que em nenhuma das imagens aparecem pontos cinzas, indicando que a superfície diafragmática não será reconstruída com pontos interpolados pelas adjacências, sem informações de registros. Nota-se também que a maioria dos pontos são vermelhos, o que indica que boa parte da superfície diafragmática será reconstruída com informações registradas diretamente. Em relação aos pontos em roxo, situação onde pode ser definida uma imagem na vertical e uma imagem na horizonal porém não há registro direto entre elas. Em relação à forma de obtenção do nível diafragmático, nota-se a ausência de pontos em cinza que indica que o nível diafragmático pode ser definido para todos os pontos.

As Fig. 5.13 a 5.30 ilustram a reconstrução da superfície diafragmática quadro-a-quadro baseada nas árvore de registros dadas. 


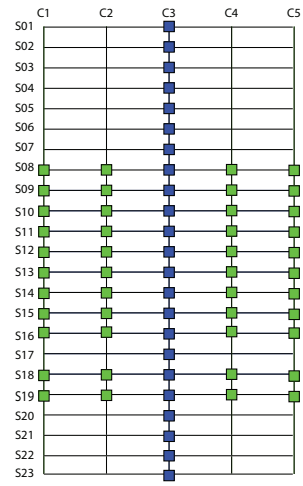

(a)

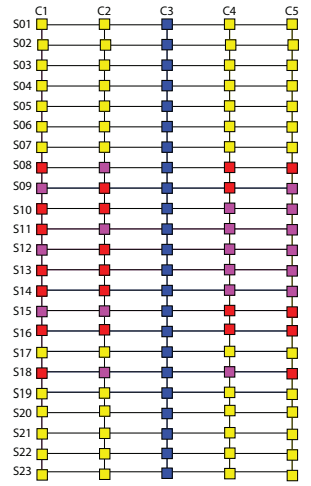

(b)

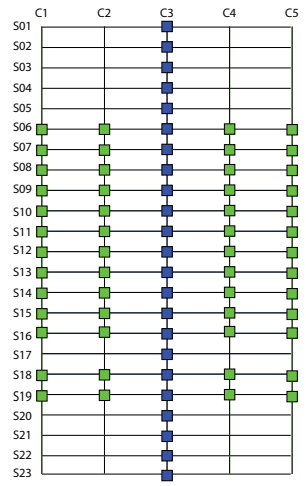

(c)

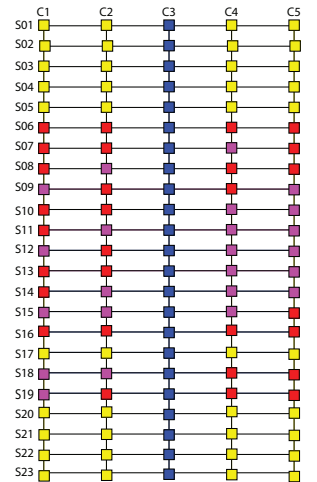

(d)

Figura 5.8: Imagem 15 (a) P2. (b) P3. Imagem 16 (c) P2. (d) P3.

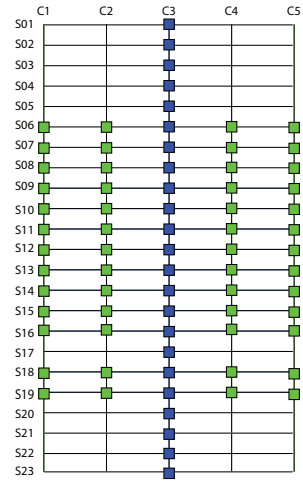

(a)

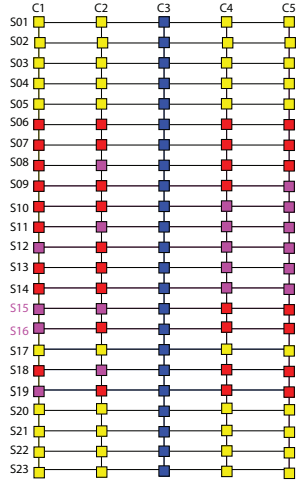

(b)

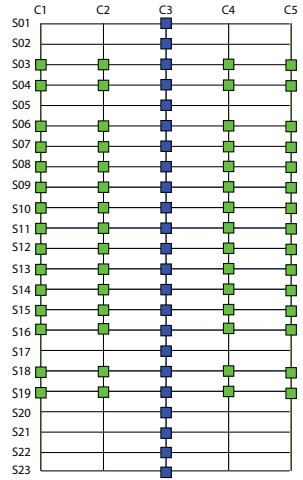

(c)

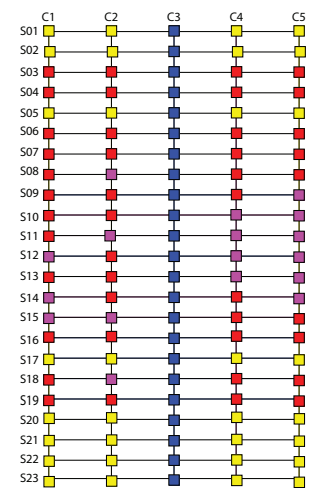

(d)

Figura 5.9: Imagem 17 (a) P2. (b) P3. Imagem 18 (c) P2. (d) P3.

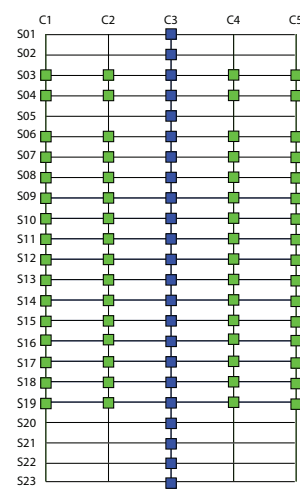

(a)

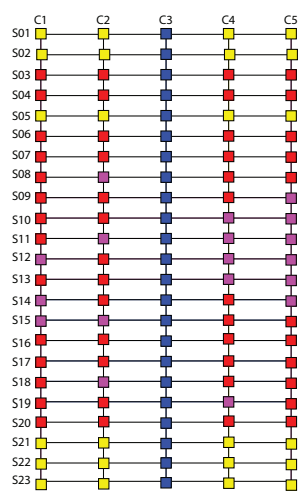

(b)

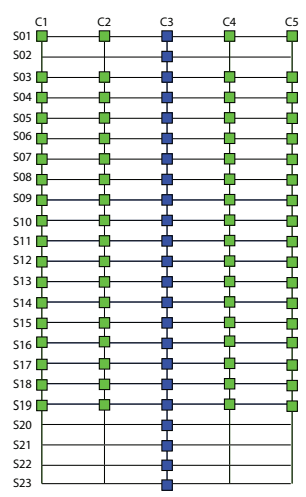

(c)

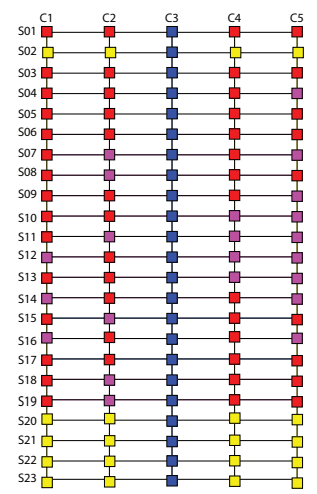

(d)

Figura 5.10: Imagem 19 (a) P2. (b) P3. Imagem 20 (c) P2. (d) P3. 


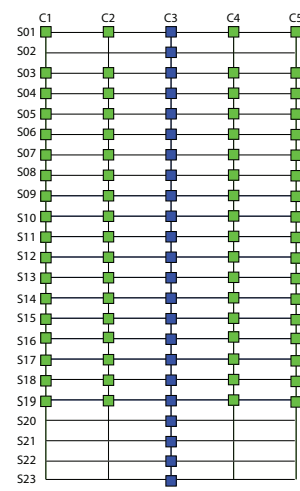

(a)

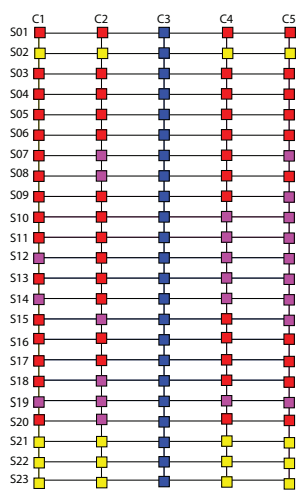

(b)

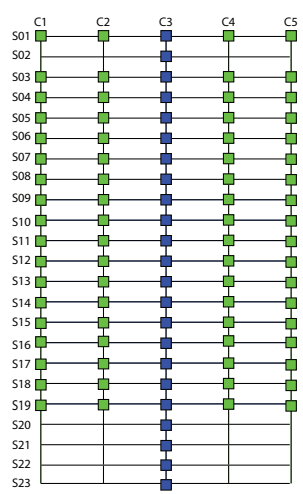

(c)

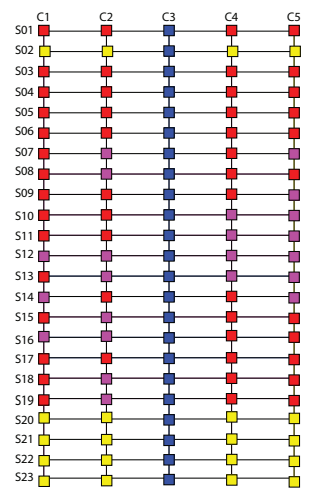

(d)

Figura 5.11: Imagem 21 (a) P2. (b) P3. Imagem 22 (c) P2. (d) P3.

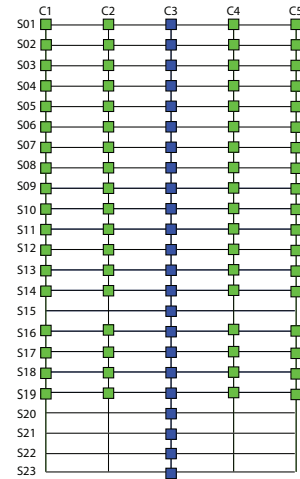

(a)

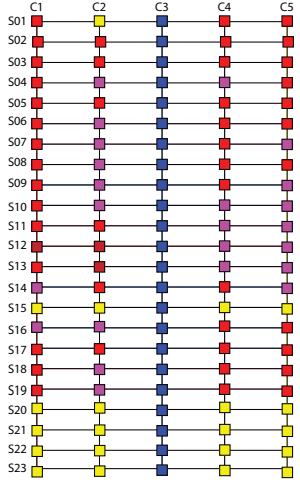

(b)

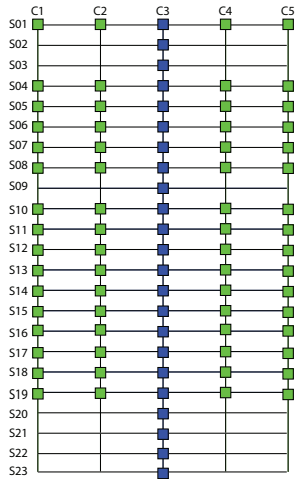

(c)

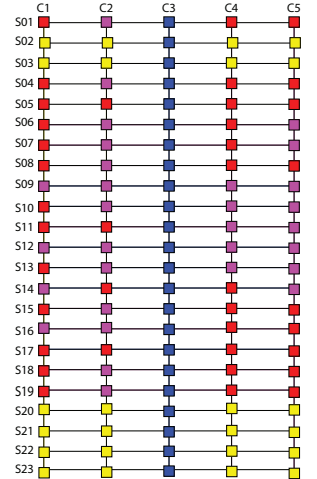

(d)

Figura 5.12: Imagem 23 (a) P2. (b) P3. Imagem 24 (c) P2. (d) P3.

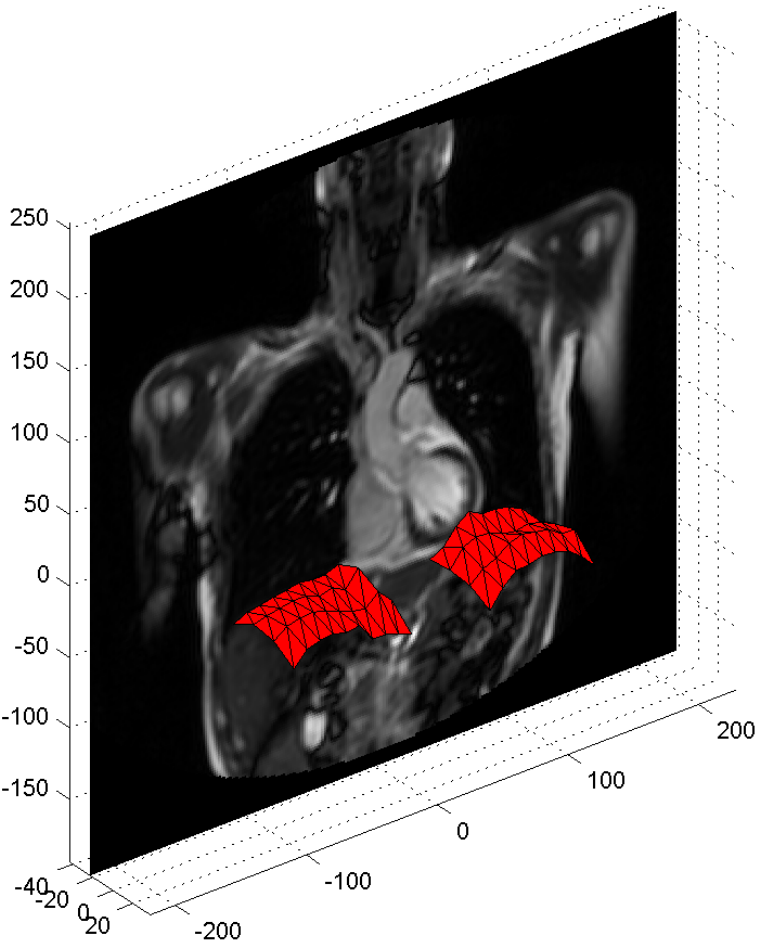

Figura 5.13: Caso 1. Imagem 1. 


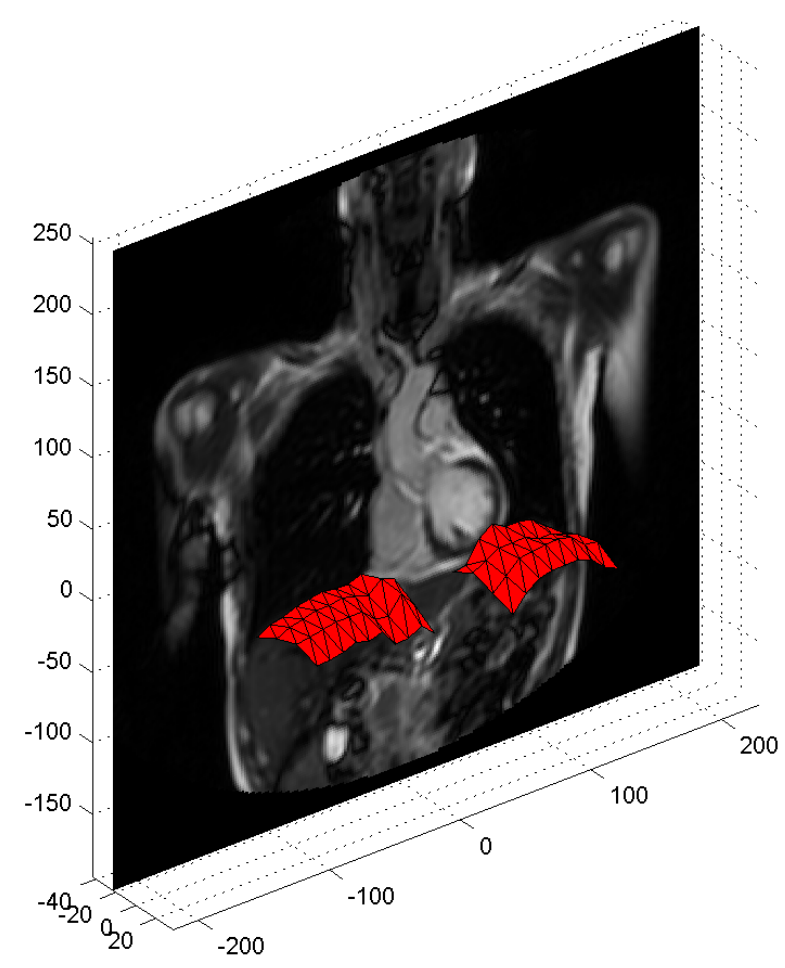

Figura 5.14: Caso 1. Imagem 2.

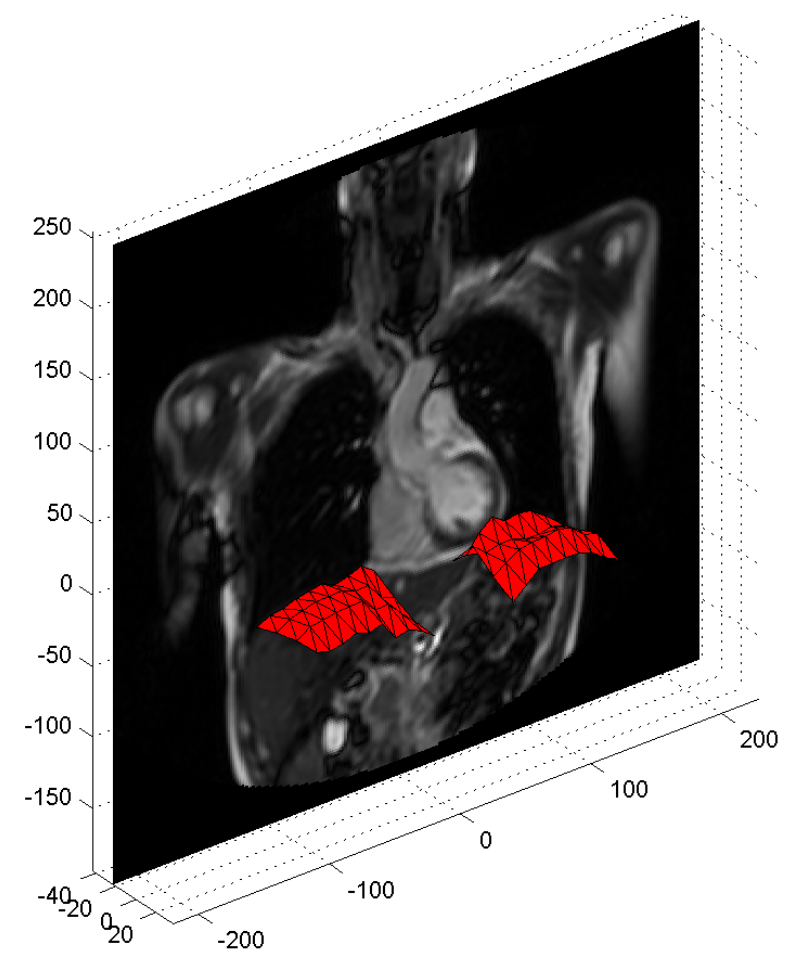

Figura 5.15: Caso 1. Imagem 3. 


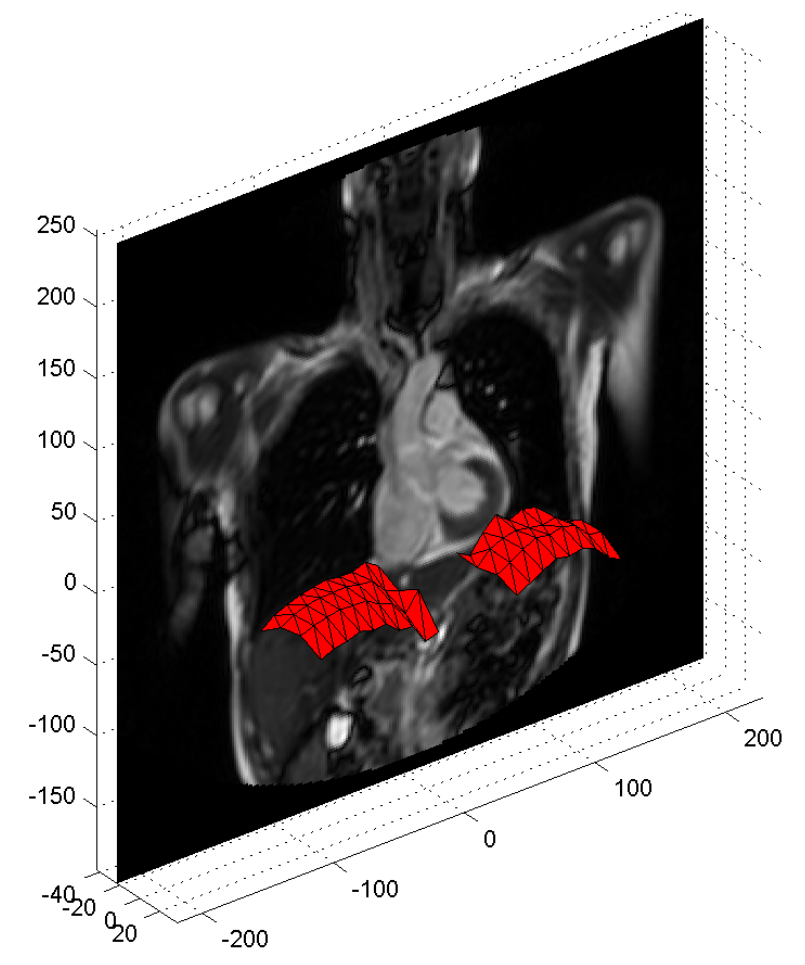

Figura 5.16: Caso 1. Imagem 4. 


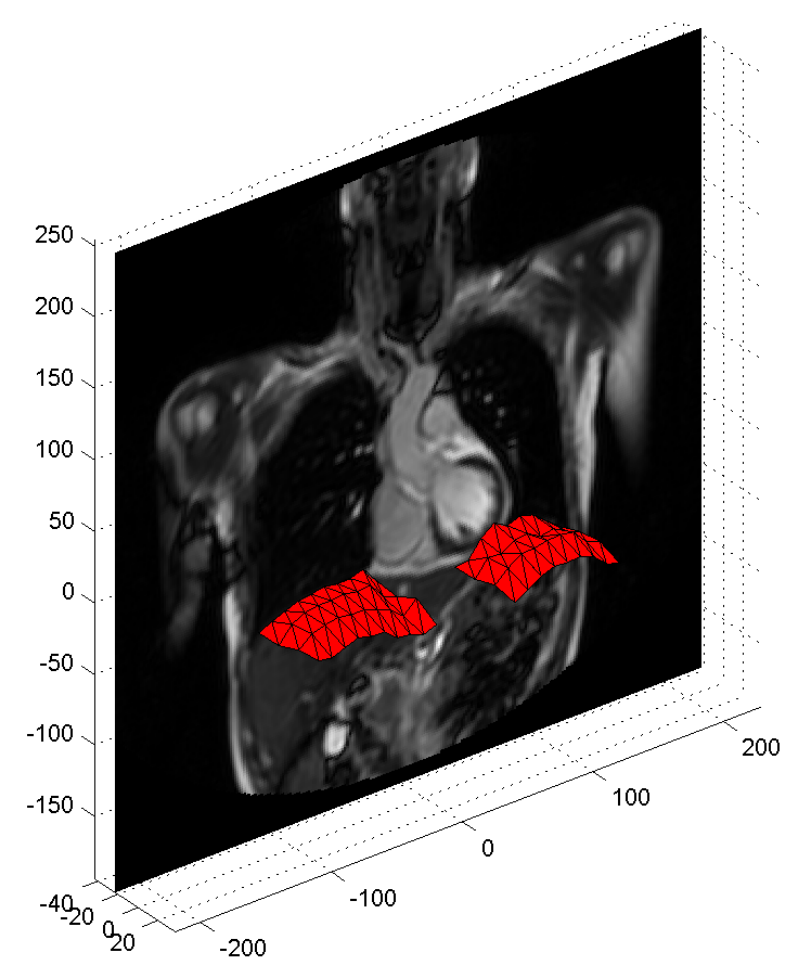

Figura 5.17: Caso 1. Imagem 1.

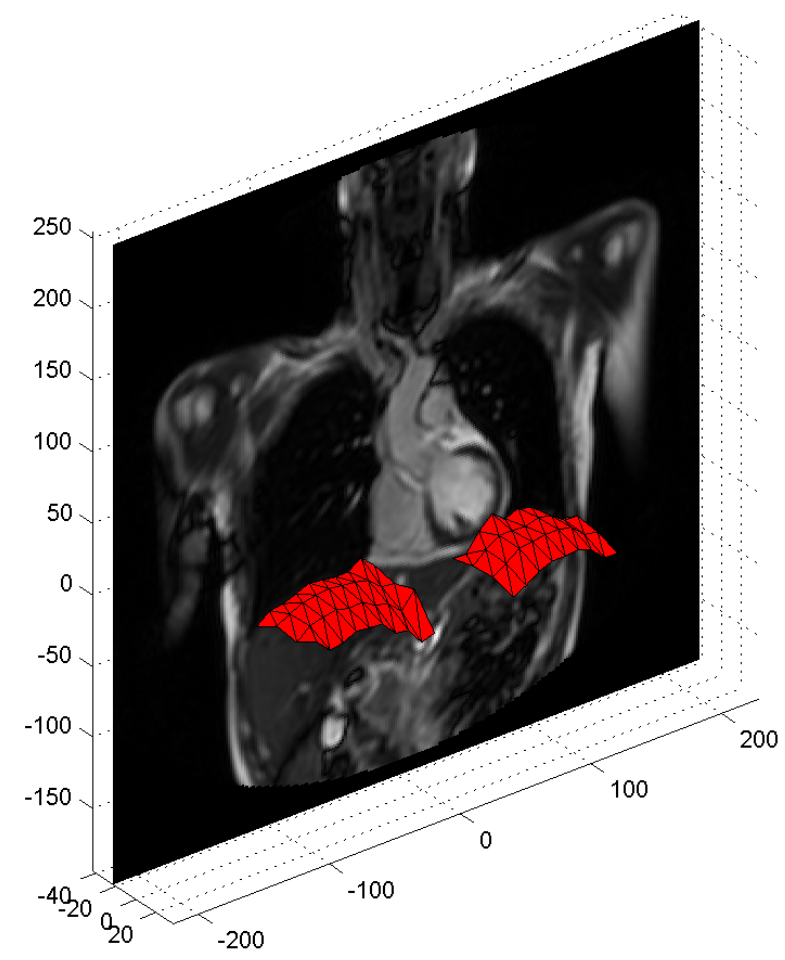

Figura 5.18: Caso 1. Imagem 6. 


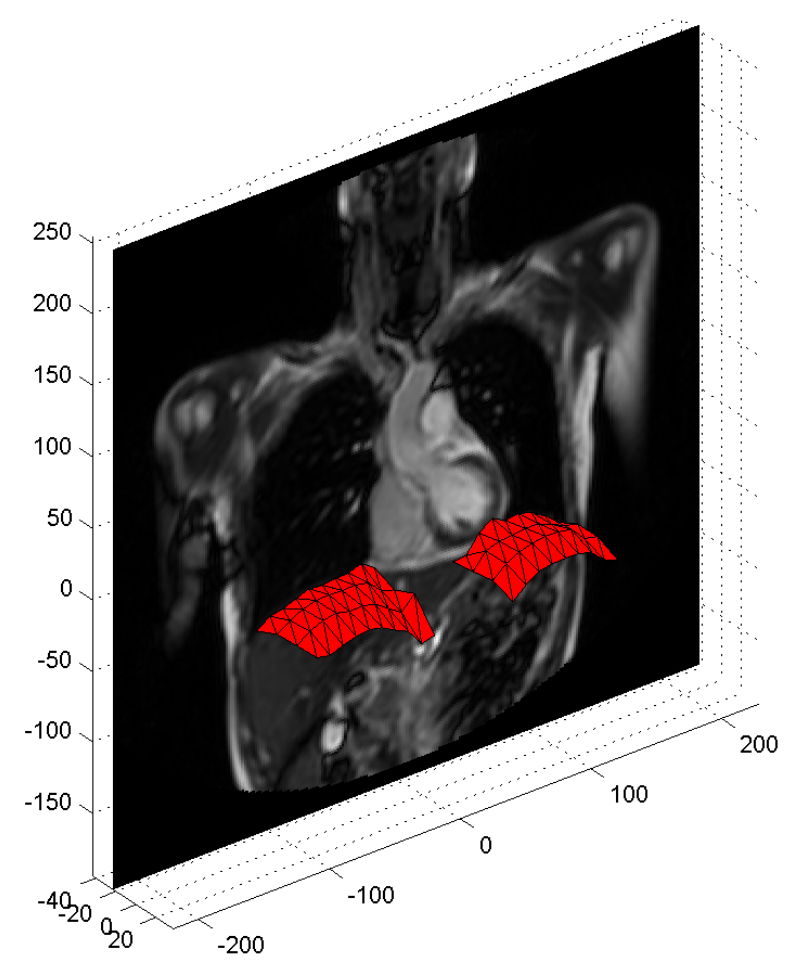

Figura 5.19: Caso 1. Imagem 7.

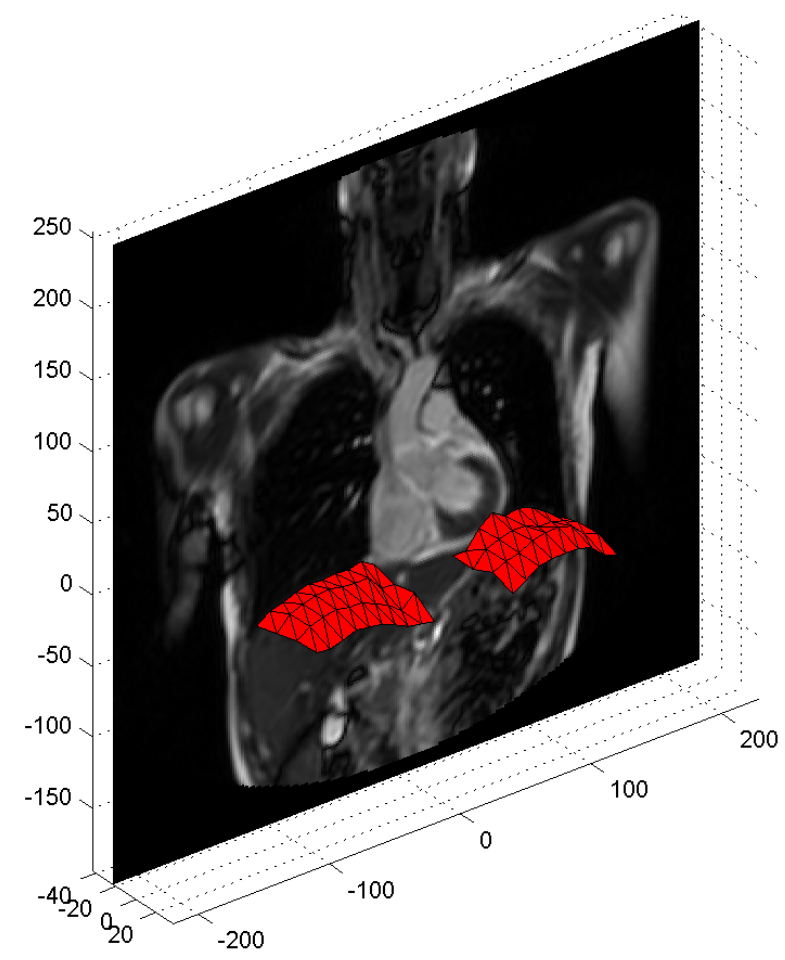

Figura 5.20: Caso 1. Imagem 8. 


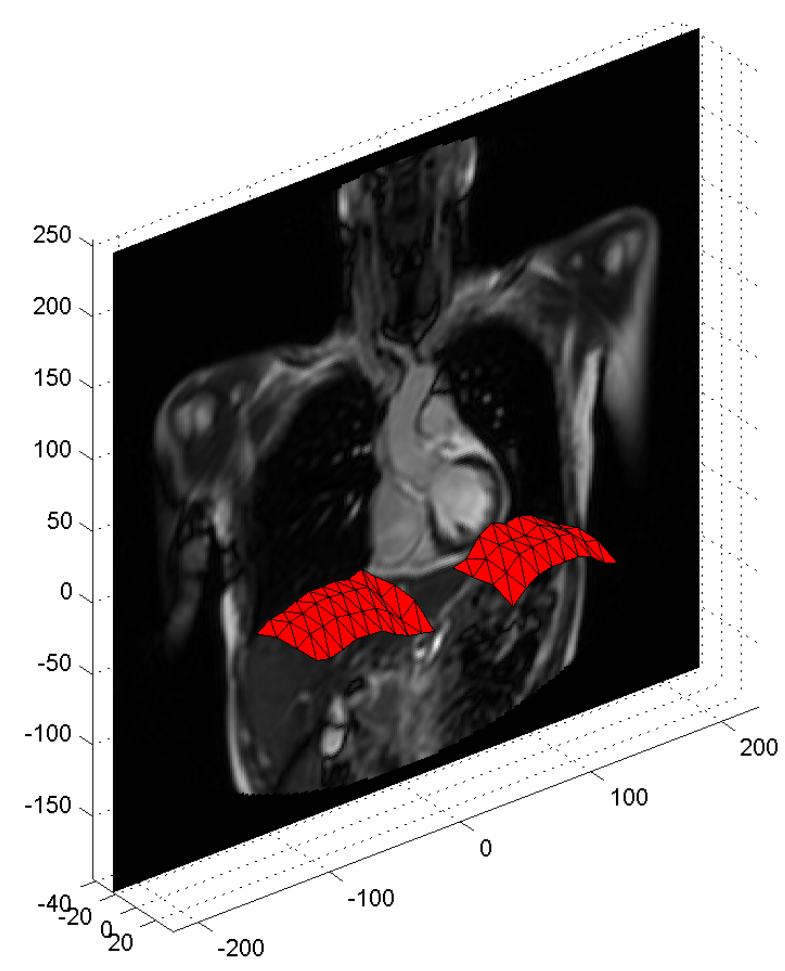

Figura 5.21: Caso 1. Imagem 9.

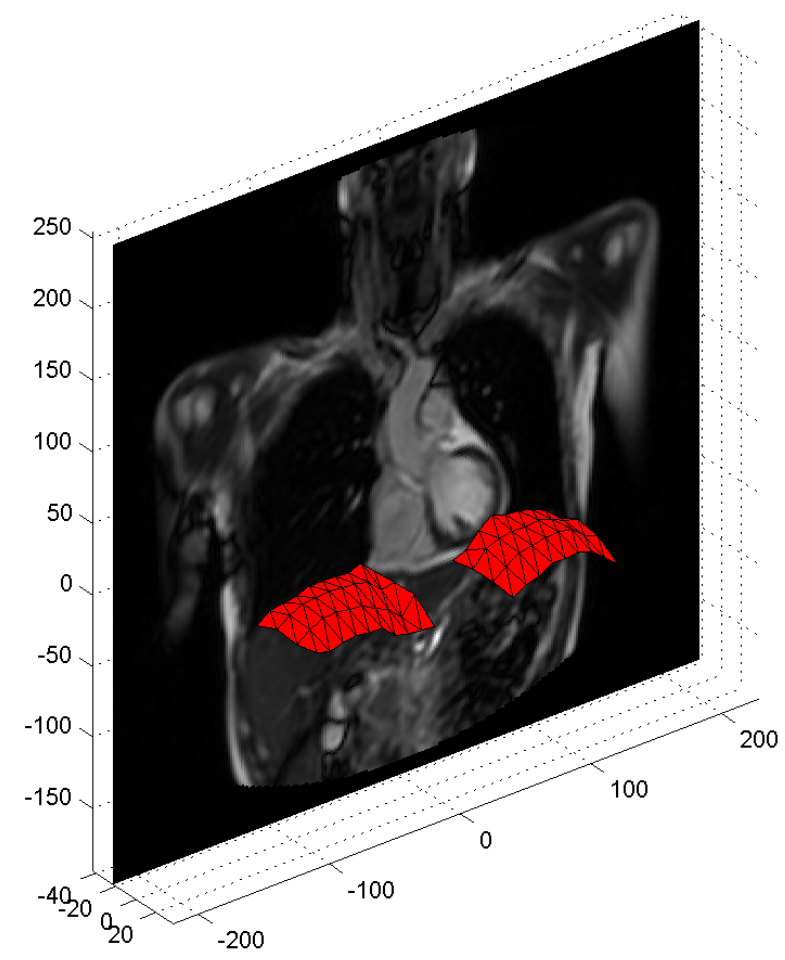

Figura 5.22: Caso 1. Imagem 10. 


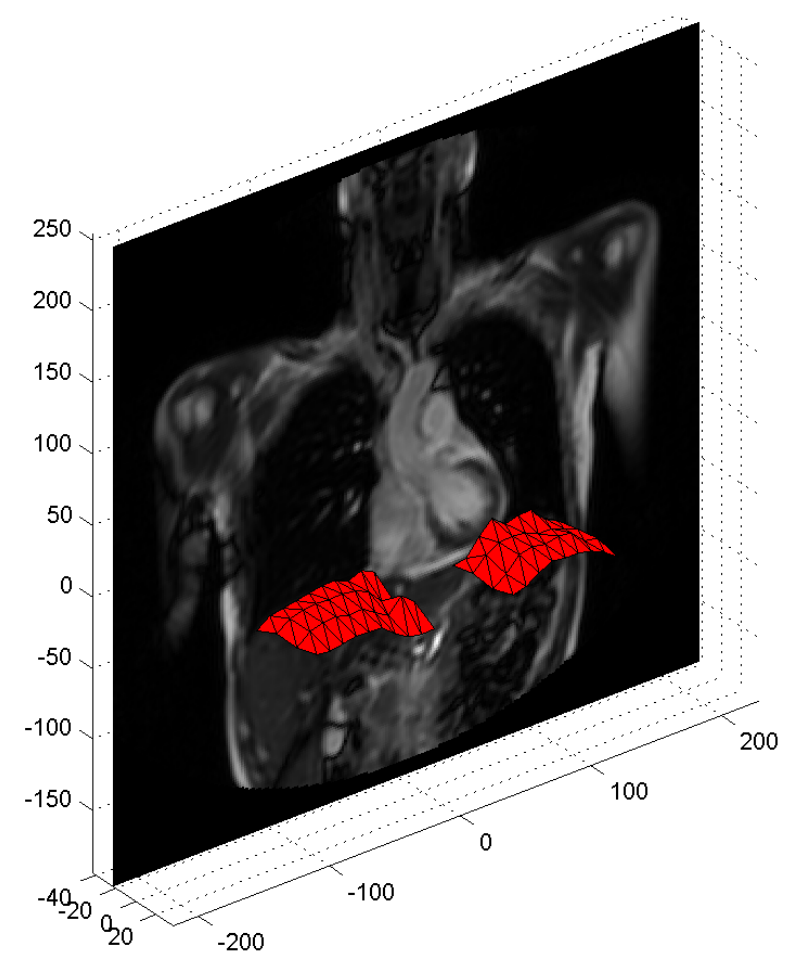

Figura 5.23: Caso 1. Imagem 11.

A Fig. 5.31 ilustra a aplicação do mesmo algoritmo porém com uma sagital de raiz, pode-se observar que os resultados são semelhantes.

O segundo caso é composto por 98 sequências temporais, sendo 50 coronais e 48 sagitais. Destas foram utilizadas 28 sagitais e 27 coronais. As demais foram descartadas por conter pouca informação da superfície diafragmática. Os padrões respiratórios diafragmáticos foram segmentados, as árvores de registros foram obtidas e a superfície diafragmática foi reconstruída. As Figs. 5.32 a 5.49 ilustram os resultados. As imagens raiz foram de uma sequência coronal, localizada em uma posição central: 


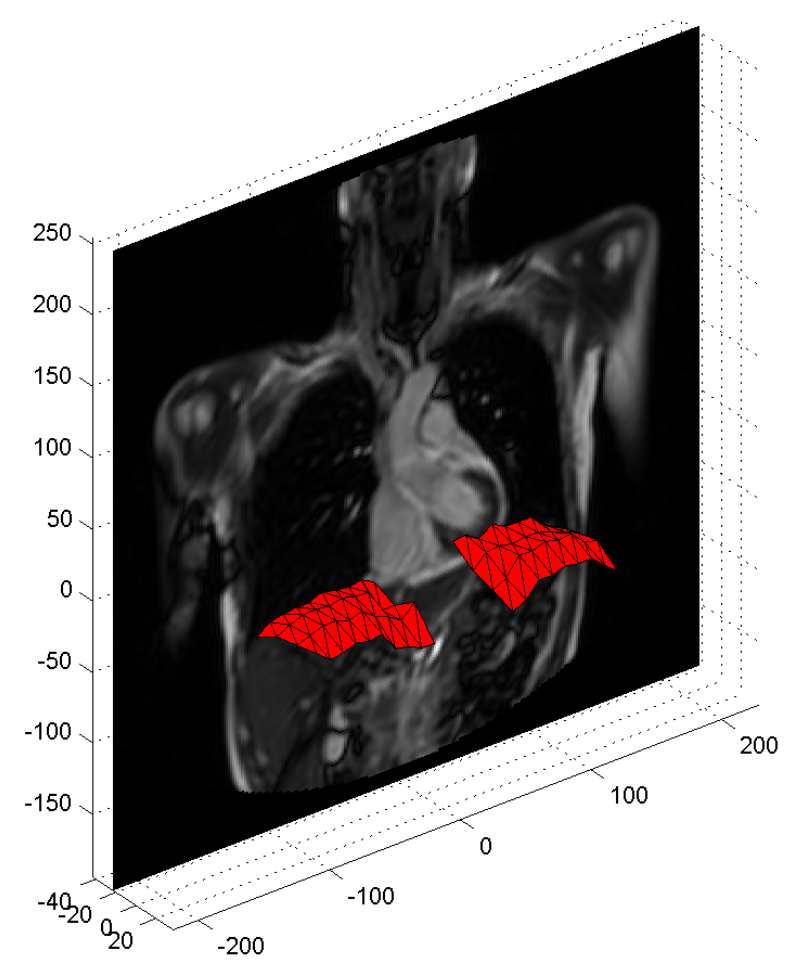

Figura 5.24: Caso 1. Imagem 12.

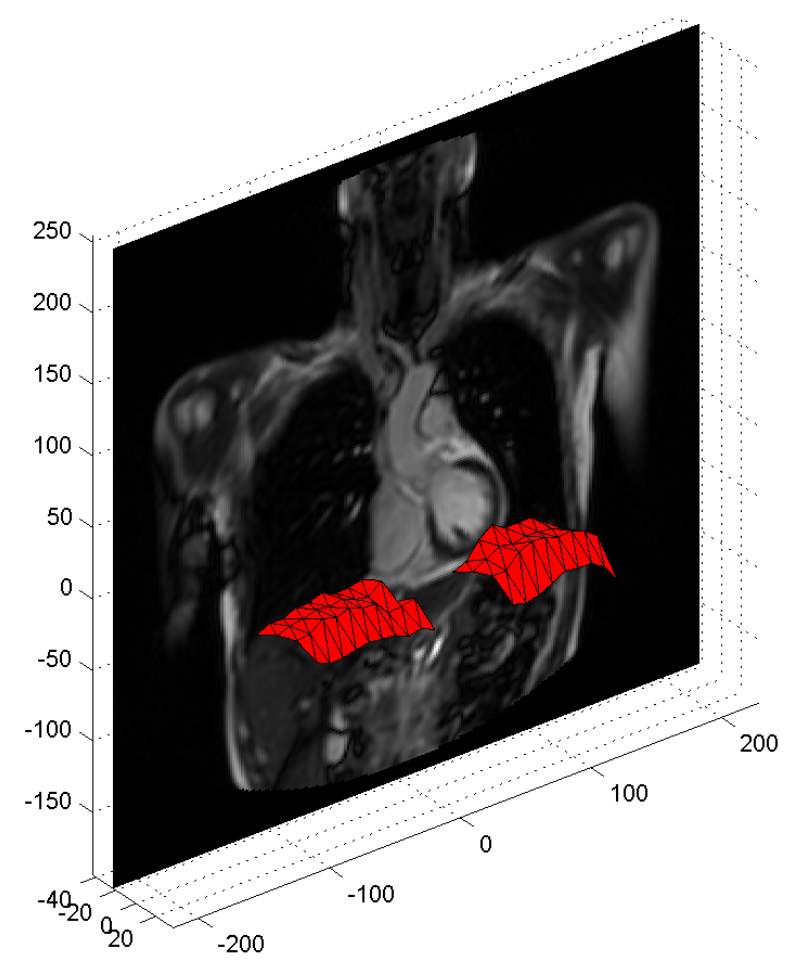

Figura 5.25: Caso 1. Imagem 13. 


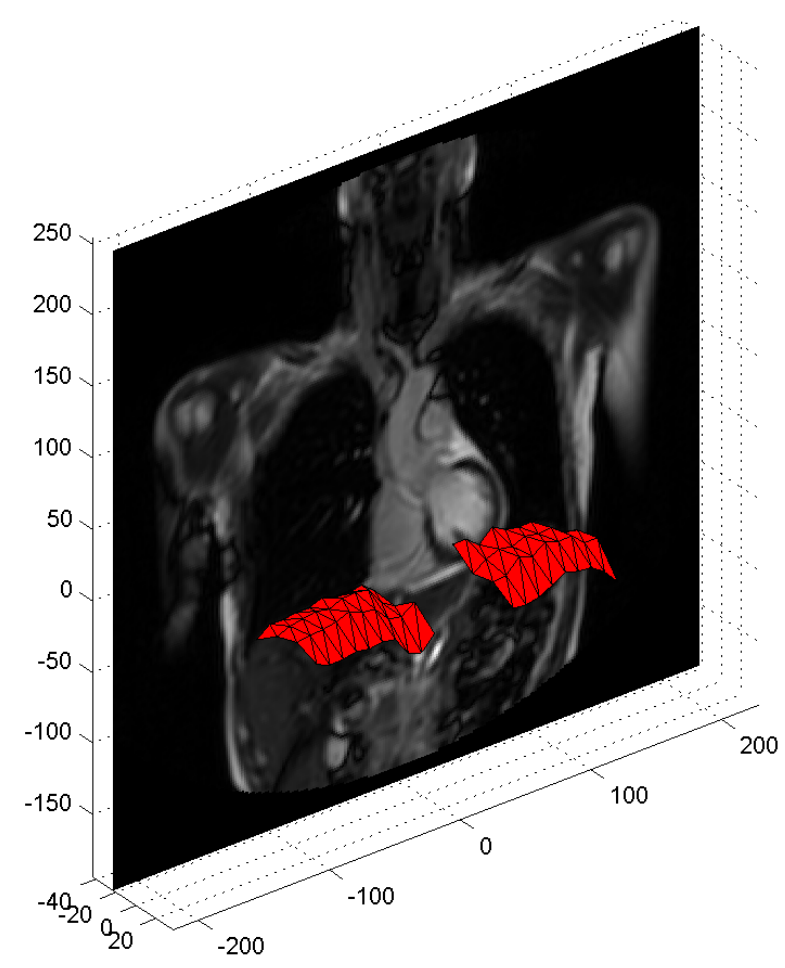

Figura 5.26: Caso 1. Imagem 14.

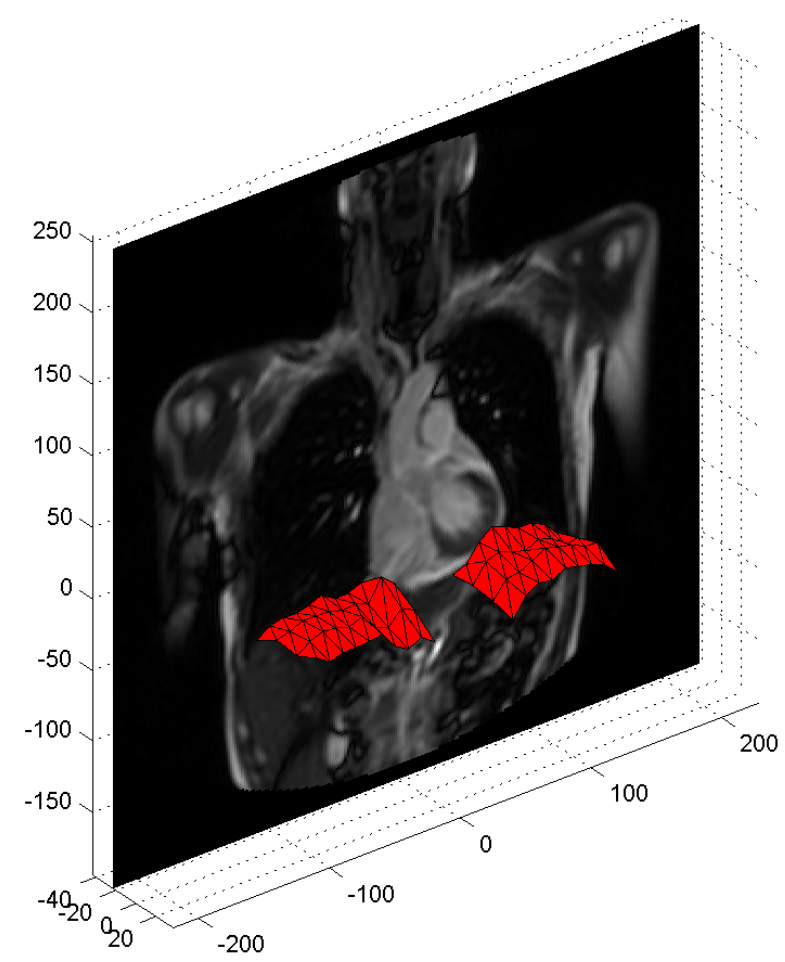

Figura 5.27: Caso 1. Imagem 15. 


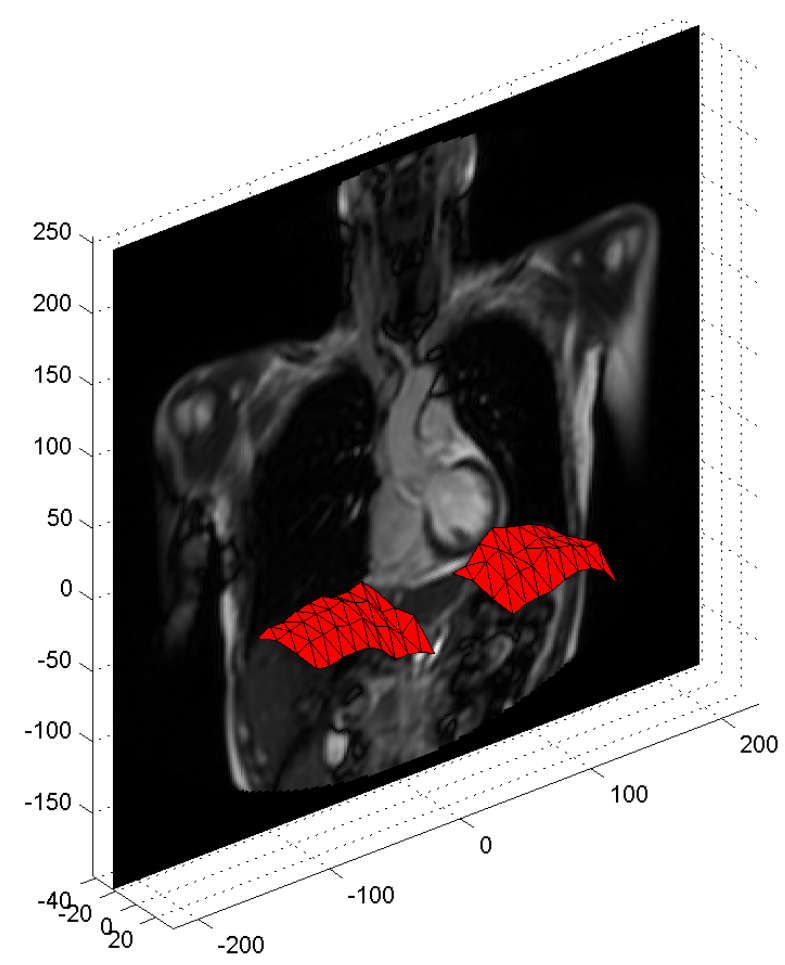

Figura 5.28: Caso 1. Imagem 16.

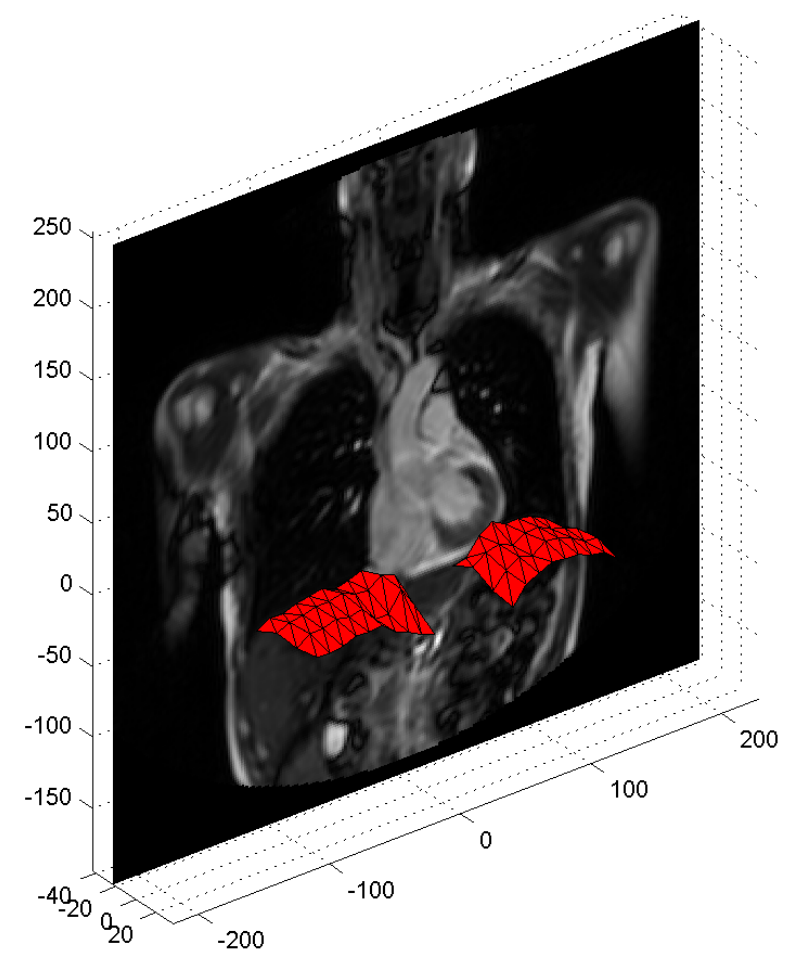

Figura 5.29: Caso 1. Imagem 17. 


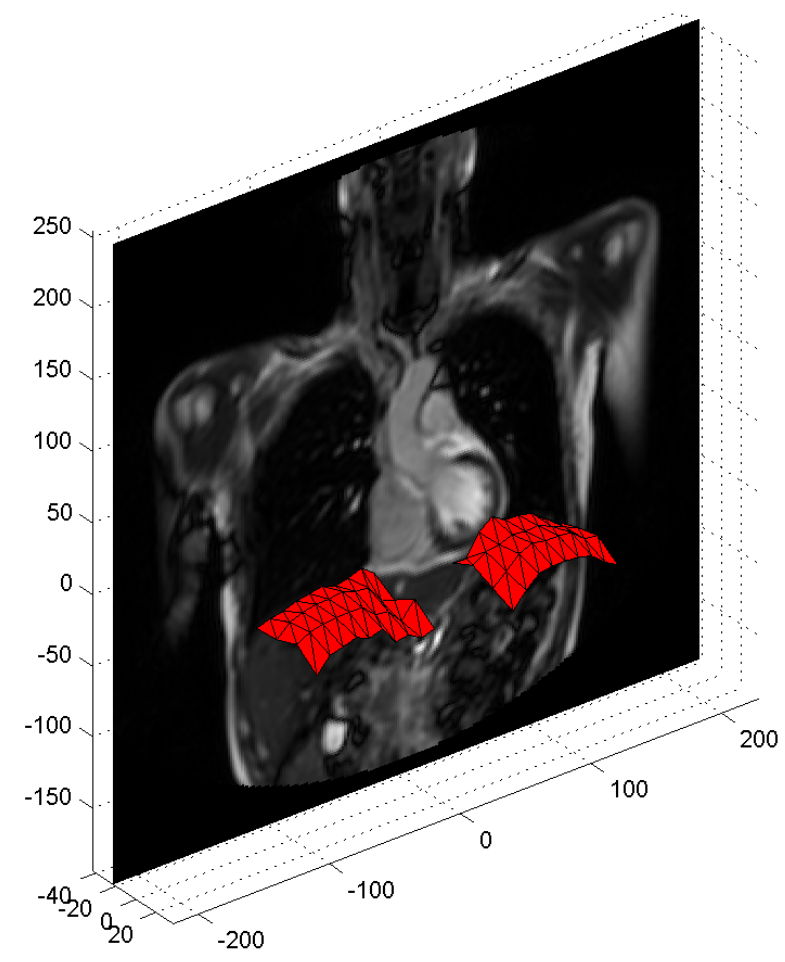

Figura 5.30: Caso 1. Imagem 18.

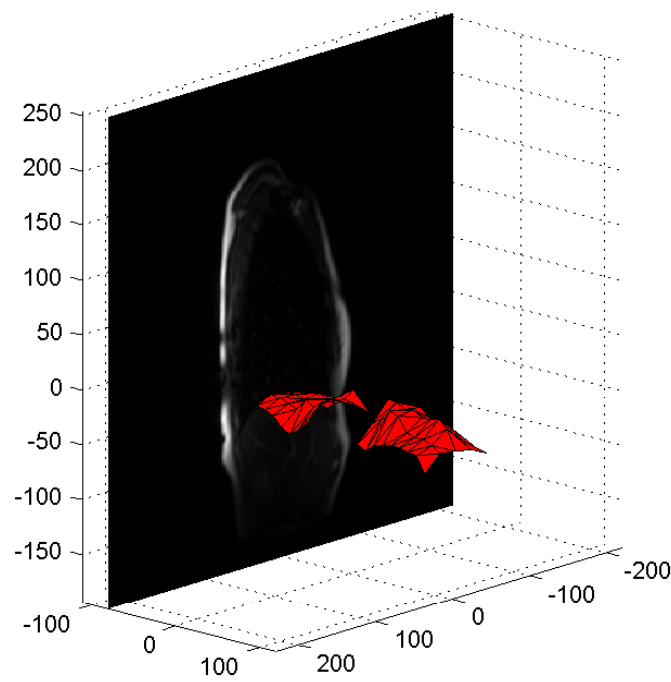

Figura 5.31: Reconstrução sagital da mesma sequência. 


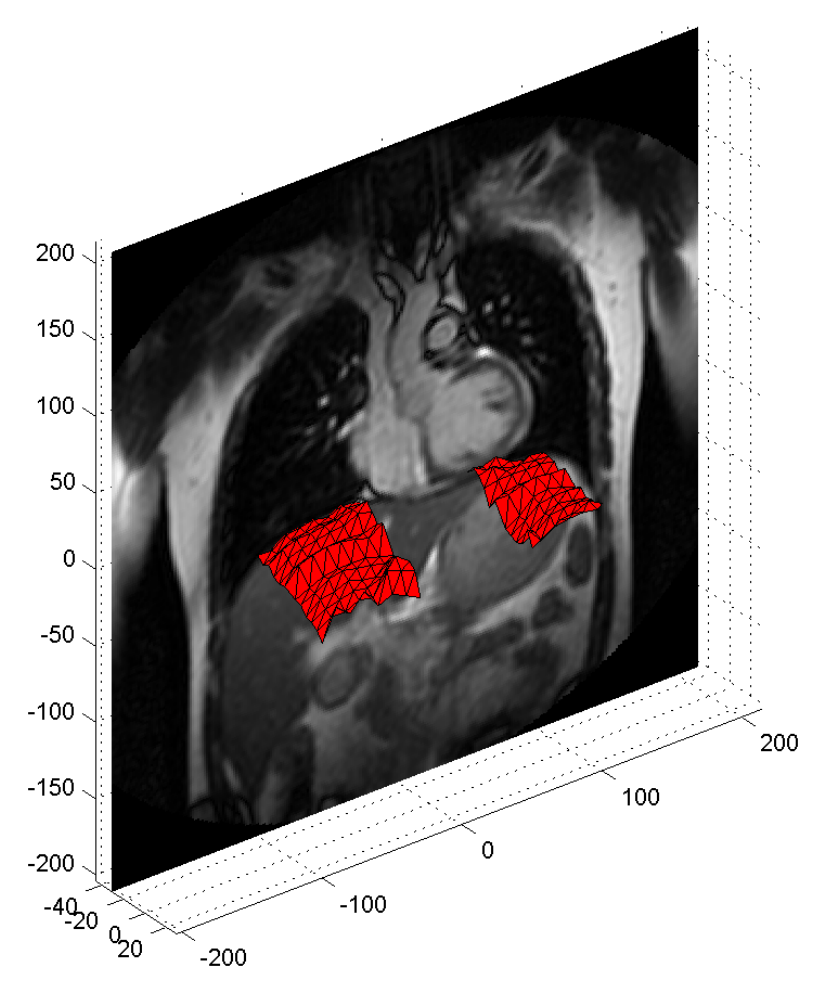

Figura 5.32: Caso 1. Imagem 1

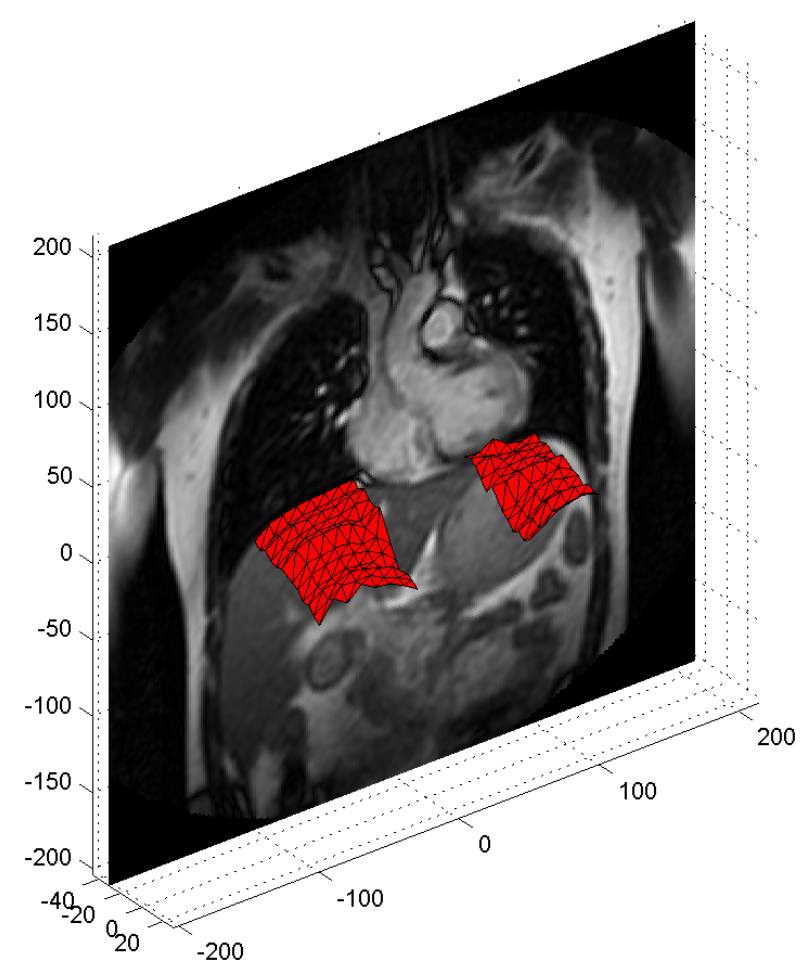

Figura 5.33: Caso 1. Imagem 2 


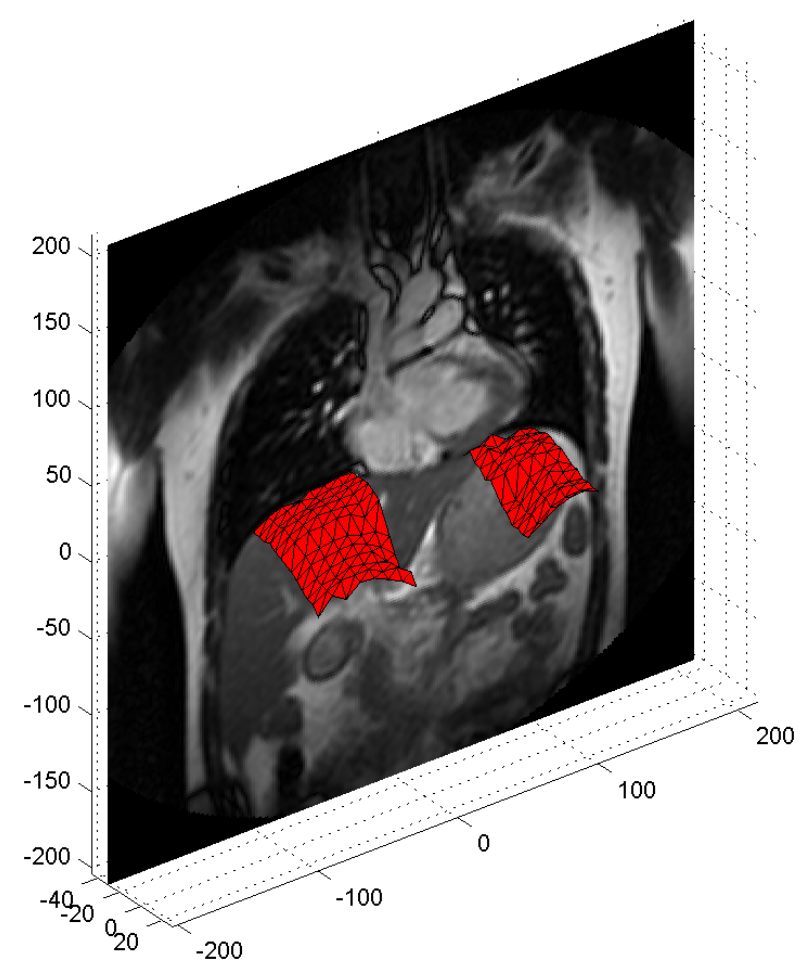

Figura 5.34: Caso 1. Imagem 3

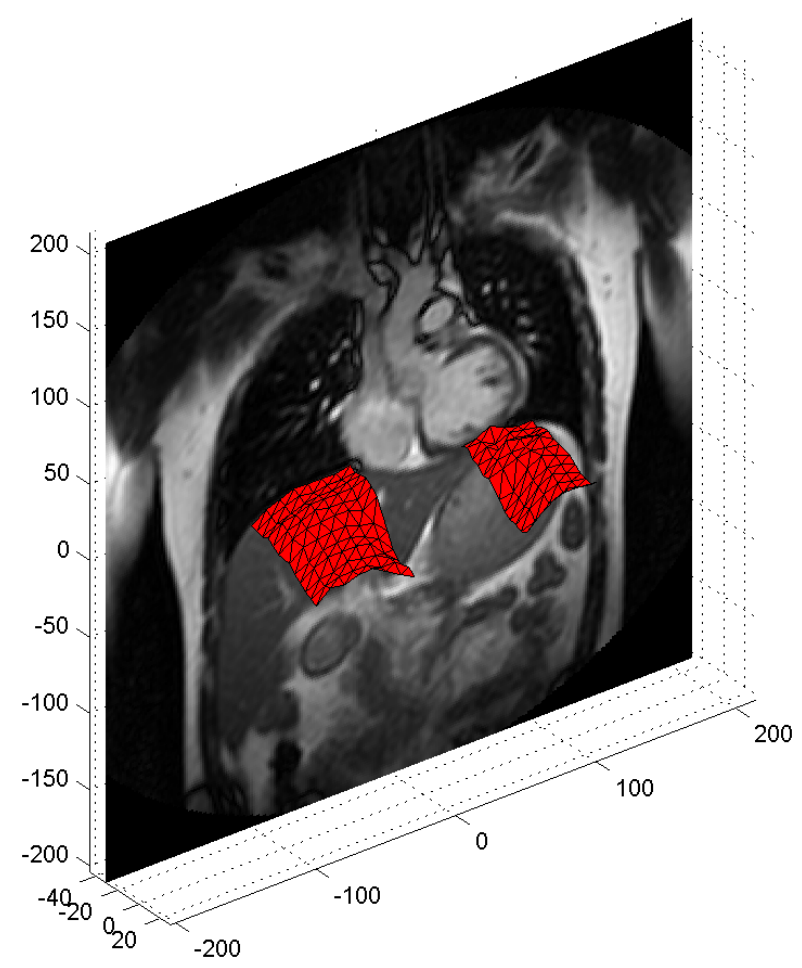

Figura 5.35: Caso 1. Imagem 4 


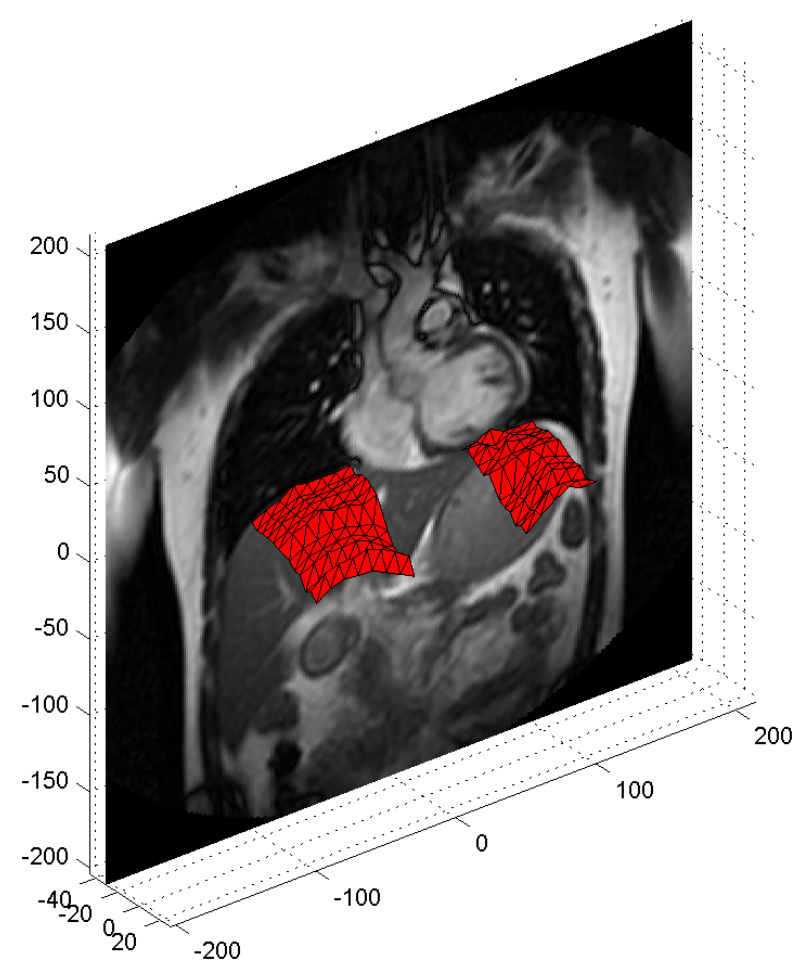

Figura 5.36: Caso 1. Imagem 5

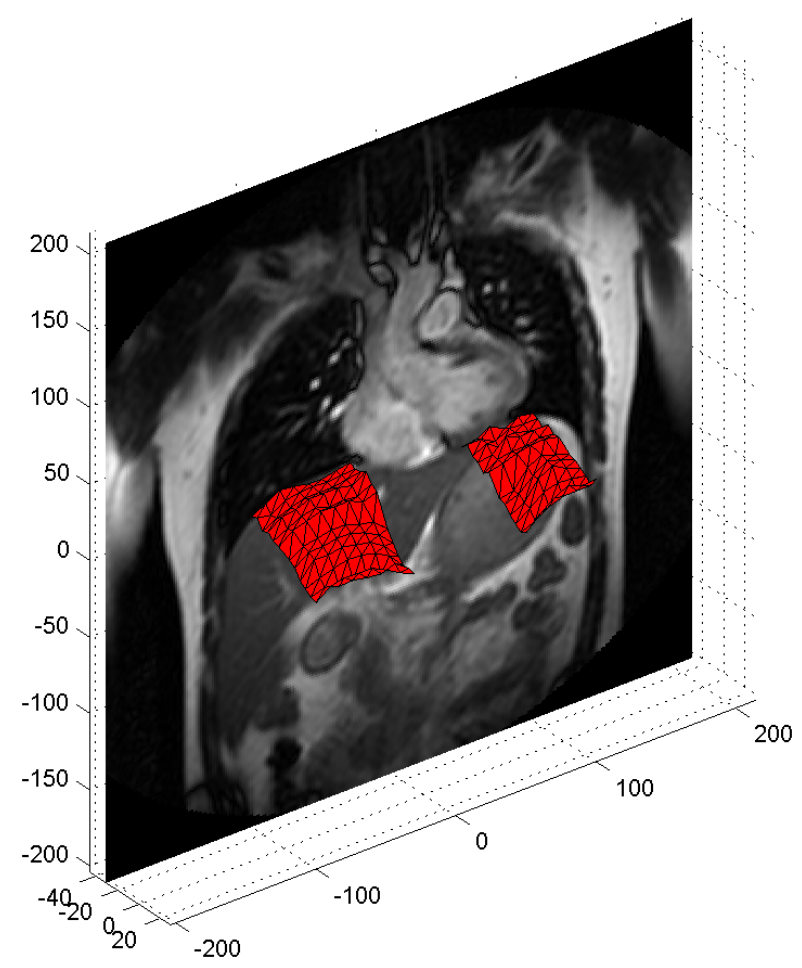

Figura 5.37: Caso 1. Imagem 6 


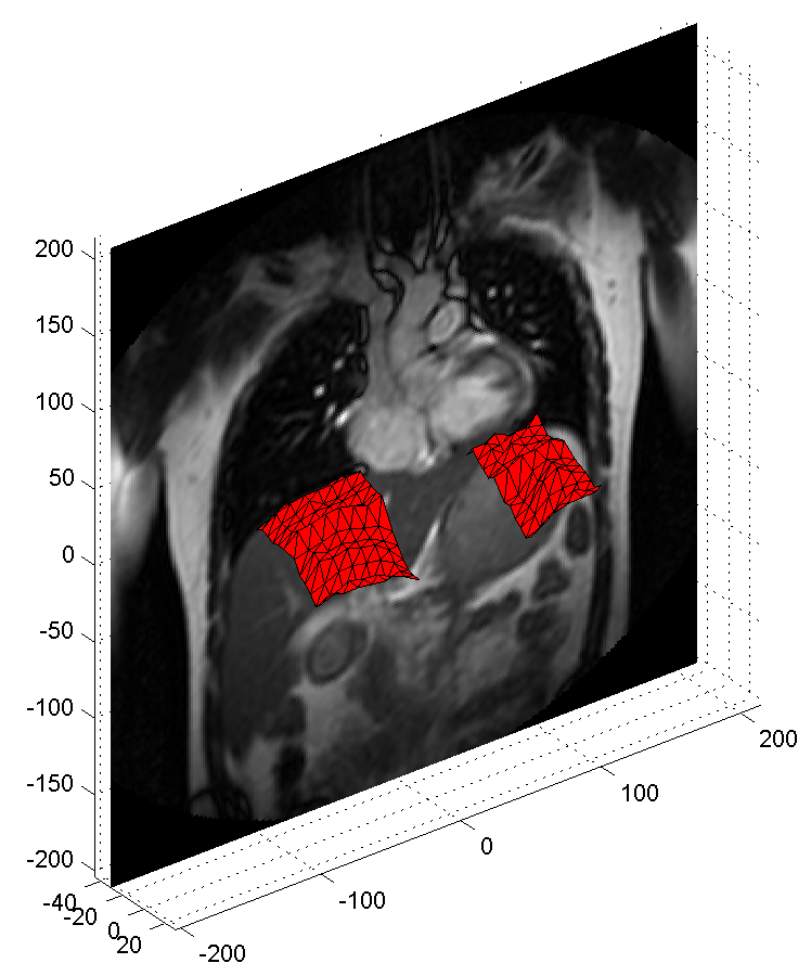

Figura 5.38: Caso 1. Imagem 7

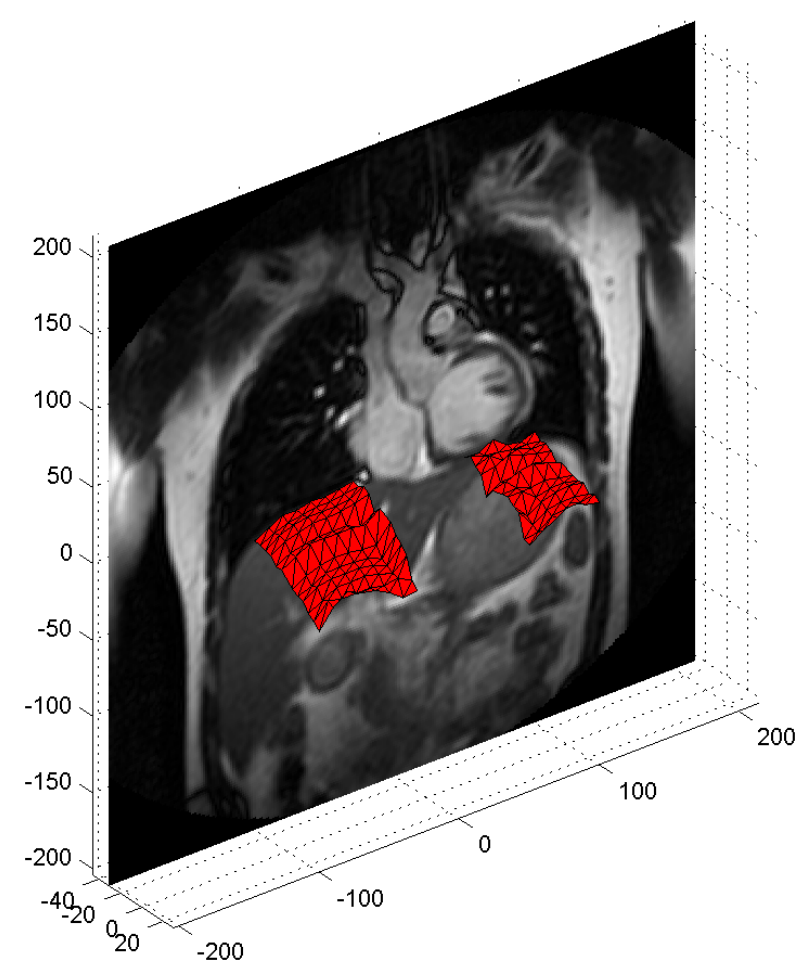

Figura 5.39: Caso 1. Imagem 8 


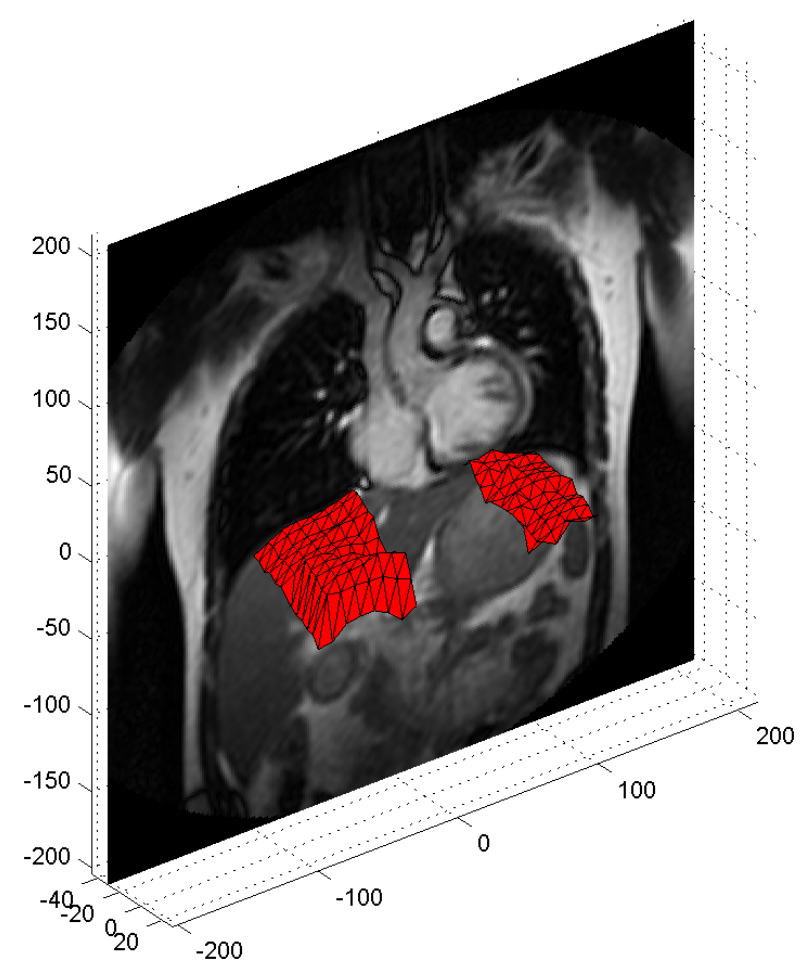

Figura 5.40: Caso 1. Imagem 9

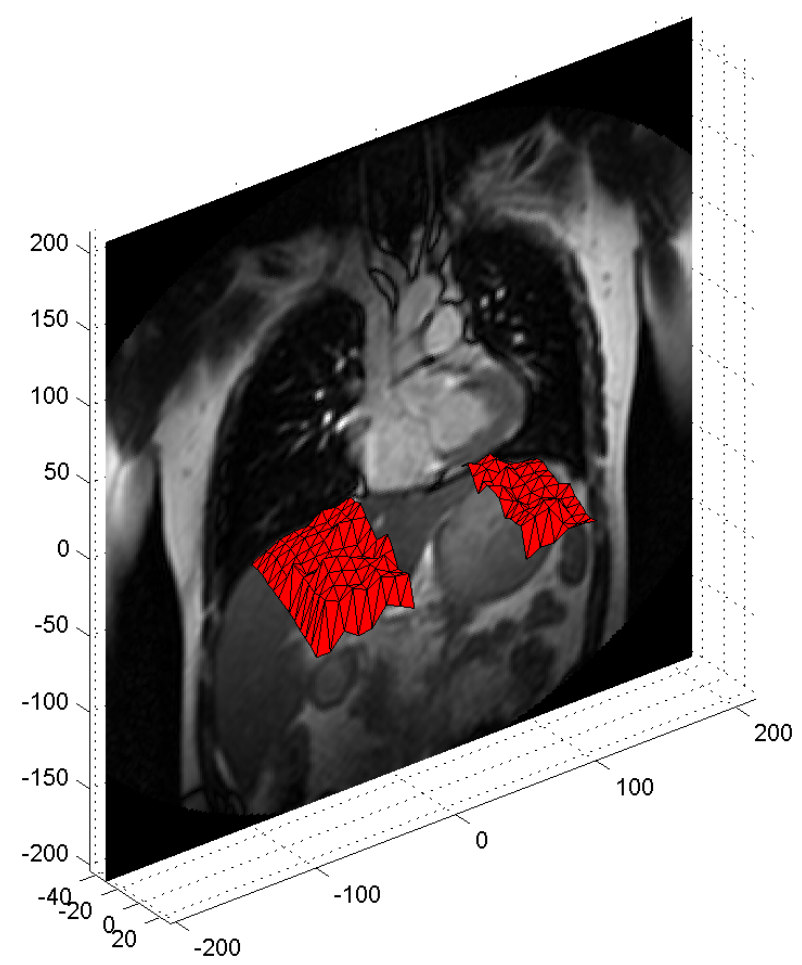

Figura 5.41: Caso 1. Imagem 10 


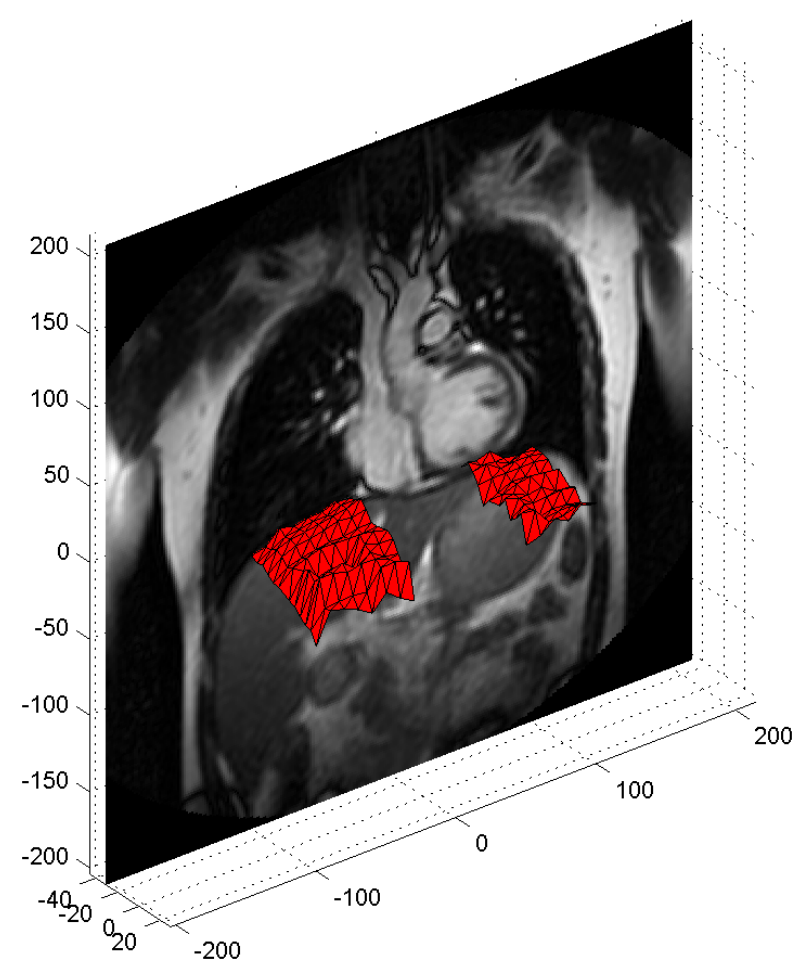

Figura 5.42: Caso 1. Imagem 11

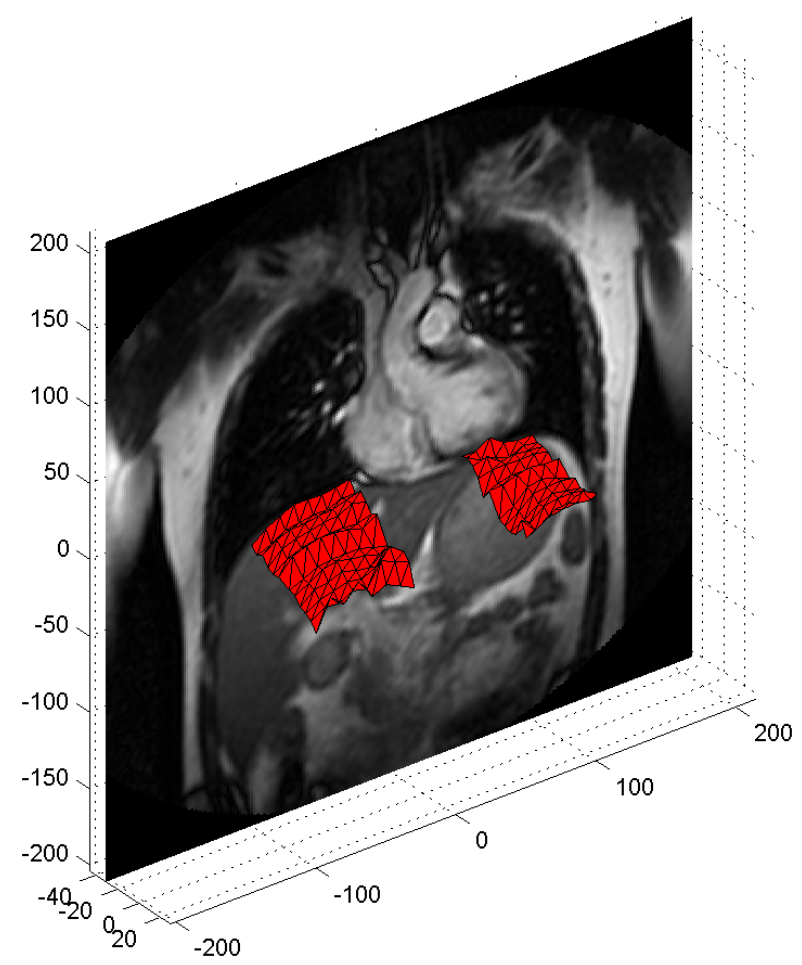

Figura 5.43: Caso 1. Imagem 12 


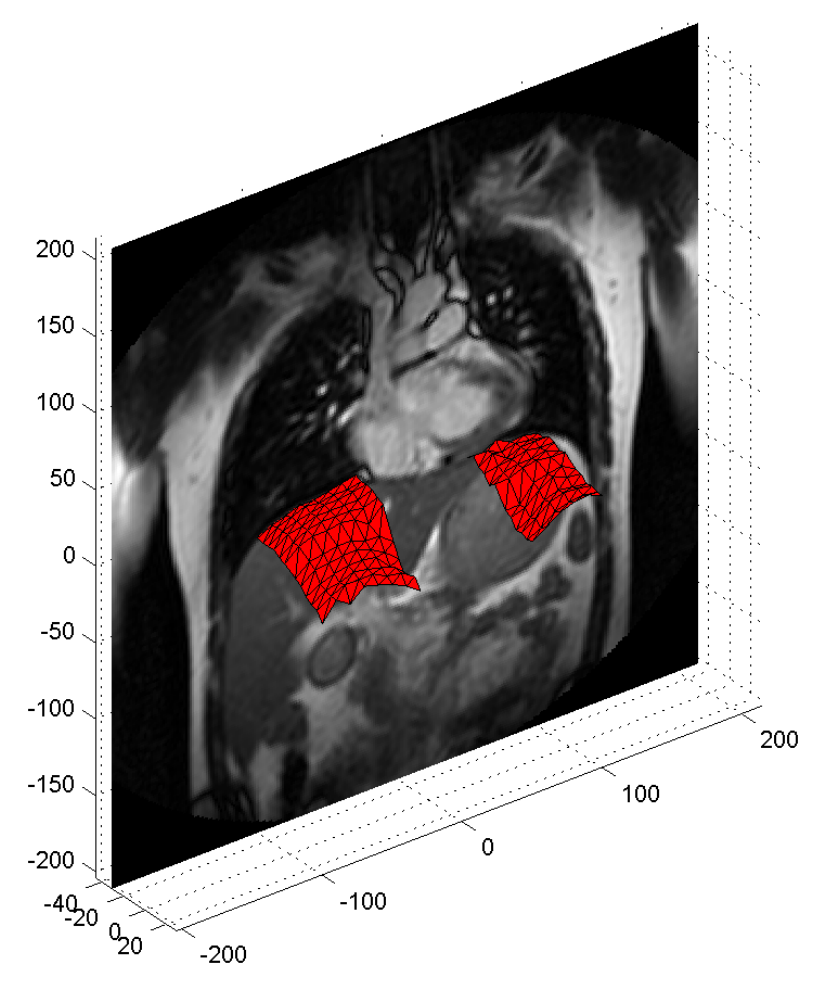

Figura 5.44: Caso 1. Imagem 13 


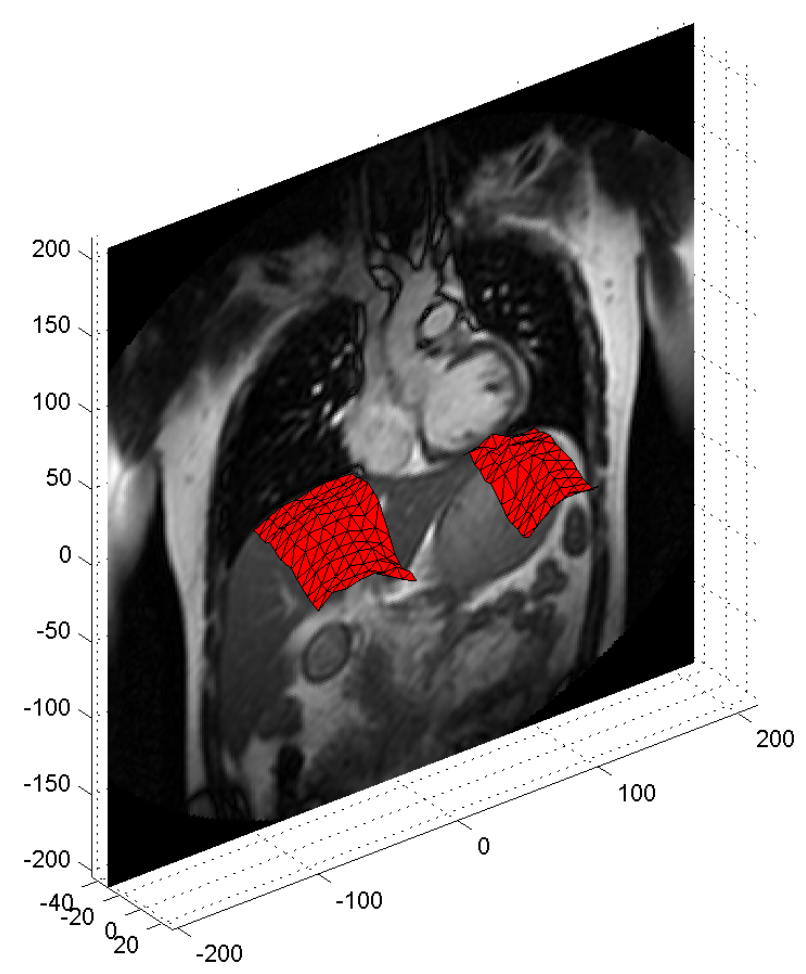

Figura 5.45: Caso 1. Imagem 14

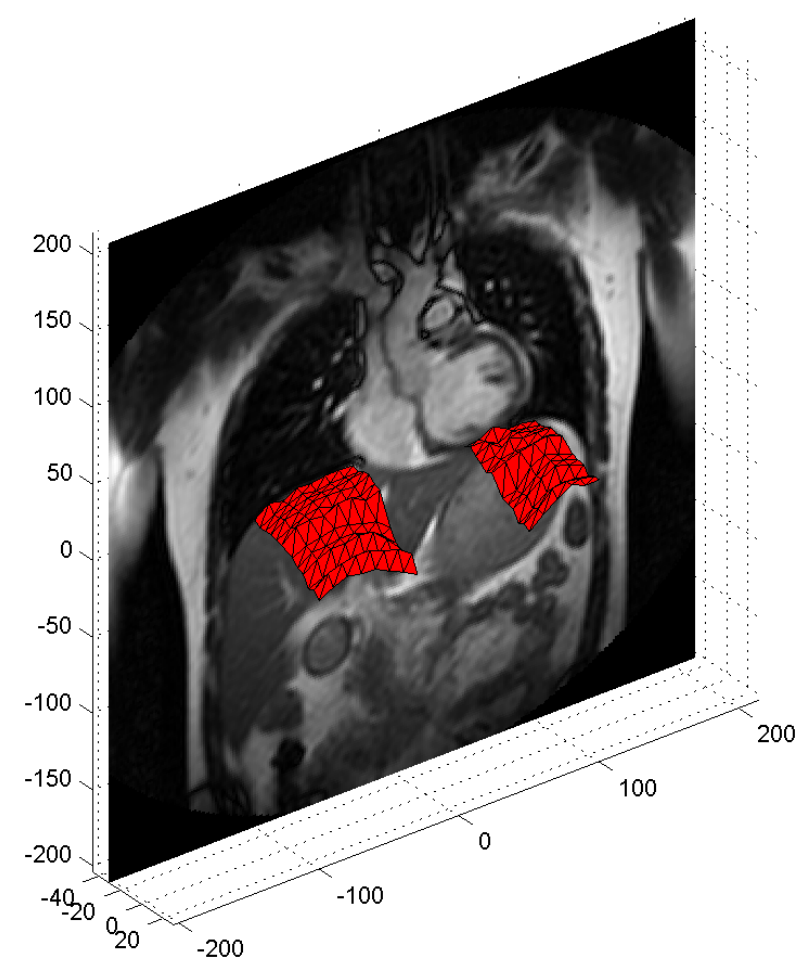

Figura 5.46: Caso 1. Imagem 15 


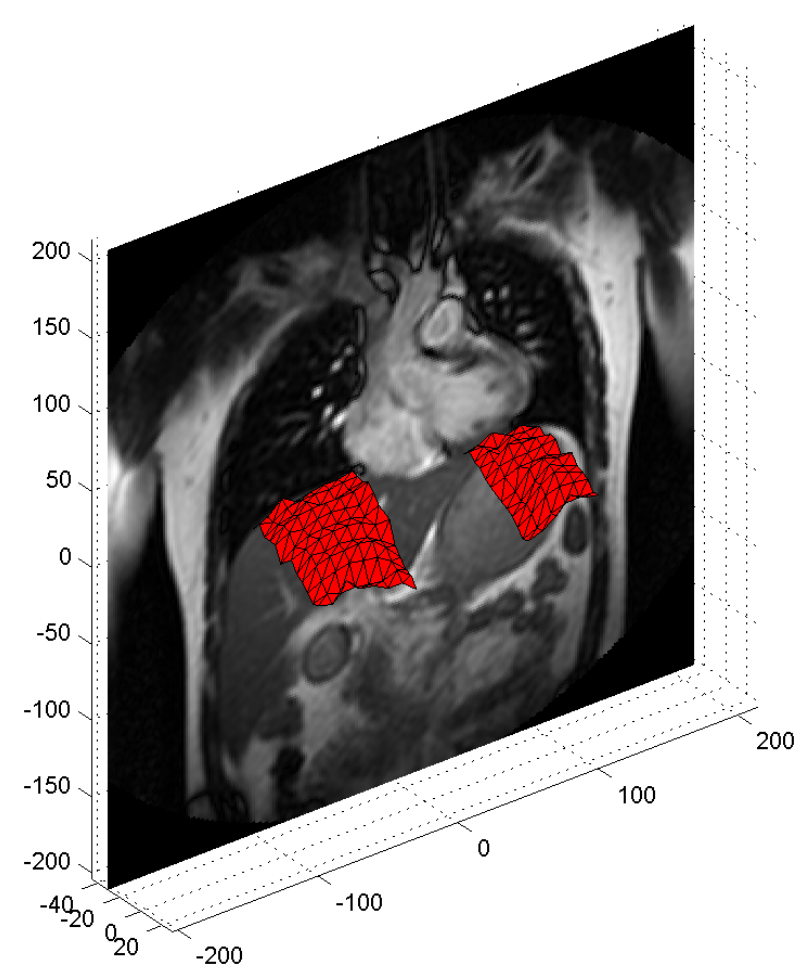

Figura 5.47: Caso 1. Imagem 16

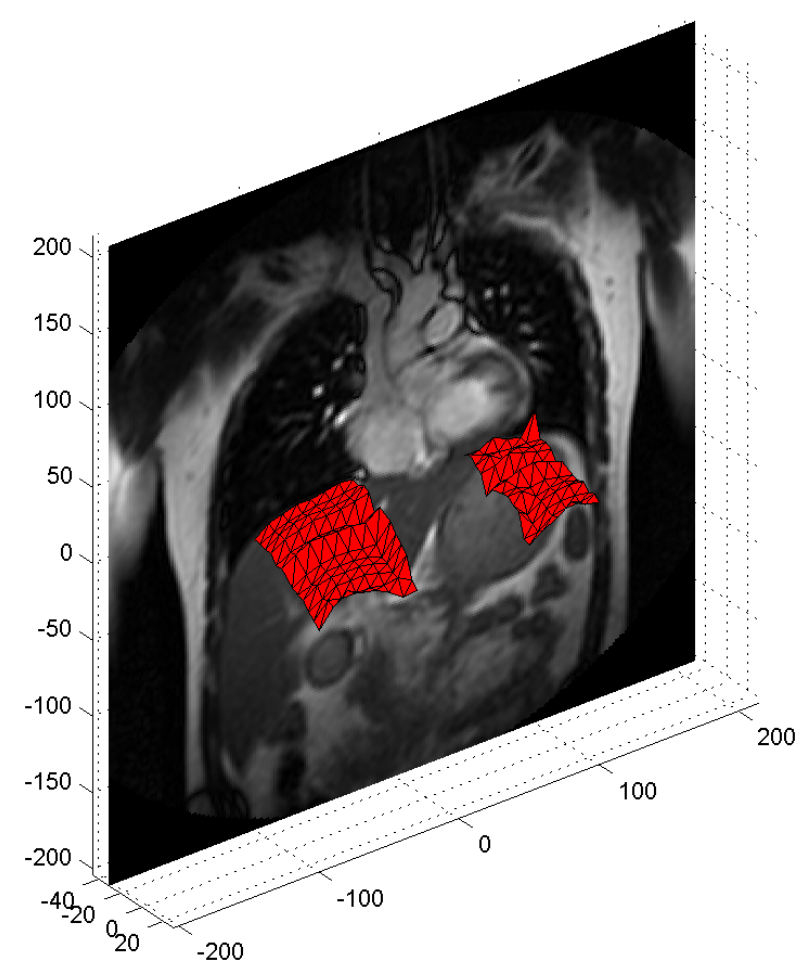

Figura 5.48: Caso 1. Imagem 17 


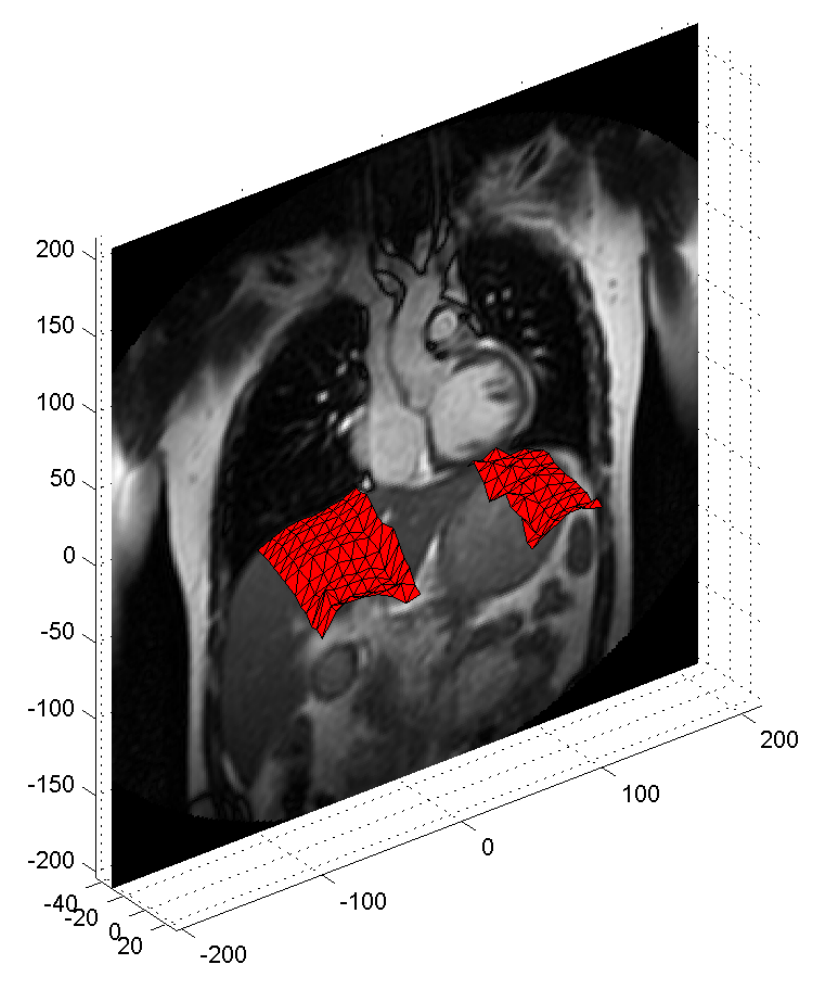

Figura 5.49: Caso 1. Imagem 18 
Detalhando sobre a eficiência de cada módulo do sistema, nota-se que o sistema de segmentação automático, utilizando a transformada de Hough modificada em conjunto com as máscaras, foi capaz de realizar a segmentação do padrão respiratório diafragmático em boa parte dos casos. Em regiões críticas, como embaixo do coração, existência de muitas veias e ossos, nenhuma das máscaras utilizadas pode ser aplicada, o que necessitou utilizar o método manual. Porém, o método manual depende de análise do próprio usuário do sistema, o que pode gerar erros, dado que a escolha do padrão certo é uma tarefa complexa e suscetível a falhas. Uma segmentação inadequada prejudica todas as etapas do algoritmo proposto.

Em relação à busca de registros temporais, o algoritmo se mostrou robusto, utilizando diferentes sequências (sagitais e coronais) como referência e gerando resultados similares como esperado. Uma complicação encontrada foi a geração da árvore em posições de troca de fase respiratória, que são condições de máximos e mínimos do nível diafragmático. No entanto, este problema é esperado, pois dado que as sequências utilizadas não foram extraídas simultaneamente, os máximos e mínimos dos níveis diafragmáticos não são os mesmos. Desta forma, é impossível obter informações nestas posições em todas imagens sem o uso de alguma forma de extrapolação. No escopo deste trabalho, foi decidido remover estas pontas para criação da animação.

Sobre a escolha dos dados utilizados, o método de melhor ajuste proposto, no qual para cada sequência, coronal e sagital, define-se um instante de tempo e todos níveis diafragmáticos são definidos a partir destes, mostrou-se uma forma adequada de obter pontos sem registro temporal direto, preservando a coerência com os pontos adjacentes. Como os instantes de tempo selecionados ocorrem mais de uma vez e em diversos pontos diferentes (as redundâncias), pode-se dizer que os níveis diafragmáticos escolhidos correspondem com maior certeza à informação procurada.

Sobre a reconstrução da superfície diafragmática, o algoritmo gerou um modelo com contornos suaves e uma animação constante. Pode-se verificar que ao sobrepor o modelo sobre a imagem raíz há um casamento da região da superfície diafragmática na imagem e do modelo, indicando que a representação feita é consistente. Avaliando a reconstrução com uma imagem raiz coronal e uma imagem raiz sagital, pode-se notar que o modelo gerado preserva a curvatura da 


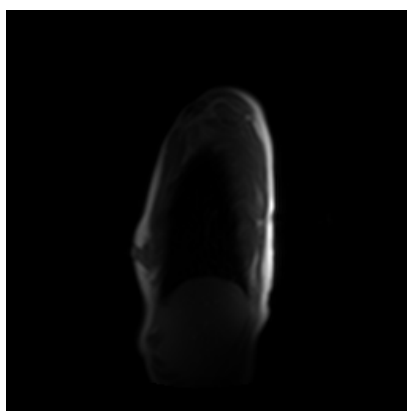

(a)

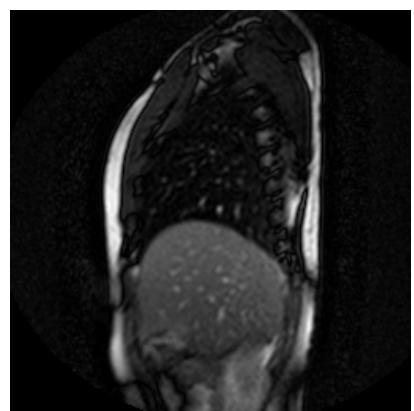

(b)

Figura 5.50: Comparação entre duas imagens sagitais das sequências utilizadas, pode pode-se observar a diferença em contraste entre elas.

superfície diafragmática, exibindo inclusive as variações de forma durante a respiração. Pela avaliação visual, nota-se que a animação é suave, de forma similar ao que pode ser visto nas sequências imagens bidimensionais de RM utilizadas.

Em relação às máscaras, foi observado que os parâmetros utilizados no algoritmo dependem principalmente da configuração do equipamento de RM na aquisição. Nos casos de teste utilizados, foi bem clara a diferença. A Fig. 5.50 ilustra duas imagens retiradas aproximadamente no mesmo corte. Nota-se que o contraste destas imagens é bem distinto, o que interfere na criação das máscaras. Com a utilização do algoritmo em outros casos, será possível estabelecer não apenas os parâmetros adequados para as máscaras mas também a configuração ideal do equipamento de RM para esta finalidade. 


\section{Conclusões e Trabalhos}

\section{Futuros}

Neste trabalho foi proposto um método de busca de registros temporais e reconstrução da superfície diafragmática em movimento, utilizando sequências temporais sagitais e coronais de RM. Determinou-se todos os cruzamentos e o padrão respiratório diafragmático foi segmentado temporalmente nos cruzamentos. Para obtenção dos registros temporais, foi proposto um algoritmo que analisa todas as sequências e determina todas as possibilidades de registros para cada quadro. Os resultados deste algoritmo foram utilizados para a reconstrução da superfície diafragmática em movimento. Dado que o volume de sequências a serem processadas era grande, um sistema automático foi desenvolvido, viabilizando a obtenção dos resultados em um tempo viável.

Dois grupos de sequências foram utilizados como teste e os resultados, gerando modelos animados da superfície diafragmática com animação suave, similar ao que pode ser visto nas imagens de entrada. Os modelos gerados apresentam coerência de forma, ou seja a curvatura e a forma do diafragma foram mantidos das imagens de RM para o modelo. Verificando os modelos sobrepostos às imagens raiz, pode-se observar o casamento entre o modelo e a superfície diafragmática e a imagem de RM.

Neste trabalho, foram utilizadas sequências de indivíduos sadios. Posteriormente, esta frente de pesquisa deve analisar sequências de indivíduos doentes e verificar se os algoritmos propostos também são aplicáveis, realizando as alterações necessárias. Além da superfície diafragmática reconstruída, um dos resultados cruciais deste trabalho foram as árvores de registros temporais. Com todas possibilidades de registro determinadas, é possível realizar diversas análises, permitindo, por exemplo, a reconstrução dos pulmões em movimento e a comparação entre diferentes instantes de tempo. A presença das várias redundâncias garante que a das informações. Futuramente, será possível realizar análises multimodais, complementando com informações de TC e TIE. 


\section{Apêndice A - Morfologia Matemática}

A morfologia digital é uma área recente. A seguir, serão descritas quatro básicas operações morfológicas utilizadas neste trabalho: dilatação, erosão, abertura e fechamento, para imagens binárias e em tons de cinza. Adicionalmente serão descritas duas operações utilizadas: abertura de área e preenchimento de buracos.

\section{A.1 Dilatação Binária}

A dilatação, ou dilação, é uma transformação morfológica que combina dois conjuntos pela adição vetorial. Ela é representada pelo $\oplus$. Como o próprio nome indica, o resultado será uma imagem dilatada. A dilatação de um conjunto $A$ por um elemento estruturante $B$ é definida por

$$
A \oplus B=\{c \mid c=a+b, a \in A, b \in B\}
$$

Seja o conjunto $A=\{(0,1),(1,1),(2,1),(2,2),(3,0)\}$ e $B=\{(0,0),(0,1)\}$ então o conjunto resultante da dilatação:

$$
\begin{aligned}
& A \oplus B=\left\{x_{1}+x_{2} \mid x_{1} \in \text { Aex }_{2} \in B\right\} \\
& A \oplus B=\{(0,1),(1,1),(2,1),(3,0),(0,2),(1,2),(2,2),(2,3),(3,1)\}
\end{aligned}
$$

A Fig. A.1 exibe a aplicação da dilatação binária em $A$ com elemento estruturante $B$.

\section{A.2 Erosão Binária}

A erosão encolhe uma imagem, uma transformação morfológica usando vetores de subtração. Ela é expressa como a intersecção de $A$ e $B$. Ou seja, $A \ominus B=B \cap A$. A erosão da imagem $A$ pelo elemento estruturante $B$ é dada por:

$$
A \ominus B=\{(x \mid x+b \in \text { Aparatodob } \in B)\}
$$

Seja o conjunto $A=\{(1,1),(1,2),(2,1),(2,2)\}$ e elemento estruturante $B=\{(0,0)(0,1))\}$

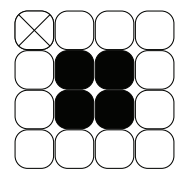

(A)

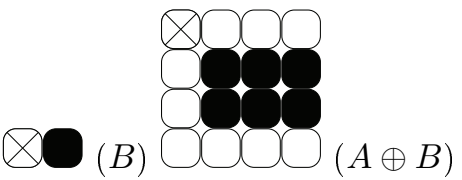

Figura A.1: Operação de dilatação binária com elemento estruturante $B$. 


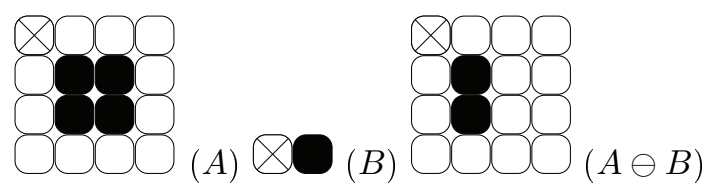

Figura A.2: Operação de erosão binária com elemento estruturante $B$.
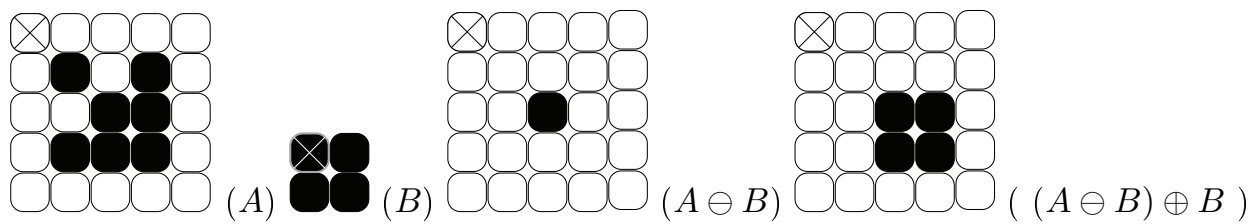

Figura A.3: Operação de abertura binária com elemento estruturante $B$.

$$
A=\{(1,1),(1,2)\}
$$

\section{A.3 Abertura (Opening)}

A abertura em geral suaviza o contorno de uma imagem, quebra estreitos e elimina proeminências delgadas, a operação de abertura é usada para remoção de ruídos da imagem. A abertura de um conjunto $A$ por elemento estruturante $B$ é denotado por $A \circ B$, e definida como

$$
A \circ B=(A \ominus B) \oplus B
$$

A aplicação de uma erosão imediatamente seguida de uma dilatação usando o mesmo elemento estrutural é uma operação de abertura, ela tende a abrir pequenos vazios ou espaços entre objetos próximos numa imagem. Ou seja, uma abertura é uma erosão seguida de uma dilatação usando um mesmo elemento estruturante. Aplicando uma erosão depois uma dilatação, prenche-se de branco os lugares onde o elemento estruturante estiver dentro do objeto. A Fig. A.3 exibe a aplicação da abertura passo-a-passo.

\section{A.4 Fechamento (Closing)}

O fechamento funde pequenas quebras, alarga golfos estreitos e elimina pequenos orifícios. O fechamento preenche os vazios. Estas operações podem remover muitos pixels brancos com ruídos. Primeiramente é feita a dilatação e depois a erosão. É definido por

$A \bullet B=(A \oplus B) \ominus B$.

O fechamento é o oposto à abertura, removendo os pixels onde o elemento 


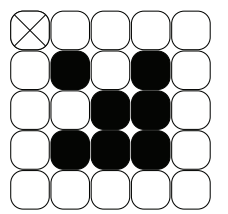

$(A)$

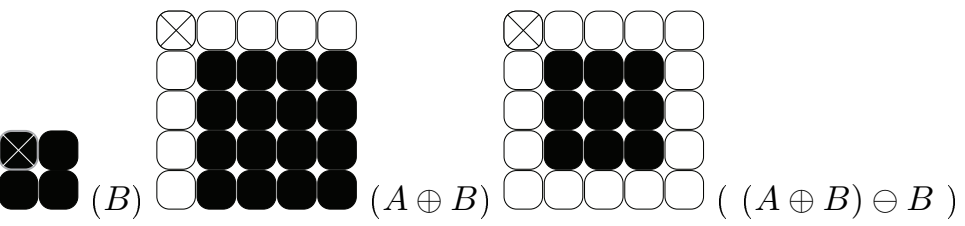

Figura A.4: Operação de fechamento binária com elemento estruturante B.

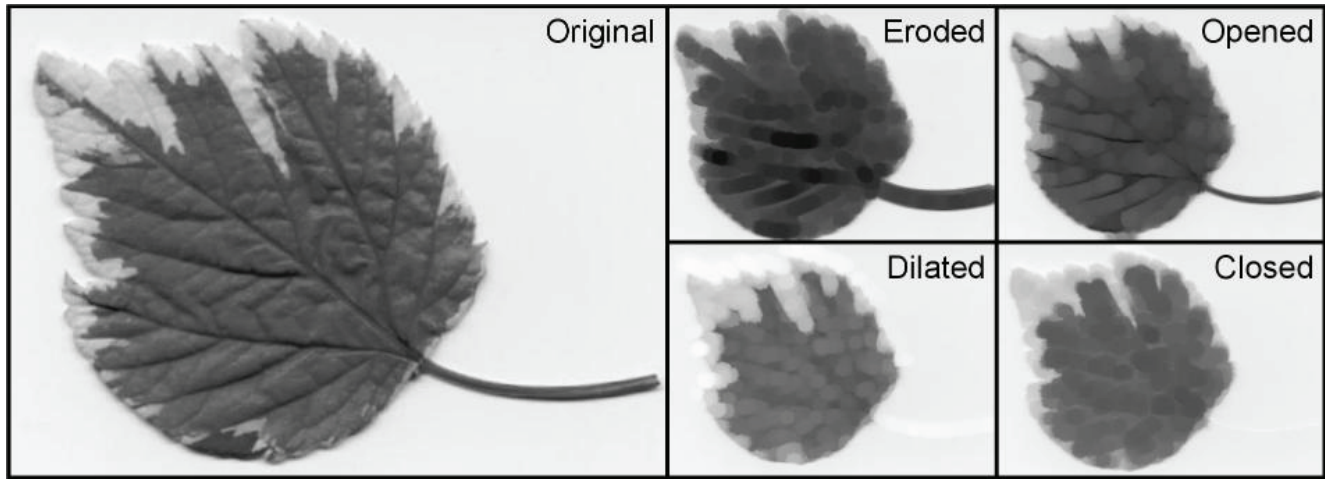

Figura A.5: Exemplo de aplicação de operadores morfológicos em imagens em tons de cinza. Fonte: http://rsbweb.nih.gov/ij/plugins/gray-morphology.html

estruturante não está dentro da imagem. Entretanto, a abertura e o fechamento não estabelecem a imagem original. A Fig. A.4 exibe a aplicação do fechamento. É possível verificar a remoção do ruído ao redor de $A$.

\section{A.5 Imagens em Tons de Cinza}

O uso de tons de cinza introduz complicações em conceito e implementação. Um pixel possui qualquer valor inteiro, assim a facilidade de considerar a imagem como um conjunto desaparece. A idéia básica de morfologia binária é estendida para tons de cinza, mas operações lógicas devem simular conversões aritméticas: uniões se tornam máximos e interseções se tornam mínimos.

A sombra é uma função de um conjunto de todas as posições $(x, y)$ tal que o valor é menor ou igual a $f(x)$. É possível considerar uma dimensão como elemento estruturante $g$ para ser um conjunto sombra. A Fig. A.5 exibe exemplos de operadores morfológicos aplicados em imagens de tons de cinza. Relembrando que imagens são $I(x, y)$. A sombra é uma função de um conjunto de todas as posições $(x, y)$ tal que o valor é menor que ou igual a $f(x)$.

\section{A.6 Dilatação em Tons de Cinza}

A dilatação em imagens de tons de cinza pode ser calculada como 


$$
\left(A \circ_{g} B\right)=\max \{A(i-x, j-y)+B(x, y) \mid(i-x, j-y) \in A,(x, y) \in B\}
$$

onde $B$ é um elemento estruturante e $A$ é a imagem em tons de cinza. A dilatação resultante é dada por:

1. Posiciona-se a origem do elemento estruturante sobre o primeiro pixel da imagem a ser dilatada;

2. Calcula-se a soma de cada par correspondente de valores de pixel do elemento estruturante e da imagem;

3. Acha-se o valor máximo de todas essas somas, e armazena-se o valor do pixel correspondente na imagem de saída;

4. Repete-se este processo para cada pixel da imagem a ser dilatada.

Os valores dos pixels do elemento estruturante também são tons de cinza e podem ser negativos. Uma vez que pixel com valores negativos não podem ser mostrados, existem dois possíveis modos de manipular pixels negativos:

1. Valores negativos podem ser alterados para zero;

2. A imagem inteira pode ter seus valores alterados, para que o menor valor de pixel seja zero sem alterar os valores relativos.

\section{A.7 Erosão de Tons de Cinza}

A erosão em imagens de tons de cinza é dada por

$$
\left(A \ominus_{g} B\right)=\min \{A(i-x, j-y)+B(x, y) \mid(i-x, j-y) \in A,(x, y) \in B\}
$$

onde $B$ é um elemento estrutural e $A$ é a imagem. Para calculo da erosão

1. Posiciona-se a origem do elemento estruturante sobre o primeiro pixel da imagem que sofre erosão;

2. Calcula-se a diferença de cada par correspondente de valores de pixels do elemento estruturante e da imagem;

3. Acha-se o valor mínimo de todas essas diferenças, e armazena-se o pixel correspondente na imagem de saída para este valor;

4. Repete-se este processo para cada pixel da imagem. 


\section{A.8 Abertura de Tons de Cinza}

O processo de abertura funciona da mesma forma que definido anteriormente só que usa dilatação e erosão de tons de cinza. Isto é, a abertura usa uma erosão de tons de cinza seguida de uma dilatação de tons de cinza usando o mesmo elemento estruturante.

$$
f \circ_{g}(G)=\left(f \oplus_{g} G\right) \ominus_{g} G
$$

\section{A.9 Fechamento de Tons de Cinza}

O processo de fechamento funciona da mesma forma que definido anteriormente só que usa a dilatação e erosão de tons de cinza. Isto é, o fechamento usa uma dilatação de tons de cinza seguida de uma erosão de tons de cinza usando o mesmo elemento estruturante e uma dilatação seguida de uma erosão:

$$
f \bullet_{g}(G)=\left(f \ominus_{g} G\right) \oplus_{g} G
$$

\section{A.10 Abertura de área}

A abertura de área (Area Opening) é uma operação morfológica que elimina componentes de área inferior a um tamanho definido. Dado uma área $\lambda$, o algoritmo define na imagem todas regiões fechadas, similar à rotulação. Caso a área interna seja inferior a $\lambda$, a região é removida (os pixels se tornam da cor do fundo). Diferente da abertura convencional com elemento estruturante, o algoritmo avalia apenas o tamanho das regiões conexas, e não a forma dos contornos.

\section{A.11 Fechamento de buracos}

Fechamento de buracos (Filling Holes), como o próprio nome diz é uma técnica usada para remoção de vales na imagem. Define-se um vales como uma região fechada por pixels de alta intensidade. O algoritmo detecta os buracos na imagem, similar à rotulação,e os buracos são preenchidos, alterando os pixels internos para o pixels de menor intensidade das bordas. Comparado à abertura por área, este algoritmo não avalia o tamanho das regiões conexas, apenas a presença dos vales. 


\section{Referências}

1 Asakura, A., Gotoh, T., Kagei, S., Iwasawa, T., And Inoue, T. Computer aided system for respiratory motion analysis of the lung region by sequential MR images. Medical Imaging Technology 23 (2005), 39-46.

2 Geva, T. Magnetic resonance imaging: historical perspective. Journal of Cardiovascular Magnetic Resonance 8 (2006), 573-580.

3 Heath, M., Sarkar, S., Sanocki, T., And Bowyer, K. Comparison of edge detectors: a methodology and initial study. Computer Vision and Image Understanding 69 (1998), 38-54.

4 Iwasawa, T., Kagei, S., Gotoh, T., Yoshimke, Y., Matsushita, K., Kurihara, H., Saito, K., And Matsubara, S. Magnetic resonance analysis of abonormal diaphragmatic motion in patients with emphysema. European Respiratory Journal 19 (2002), 225-331.

5 Kadota, E., Gotoh, T., Kagei, S., and Iwasawa, T. Shape tracking and motion pattern analysis on chest MR sequence images using respiratory and heartbeat patterns. IEICE Tec Rep 105 (2005), 9-12.

6 Kass, M., Witkin, A., And Terzopoulos, D. Snakes: active contour models. International Journal of Computer Vision 1 (1988), 321-331.

7 Kauczor, H. U. MRI of the lung. Springer-Verlag, Berlim, 2009.

8 Keall, P. J., Joshi, S., Vedam, S. S., Siebers, J. V., Kini, V. R., And Mohan, R. Four-dimensional radiotherapy planning for DMLC-based respiratory motion tracking. Medical Physics 32 (2005), 942-951.

9 Kiryati, N., Eldar, Y., And Bruckstein, A. M. A probabilistic hough transform. Pattern Recognition 24 (1991), 303-316.

10 Lujan, A. E., Larsen, E. W., Balter, J. M., and Haken, R. K. T. A method for incorporating organ motion due to breathing into $3 \mathrm{D}$ dose calculations. Medical Physics 26 (1999), 715-720.

11 Matsushita, K., Asakura, A., Kagei, S., Gotoh, T., Iwasawa, T., And InOue, T. Shape tracking on chest MR sequence images using respiratory patterns. The Journal of the Institute of Image Electronics Engineers of Japan 33 (2004), 1115-1122.

12 Moller, H. E., Chen, X. J., SaAm, B., Hagspiel, K. D., Johnson, G. A., Altes, T. A., De Lange, E. E., And Kauczor, H.-U. Mri of the lungs using hyperpolarized noble gases. Magnetic Resonance in Medicine 47 (2002), 1029-1051.

13 Nakamura, C., Asakura, A., Tsuzuki, M. S. G., Gotoh, T., Kagei, S., AND IWASAWA, T. Three dimensional lung modeling from sequential MR images based on respiratory motion analysis. IEICE Technical Report 105 (2005), $33-38$. 
14 Pianykh, O. Digital Imaging and Communications in Medicine (DICOM): A Practical Introduction and Survival Guide. Springer, United States of America, 2008.

15 Piegl, L., ANd Tiller, W. The NURBS Book 2nd edition. Springer, Germany, 1997.

16 Santhanam, A., Pattanaik, S., Fidopiastis, C., Rolland, J. P., And Davenport, P. Physically-based deformation of high-resolution 3D lung models for augmented reality based medical visualization. In $M I C C A I-A M I-$ ARCS international workshop on augmented environments for medical imaging and computer-aided surgery (Rennes (St. Malo France), 2004).

17 Sarrut, D., Delhay, B., Villard, P.-F., Boldea, V., Beuve, M., And Clarysse, P. A comparison framework for breathing motion estimation methods from 4D imaging. IEEE Transactions on Medical Imaging 26 (2007), 1636-1648.

18 Sato, A. K., Stevo, N., Tavares, R. S., Tsuzuki, M. S. G., Kadota, E., Gotoh, T., Kagei, S., and Asakura, T. I. A. Registration of temporal sequences of coronal and sagittal MR images through respiratory patterns. Biomed Signal Proces Control 6 (2011), 34-47.

19 Sezgin, M., And Sankur, B. Survey over image thresholding techniques and quantitative performance evaluation. J Electron Imaging 13 (2004), 146-168.

20 Stevo, N., Campos, R., Tavares, R. S., Tsuzuki, M. S. G., Gotoh, T., Kagei, S., And IwASAWA, T. Registration of temporal sequences of coronal and sagittal images obtained from magnetic resonance. In Proceedings of the COBEM 2009 - 20 $0^{\text {th }}$ International Congress of Mechanical Engineering (2009).

21 Stevo, N. A. Registro múltiplo de sequências temporais coronais e sagitais obtidas por ressonância magnética baseada em transformada de Hough. Master's thesis, Escola Politécnica da USP, 2010.

22 Takashi Maekawa, Yasunori Matsumoto, K. N. Interpolation by geometric algorithm. Computer-Aided Design 39 (2007), 313-323.

23 Tavares, R. S., Tsuzuki, M. S. G., Gotoh, T., Kagei, S., and IwaSAWA, T. Lung movement determination in temporal sequences of MR images using Hough transform and interval arithmetics. In Proceedings of the rth IFAC Symposium on Modelling and Control in Biomedical Systems (2009), pp. 192-197.

24 Trigo, F. C., Gonzalez-Lima, R., and Amato, M. B. P. Electrical impedance tomography using the extended kalman filter. IEEE TRANSACTIONS ON BIOMEDICAL ENGINEERING 51 (2004), 72-81.

25 Tsuzuki, M. S. G., Takase, F. K., Asakura, A., Gotoh, T., KaGEI, S., AND IWASAWA, T. 4d thoracic organ modelling from unsynchronized mr sequential images. In Proceedings of the $12^{\text {th }}$ ICBME - 12 th International Conference on Biomedical Engineering (2005).

26 Tsuzuki, M. S. G., Takase, F. K., Gotoh, T., Kagei, S., Asakura, A., Iwasawa, T., And InOue, T. Animated solid model of the lung constructed from unsynchronized MR sequential images. Computer Aided Design 41 (2009), $573-585$. 
27 VAN Herk, M. Errors and margins in radiotherapy. Seminars in Radiation Oncology 14 (2004), 52-64.

28 Williams, D. J., AND Shah, M. A fast algorithm for active contours and curvature estimation. Computacional Visual Graphical Image Processing 1 (1992), 14-26. 